\title{
Recent advances in transition-metal-catalyzed incorporation of fluorine-containing groups
}

\author{
Xiaowei $\mathrm{Li}^{1,2,3}$, Xiaolin Shi ${ }^{1,2,3}$, Xiangqian $\mathrm{Li}^{*}$ and Dayong Shi ${ }^{*}$
}

Review

Address:

${ }^{1}$ Key Laboratory of Experimental Marine Biology, Institute of Oceanology, Chinese Academy of Sciences, 7 Nanhai Road, Qingdao 266071, China, ${ }^{2}$ Laboratory for Marine Drugs and Bioproducts of Qingdao National Laboratory for Marine Science and Technology, Qingdao 266000, China, ${ }^{3}$ University of Chinese Academy of Sciences, Beijing 100049, China and ${ }^{4}$ State Key Laboratory of Microbial Technology, Shandong University, 72 Binhai Road, Qingdao 266237, China

Email:

Xiangqian Li - xqli@qdio.ac.cn; Dayong Shi ${ }^{*}$ - shidayong@sdu.edu.cn

* Corresponding author

Keywords:

catalysis; $\mathrm{C}-\mathrm{R}_{\mathrm{F}}$ bond; fluorination; fluoroalkylation; transition metals
Beilstein J. Org. Chem. 2019, 15, 2213-2270. doi:10.3762/bjoc. 15.218

Received: 12 April 2019

Accepted: 03 September 2019

Published: 23 September 2019

Associate Editor: L. Ackermann

(c) 2019 Li et al.; licensee Beilstein-Institut. License and terms: see end of document.

\begin{abstract}
Fluorine chemistry plays an increasingly important role in pharmaceutical, agricultural, and materials industries. The incorporation of fluorine-containing groups into organic molecules can improve their chemical and physical properties, which attracts continuous interest in organic synthesis. Among various reported methods, transition-metal-catalyzed fluorination/fluoroalkylation has emerged as a powerful method for the construction of these compounds. This review attempts to describe the major advances in the transition-metal-catalyzed incorporation of fluorine, trifluoromethyl, difluoromethyl, trifluoromethylthio, and trifluoromethoxy groups reported between 2011 and 2019.
\end{abstract}

\section{Introduction}

Compared with other halogens $(\mathrm{Cl}, \mathrm{Br}$, I), fluorine (F) has completely different physical and chemical properties, such as a unique electronic structure, strongest electronegativity, and small atomic radius similar to that of hydrogen atoms. Due to these unique properties, the introduction of fluorine into a molecule can cause dramatic changes, such as the acidity or basicity of neighboring groups, dipole moment, and properties such as lipophilicity, metabolic stability, and bioavailability [1]. Consequently, carbon-fluorine bonds have become an integral part of pharmaceutical [2,3], agricultural [4], materials industries [5], and tracers for positron emission tomography [6]. According to statistics, about $35 \%$ of agrochemicals and $20 \%$ of pharmaceuticals contain fluorine [7].

Although the content of fluorine in the Earth's crust is relatively abundant (13th most abundant element), scientists have identified only 21 kinds of fluorine-containing natural molecules $[8,9]$. Therefore, it is highly desirable to introduce a fluorine- 
containing substituent into a molecule artificially. However, traditional fluorination methods to these building blocks, such as Friedel-Crafts-type electrophilic halogenation [10,11], Sandmeyer-type reactions of diazonium salts [12], and halogenations of preformed organometallic reagents [13], commonly involve multiple steps, harsh reaction conditions, and the use of stoichiometric amounts and/or toxic reagents [14]. Also, low functional group tolerance, being limited to activated arenes, the production of metal salts as stoichiometric byproducts, and poor levels of regioselectivity would always be observed, limiting the progress of fluorine chemistry to some extent. In this regard, the use of various transition metals to catalyze the synthesis of organic fluorides has become a mature field, and the application of these methodologies has allowed decreasing the need of pre-functionalized substrates, less consumption of reaction time and costs, and enabled to produce enantioenriched target compounds [15-20]. Furthermore, transition metals have the unique advantage of possessing multiple mechanistic features, which translates into the ability to apply new substrate classes and provide hitherto novel and inaccessible structures. Therefore, transition-metal-catalyzed fluorination/ fluoroalkylation reactions represent an important and hot topic in fluorine chemistry. In addition, among the various metals developed, palladium is the most commonly employed transition metal, followed by copper owing to its high efficiency and cheapness. Meanwhile, other transition metals, such as $\mathrm{Fe}, \mathrm{Ni}$, $\mathrm{Rh}, \mathrm{Ag}, \mathrm{Co}$, etc., have received considerable attention and are widely applied due to their respective characteristics.

Over the past few years, several reviews on fluorination/fluoroalkylation have disclosed. Kamlet [17] mainly discussed progresses in catalyzed fluorination and trifluoromethylation before 2011, and Besset [21] focused on the direct introduction of fluorinated groups into alkenes and alkynes. Then, Toste [1] covered advances in catalytic enantioselective fluorination, mono-, di-, and trifluoromethylation, and trifluoromethylthiolation reactions. Recently, Zhang [14] offered a brief summary of the recent achievements in the ever-growing field of green fluoroalkylation. However, until now, no comprehensive survey of the literature has been reported on this topic. In this review, we highlight the recent progress of transition-metal-catalyzed fluorination and trifluoromethylation reported between 2011 and 2019. Meanwhile, we also present the incorporation of difluoromethyl, trifluoromethylthiol and trifluoromethoxy groups. Some sections of this review are structured around the synthesis of alkyl-, aryl- and vinyl- as well as alkynyl organofluorides. Notably, the current review covers mainly two types of transition-metal-catalyzed reactions: 1) crosscouplings with a fluorinated organometallic species or a halogenated fluorinated species and 2) the direct introduction of fluorinated moieties into nonfunctionalized substrates with a fluorinated reagent. We hope that this review will provide a comprehensive overview of this topic and attract significant attention.

\section{Review \\ Fluorination}

For many years, specialists in the field of fluorine chemistry have been actively studying ways to introduce fluorine into organic molecules by aid of transition-metal catalysis. Depending on the transfer form of fluorine, there are three general strategies for constructing $\mathrm{C}-\mathrm{F}$ bonds: nucleophilic, electrophilic and radical fluorination (Scheme 1) [22].

In nucleophilic fluorination reactions, the fluoride anion $\left(\mathrm{F}^{-}\right)$or a derivative thereof, such as tetrafluoroborate $\left(\mathrm{BF}_{4}{ }^{-}\right)$, is the fluorine source and behaves as a nucleophile. The electrophile, such as an alkyl chain or an aryl ring with halides or sulfonates, reacts with the fluoride source (Scheme 1a). On the other hand, in the electrophilic fluorination, the nucleophile may be a carbon anion (e.g., Grignard reagent), a compound with electronrich unsaturated bonds (arene, alkene, or alkyne), or a substrate having a nucleophilic and labile bond (e.g., $\mathrm{C}-\mathrm{Si}, \mathrm{C}-\mathrm{Sn}$, and $\mathrm{C}-\mathrm{B}$ ), while the electrophile is the fluorination reagent (Scheme 1b). As shown in Scheme 1d, many nucleophilic and electrophilic fluorination reagents have been developed by chemists. In the radical fluorination, $\mathrm{C}-\mathrm{F}$ bonds are produced by carbon-based radicals (generated in situ by various methods) with "atomic fluorine" sources, such as $\mathrm{XeF}_{2}$, hypofluorite, or molecular fluorine (Scheme 1c). Notably, transition metals are not biased to one reaction class, and the same metal may be successfully applied to all three kinds of fluorination.

Several reviews of fluorination have been published within the past few years, Buchwald [23], Weng [24], Gouverneur [25], Reiser [26], and etc. [22,27-33] discussed progresses of fluorination, such as Weng who focused on the recent advances in the transition-metal-assisted synthesis of alkyl fluorides, and Buchwald introduced the discovery and development of $\mathrm{Pd}(0) / \mathrm{Pd}(\mathrm{II})-$ catalyzed aromatic fluorination reactions. Herein, we focus on the developments towards the construction of $\mathrm{C}\left(\mathrm{sp}^{3}\right)-\mathrm{F}$ and $\mathrm{C}\left(\mathrm{sp}^{2}\right)-\mathrm{F}$ bonds with different catalysts, such as palladium, copper, silver, iron, nickel, ruthenium, cobalt, etc.

\section{Palladium catalysis}

Palladium is a member of the nickel triad in the periodic table, and palladium complexes exist in three oxidation states, $\operatorname{Pd}(0)$, $\mathrm{Pd}(\mathrm{II})$, and Pd(IV). Straightforward interconversion between different oxidation states, tolerance to various guiding groups, easy electroplating of $\mathrm{C}-\mathrm{H}$ bonds, and the compatibility of many $\mathrm{Pd}(\mathrm{II})$ catalysts with oxidants make them act as ideal catalysts for $\mathrm{C}-\mathrm{H}$ activations [34]. Over the last decade, a num- 
a. nucleophilic fluorination

$$
\text { (C) }-X+F^{-} \longrightarrow \text { (C) }-F
$$

$X=$ halides or sulfonates

b. electrophilic fluorination

$$
\text { (C) }-\mathrm{H} / \mathrm{X}+\mathrm{F}^{+} \longrightarrow \text { (C) }-\mathrm{F}
$$

$\mathrm{X}=\mathrm{SiR}_{3}, \mathrm{SnR}_{3}, \mathrm{BR}_{2}$ or $\mathrm{BR}_{3}{ }^{-}$

c. radical fluorination

$$
\text { (C) } \quad+\mathrm{F}^{\cdot} \longrightarrow \text { (C) }-\mathrm{F}
$$

d. fluorination reagents

source of " $\mathrm{F}^{-"}$

AgF $\quad \mathrm{CsF} \quad \mathrm{KF} \quad \mathrm{NaF} \quad n-\mathrm{Bu}_{4} \mathrm{~N}^{+} \mathrm{F}^{-}(\mathrm{TBAF}) \quad n-\mathrm{Bu}_{4} \mathrm{~N}^{+} \mathrm{Ph}_{2} \mathrm{SiF}_{2}^{-}$(TBAT) $\quad \mathrm{Me}_{4} \mathrm{~N}^{+} \mathrm{F}^{-}(\mathrm{TMAF})$

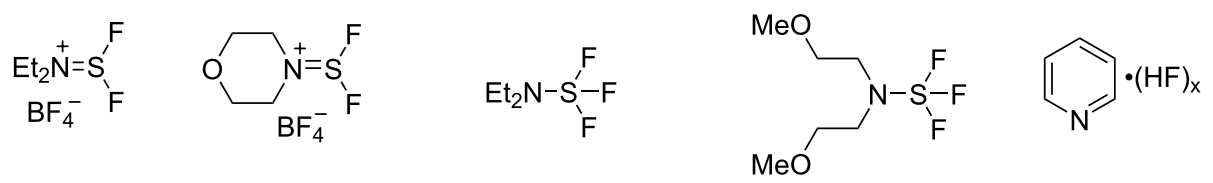

Xtalfluor-E Xtalfluor-M DAST(Deoxofluor) BAST(Deoxofluor) HF/pyridine

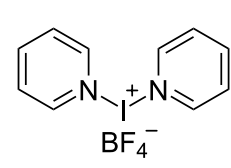

$\mathrm{IPy}_{2} \mathrm{BF}_{4}$<smiles>Cc1ccc(I(F)F)cc1</smiles>

$p$-Tol-IF 2<smiles>F[B-]c1ccc(C(F)(F)F)cc1</smiles>

$p-\mathrm{CF}_{3}-\mathrm{C}_{6} \mathrm{H}_{4}-\mathrm{BrF}_{2}$<smiles>CC(C)c1cccc(C(C)C)c1N1C=CN(c2c(C(C)C)cccc2C(C)C)C1(C(C)C)C(C)C</smiles>

PhenoFluor

source of "F"<smiles>F[n+]1ccccc1</smiles><smiles>Cc1cc(C)[n+](F)c(C)c1</smiles><smiles>Cc1cc(C)[n+](F)c(C)c1</smiles><smiles>Cc1cc(C)[n+](F)c(C)c1</smiles><smiles>O=S(=O)(Oc1ccccc1)N(F)S(=O)(=O)c1ccccc1</smiles>

$[\mathrm{pyF}] \mathrm{BF}_{4}$

$\left[\mathrm{Me}_{3} \mathrm{pyF}_{\mathrm{B} F}\right.$

[Me ${ }_{3}$ pyF]OTf (NFTPT)

$\left[\mathrm{Me}_{3} \mathrm{pyF}\right] \mathrm{PF}_{6}$

NFSI<smiles>F[n+]1c(Cl)cccc1Cl</smiles><smiles>F[n+]1ccccc1</smiles>

$\left[\mathrm{Cl}_{2}\right.$ pyF $] \mathrm{BF}_{4}$

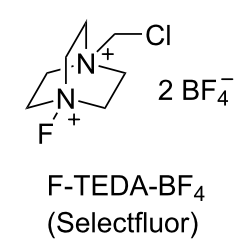

$\overbrace{\mathrm{F}^{\prime+}}^{\mathrm{N}^{+}}>^{-\mathrm{Cl}} 2 \mathrm{PF}_{6}^{-}$<smiles>O[N+]1(O)CCN2CC[N+]1(F)C2</smiles>

F-TEDA-PF 6

Accufluor 
ber of Pd-catalyzed methods have been developed to synthesize aryl fluorides [23,32].

Allylic fluorination: In 2010, Doyle and co-worker [35] developed a strategy for $\mathrm{C}-\mathrm{F}$ bond formation of readily available cyclic allylic chlorides and $\mathrm{AgF}$ using a $\mathrm{Pd}(0)$ catalyst in combination with Trost's bisphosphine ligand at room temperature (Scheme 2a). They also proved that the allylic fluorination was achieved by an $\mathrm{S}_{\mathrm{N}}$ 2-type attack of fluoride on an electrophilic $\mathrm{Pd}(\mathrm{II})$-allyl intermediate. One year later, the same author extended this method to a highly regio- and enantioselective fluorination of acyclic allylic chlorides. Compared to the previous process, this reaction used a different chiral bisphosphine ligand resulting in larger bite angles and afforded the products in good yields (Scheme 2b) [36].

A palladium-catalyzed method for the formation of allylic $\mathrm{C}-\mathrm{F}$ bonds from allyl $p$-nitrobenzoate using $\operatorname{TBAF}(t-\mathrm{BuOH})_{4}$ as the fluoride source was explored by Gouverneur et al. in the same year (Scheme 3) [37]. The 2- and 3-arylpropenyl fluorides can be quickly synthesized under mild conditions in moderate to good yields.

In 2012, a Pd(0)-catalyzed allylic fluorination of allylic phosphorothioate esters with AgF was accomplished by Wu's group (Scheme 4) [38]. The formation of fluorinated products with an overall retention of the stereochemical configuration suggests a mechanism wherein a palladium- $\pi$-allyl intermediate undergoes a rapid $\pi-\sigma-\pi$ isomerization.

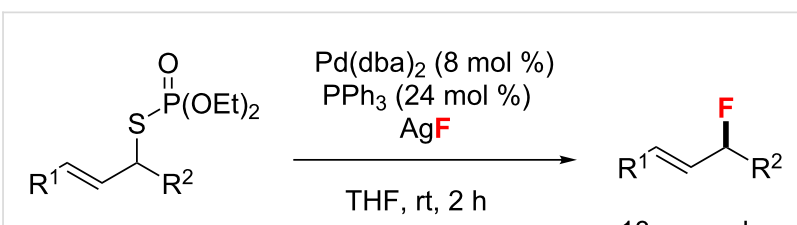

$$
\begin{aligned}
& \mathrm{R}^{1}=\text { aryl, heteroaryl } \mathrm{CH}_{3} \quad 13 \text { examples } \\
& \mathrm{R}^{2}=\text { alkyl, } \mathrm{Ph} \\
& 50-79 \%
\end{aligned}
$$

Scheme 4: Regioselective allylic fluorination of cinnamyl phosphorothioate esters.

In 2013, the first example of an allylic $\mathrm{C}-\mathrm{H}$ fluorination reaction of simple alkenes with $\mathrm{Et}_{3} \mathrm{~N} \cdot 3 \mathrm{HF}$ as a nucleophilic fluoride source was reported by Doyle and co-worker (Scheme 5) [39]. Herein, the authors utilized a $\mathrm{Pd} / \mathrm{Cr}$ cocatalytic system to generate the allylic fluorides with high regioselectivity (branched $>$ linear).

Alkyl fluorination of acidic carbonyl compounds and other compounds: In 2012, the group of Sodeoka [40] reported the first example of an enantioselective monofluorination of $\alpha$-keto esters catalyzed by $\mathrm{Pd}-\mu$-hydroxo complexes with cyclopentyl a<smiles>[X]C1C=CC(Cl)CC1</smiles>

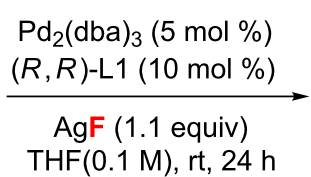

$\mathrm{X}=\mathrm{CH}_{2}, \mathrm{O}, \mathrm{NTs}, \mathrm{CCO}_{2} \mathrm{Me}, \mathrm{CCON}(\mathrm{Me}) \mathrm{OMe}$, $\mathrm{CCH}_{2} \mathrm{OTBS}, \mathrm{CC}(\mathrm{OH}) \mathrm{Me}_{2}$

b<smiles>[R]C1CCCCC1[R]</smiles>

$\mathrm{Pd}_{2}(\mathrm{dba})_{3}(5 \mathrm{~mol} \%)$ $(R, R)$-L2 (10 $\mathrm{mol} \%)$

AgF (3 equiv) toluene, rt, $48 \mathrm{~h}$

$\mathrm{R}^{1}, \mathrm{R}^{2}=$ benzyl, silyl ethers, aldehydes, alkyl bromides, $\alpha$-branching, heteroatom substituents
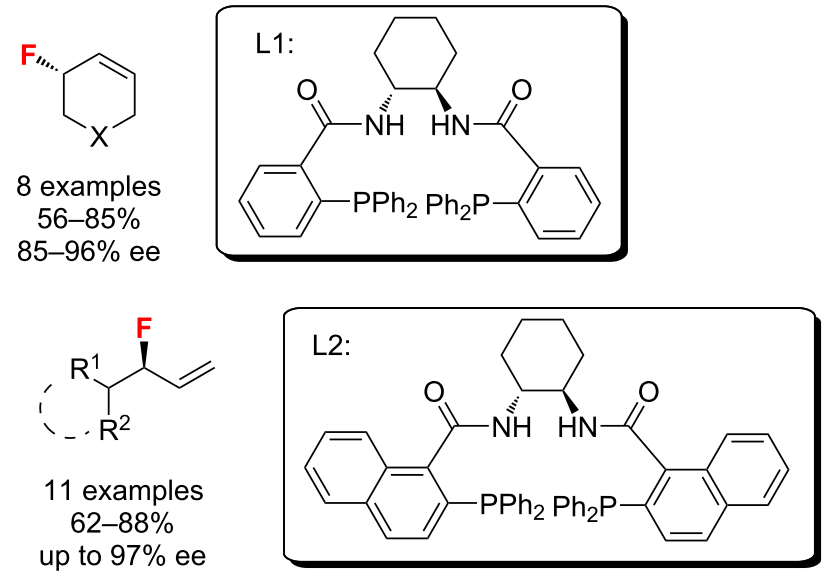<smiles></smiles>

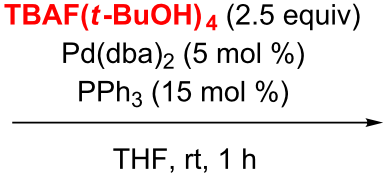

THF, rt, $1 \mathrm{~h}$

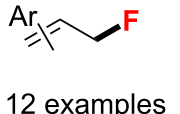

$35-95 \%$ 
$\mathrm{Pd}\left(\mathrm{CF}_{3} \mathrm{CO}_{2}\right)_{2} / \mathrm{L}(15 \mathrm{~mol} \%)$

$(R, R)-($ salen $) \mathrm{CrCl}(10 \mathrm{~mol} \%)$

$\widehat{R}+\mathrm{Et}_{3} \mathrm{~N} \cdot 3 \mathrm{HF}$

benzoquinone ( 2.0 equiv)

DCE $(2 \mathrm{M}), 23^{\circ} \mathrm{C}, 72 \mathrm{~h}$
$\overbrace{R}^{\mathrm{F}}$

14 examples

$33-68 \%$

branched:linear $=2.0: 1$ to $7.8: 1$

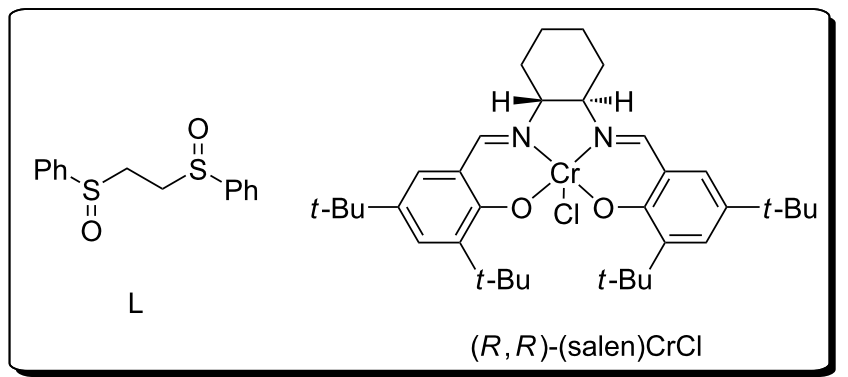

Scheme 5: Palladium-catalyzed aliphatic C-H fluorination reported by Doyle.

methyl ether (CPME) as the best solvent (Scheme 6). Also, they achieved the diastereoselective reduction of the remaining keto group with lithium tri(sec-butyl)borohydride (L-Selectride). The syn- $\beta$-fluoro- $\alpha$-hydroxy esters were obtained finally in good yields with excellent enantioselectivities (83-95\% ee).

There are two examples of a Pd-catalyzed fluorination of oxindoles. In 2012, Shi and co-workers [41] described the enantioselective asymmetric fluorination of oxindoles with an axially chiral $\mathrm{C}_{2}$-symmetric $N$-heterocyclic carbene (NHC) palladium complex as a catalyst (Scheme 7a). The corresponding products were obtained in excellent yields but low to moderate en- antioselectivities. Meanwhile, Wu and co-workers [42] developed a similar system using a BINAP-derived palladium complex to perform the similar reaction with 4,4 '-diF-NFSI as the fluorinating agent in higher enantioselectivities (Scheme 7b).

In 2012 the group of Sanford [43] achieved the palladium-catalyzed $\mathrm{C}-\mathrm{H}$ fluorination of 8-methylquinoline derivatives using $\mathrm{AgF}$ as the nucleophilic fluoride source and $\mathrm{PhI}(\mathrm{OPiv})_{2}$ as a hypervalent iodine oxidant (Scheme 8). Very recently, they [44] optimized this transformation and achieved the benzylic $\mathrm{C}-\mathrm{H}$ radiofluorination with no-carrier-added $\mathrm{Ag}\left[{ }^{18} \mathrm{~F}\right] \mathrm{F}$. This method
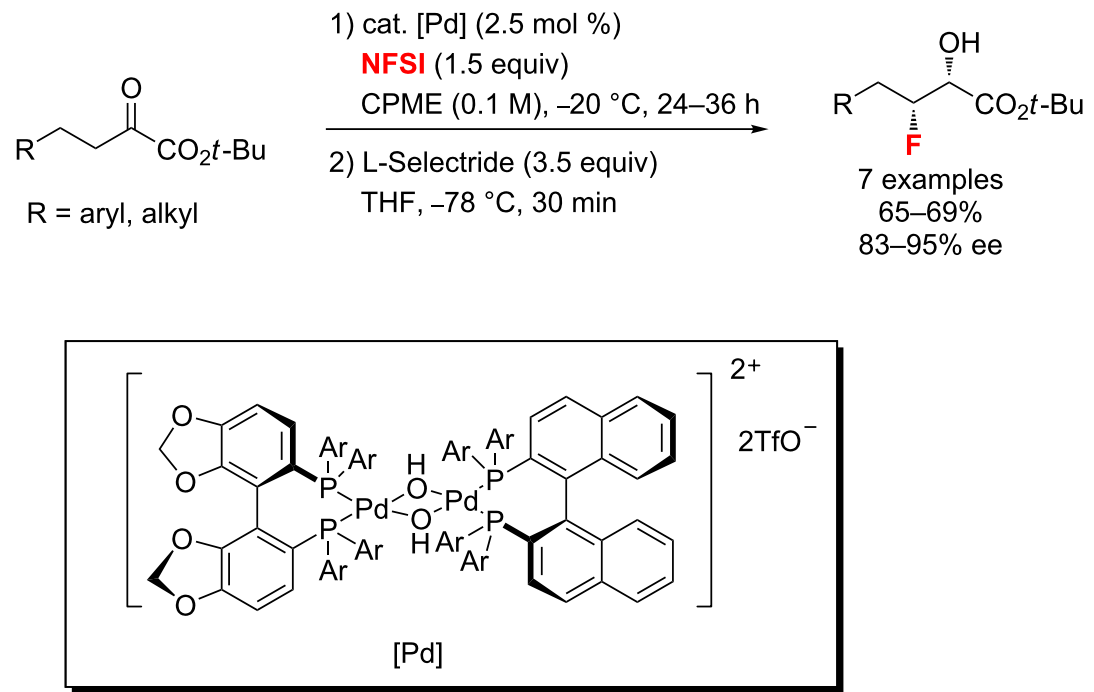
a)<smiles>[R]c1ccc2c(c1)C(Br)C(=O)N2[R]</smiles>

$\mathrm{R}^{1}=\mathrm{H}, \mathrm{F}, \mathrm{Me}, \mathrm{OMe}$

$\mathrm{R}^{2}=\mathrm{Boc}, \mathrm{Bn}$ cat. $[\mathrm{Pd}](3 \mathrm{~mol} \%)$

Selectfluor (1.5 equiv)

MS, acetone, 24-48 h<smiles>[R1]c1ccc2c(c1)C(F)([Al])C(=O)N2[R]</smiles>

$88-98 \%$ $20-59 \%$ ee

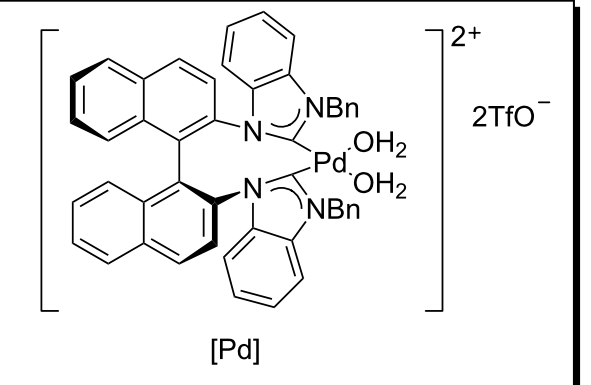

b)

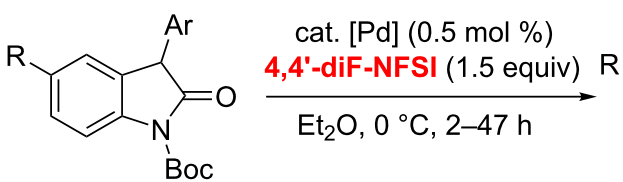

$\mathrm{R}=\mathrm{H}, \mathrm{F}, \mathrm{Cl}, \mathrm{Me}, \mathrm{OMe}$<smiles>CC(C)(C)OC(=O)N1C(=O)C(F)([Al])c2ccccc21</smiles>

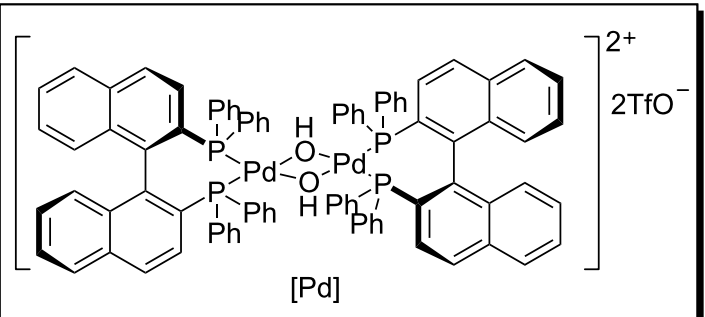

Scheme 7: Pd-catalyzed $\mathrm{C}\left(\mathrm{sp}^{3}\right)-\mathrm{H}$ fluorination of oxindoles

was applied to the radiolabeling of diversely substituted 8-methylquinoline derivatives. Notably, in this process, a new method was developed for generating $\mathrm{Ag}\left[{ }^{18} \mathrm{~F}\right] \mathrm{F}$ by using a seppak cartridge.<smiles>[R]c1cc([R])c2cccnc2c1C</smiles>

$$
\begin{gathered}
\mathrm{Pd}(\mathrm{OAc})_{2}(10 \mathrm{~mol} \%) \\
\mathrm{AgF}(5.0 \text { equiv) } \\
\mathrm{Phl}(\mathrm{OPiv})_{2} \text { (2.0 equiv) } \\
\mathrm{MgSO}_{4}(2.0 \text { equiv) } \\
\mathrm{CH}_{2} \mathrm{Cl}_{2}, 16 \mathrm{~h}, 60^{\circ} \mathrm{C}
\end{gathered}
$$

$\mathrm{R}^{1}=\mathrm{H}, \mathrm{NO}_{2}, \mathrm{CN}, \mathrm{CO}_{2} \mathrm{CH}_{3}, \mathrm{~F}, \mathrm{Br}, \mathrm{I}, \mathrm{CH}_{3}, \mathrm{Ph}$ $\mathrm{R}^{2}=\mathrm{H}, \mathrm{Br}$<smiles>[R]c1ccc(CO)c2ncccc12</smiles>

$$
\begin{gathered}
\mathrm{Pd}(\mathrm{OAc})_{2}(10 \mathrm{~mol} \%) \\
\mathrm{Ag}\left[{ }^{18} \mathrm{~F}\right] \mathrm{F} / \mathrm{K}_{2.2 .2} \\
\mathrm{Phl}(\mathrm{OPiv})_{2}(2.0 \text { equiv }) \\
\mathrm{CH}_{2} \mathrm{Cl}_{2} \\
145^{\circ} \mathrm{C}, 30 \mathrm{~min}
\end{gathered}
$$

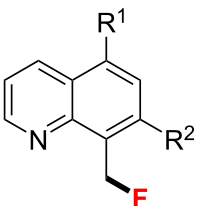

$$
10 \text { examples }
$$
$30-70 \%$ reagents

In 2012, van Leeuwen and co-workers [45] described the synthesis of new enantiopure wide-bite-angle diphosphanes and their application in the asymmetric fluorination of $\alpha$-cyanoacetates with a palladium catalyst (Scheme 9). Under these conditions, the fluorination of ethyl 2-cyano-2-phenylacetate afforded the product with highest enantiomeric excess (93\%).

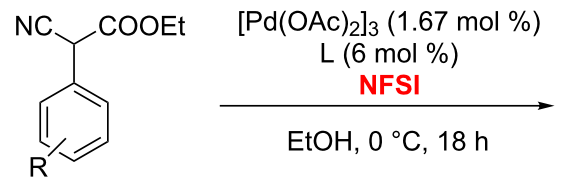

$\mathrm{R}=\mathrm{H}, 2-\mathrm{Cl}, 2-\mathrm{Br}$, 4-Me, 4- $\mathrm{CO}_{2} \mathrm{Et}, 4-\mathrm{Me}$, naphthyl derivative<smiles>[R][R]1cccc(C(F)([N+]#N)C(=O)OCC)c1</smiles>

7 examples $35-97 \%$ $9-93 \%$ ee

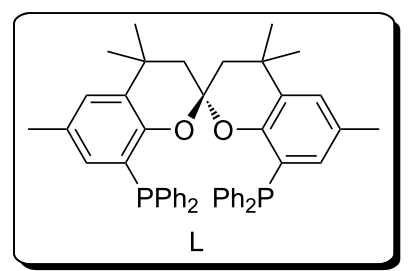

Scheme 9: Fluorination of $\alpha$-cyano acetates reported by van Leeuwen.

In 2013, Kim's group [46] described an enantioselective electrophilic fluorination of $\alpha$-chloro- $\beta$-keto phosphonates with up to $95 \%$ ee (Scheme 10). Notably, this reaction used an air and moisture-stable chiral palladium complex as the catalyst, which worked well at low catalyst loading (as low as $0.5 \mathrm{~mol} \%$ ).

In 2015, Shi et al. [47] introduced a $\mathrm{Pd}(\mathrm{II}) / \mathrm{Pd}(\mathrm{IV})$-catalyzed fluorination of $\beta$-methylene $\mathrm{C}\left(\mathrm{sp}^{3}\right)-\mathrm{H}$ bonds of $\alpha$-amino acid derivatives (Scheme 11a). This process was carried out under the strongly binding bidentate 2-(pyridine-2-yl)isopropylamine (PIP) auxiliary. A range of substrates containing both aliphatic and benzylic $\mathrm{C}\left(\mathrm{sp}^{3}\right)-\mathrm{H}$ bonds was finally converted to the cor- 


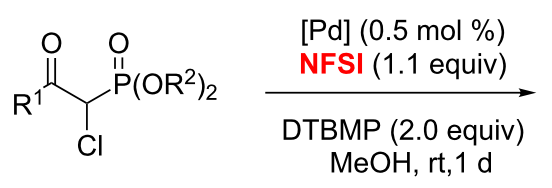

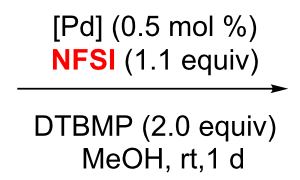

$\mathrm{R}^{1}=$ aryl, alkyl

$\mathrm{R}^{2}=\mathrm{Me}, \mathrm{Et}$<smiles>[R]C(Cl)C(F)(Cl)[PH]([R20])=O</smiles>

11 examples $40-88 \%$

$83-95 \%$ ee

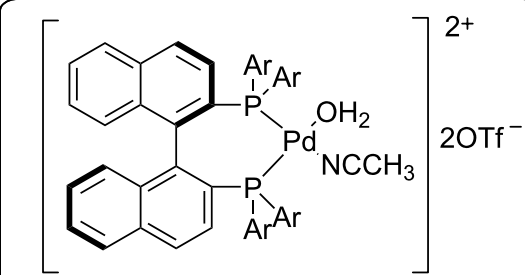

[Pd]

$\mathrm{Ar}=3,5-\left(\mathrm{CH}_{3}\right)_{2}-\mathrm{C}_{6} \mathrm{H}_{3}$

Scheme 10: The catalytic enantioselective electrophilic $\mathrm{C}-\mathrm{H}$ fluorination of $\alpha$-chloro- $\beta$-keto phosphonates

a)<smiles></smiles>

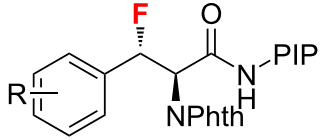

21 examples, $33-73 \%$

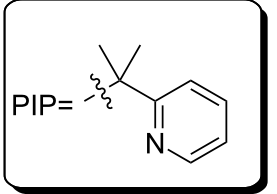

$\mathrm{R}=\mathrm{H}, \mathrm{Me}, t-\mathrm{Bu}, \mathrm{CF}_{3}, \mathrm{OMe}, \mathrm{F}, \mathrm{O}_{2} \mathrm{Me}, \mathrm{Br}, \mathrm{Ac}, \mathrm{Cl}, \mathrm{CN}, \mathrm{NO}_{2}$

$\mathrm{Pd}(\mathrm{OPiv})_{2}(10 \mathrm{~mol} \%)$<smiles>[R]CC(NP)C(=O)N[PH2+]</smiles>
Selectfluor (1.2 equiv) 2-Me-BAN (0.2 equiv)

DCM/iPrCN 30:1

$$
\mathrm{R}=\text { alkyl }
$$

b)

$$
\begin{aligned}
& \mathrm{R}^{1}=\text { alkyl, aryl } \\
& \mathrm{R}^{2}=\mathrm{NPhth}, \text { alkyl, aryl }
\end{aligned}
$$

$\mathrm{Pd}(\mathrm{OAc})_{2}(10 \mathrm{~mol} \%)$

Selectfluor (2.5 equiv)

$\mathrm{Fe}(\mathrm{OAc})_{2}$ ( 0.75 equiv)

$\mathrm{Ag}_{2} \mathrm{CO}_{3}$ (2.0 equiv)

air, $\mathrm{iPrCN}$ or $\mathrm{MeCN}$ DCE, $150^{\circ} \mathrm{C}, 14 \mathrm{~h}$<smiles>[R]C(F)C([NH2+]P)C(=O)NPCP</smiles>

11 examples, $32-46 \%$

proposed catalytic cycle of $\beta$-fluorination

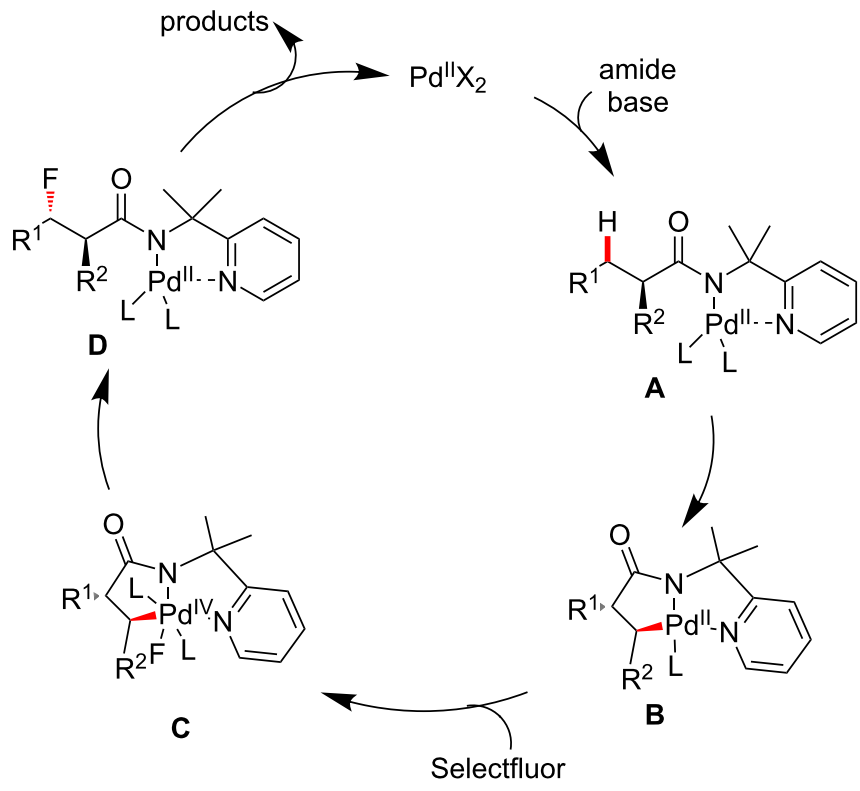

Scheme 11: Fluorination of unactivated $\mathrm{C}\left(\mathrm{sp}^{3}\right)-\mathrm{H}$ bonds directed by the bidentate PIP auxiliary. 
responding fluorinated products with excellent diastereoselectivities. Based on the PIP auxiliary developed by Shi, Ge's group [48] developed a similar direct, highly site- and diastereoselective fluorination of aliphatic amides (Scheme 11b). Although the roles of $\mathrm{Fe}(\mathrm{OAc})_{2}$ and $\mathrm{Ag}_{2} \mathrm{CO}_{3}$ were unclear, their addition significantly improved the reaction yield. A catalytic cycle of these $\beta$-fluorination reactions is proposed in Scheme 11. Initially, coordination of the amide with the palladium species followed by a base-promoted ligand-exchange process yields the palladium complex A. Subsequently, cyclometallation of the palladium complex $\mathbf{A}$ occurs to produce the intermediate $\mathbf{B}$ through the $\mathrm{C}-\mathrm{H}$ bond-activation process. Oxidative addition of the intermediate $\mathbf{B}$ with Selectfluor affords the palladium(IV) species $\mathbf{C}$, followed by reductive elimination and ligand dissociation to give the final product.

Similar to these publications in strategy and products, in the same year, Xu's group [49] presented the palladium-catalyzed direct fluorination of unactivated $\mathrm{C}\left(\mathrm{sp}^{3}\right)-\mathrm{H}$ bonds at the $\beta$-position of carboxylic acids with NFSI (Scheme 12). To achieve this transformation, an 8-aminoquinoline-derived auxiliary was developed as an effective directing group for the activation of the $\mathrm{C}-\mathrm{H}$ bonds. In this transformation the presence of $\mathrm{Ag}_{2} \mathrm{O}$ and pivalic acid was found to be crucial for the successful synthesis of $\beta$-fluorinated carboxylic acids.

Recently, the first example of a Pd-catalyzed protocol for the general enantioselective electrophilic $\mathrm{C}\left(\mathrm{sp}^{3}\right)-\mathrm{H}$ fluorination of benzaldehyde substrates was reported by $\mathrm{Yu}$ and co-workers
(Scheme 13) [50]. Enantioenriched benzyl fluorides were obtained by aid of a chiral $\alpha$-amino amide transient directing group (TDG). Notably, the condensation of this bulky amino amide with the aldehyde led to control of the stereochemistry of the $\mathrm{C}-\mathrm{H}$ insertion step, promoting the $\mathrm{C}-\mathrm{F}$ over $\mathrm{C}-\mathrm{O}$ bond formation via an inner-sphere pathway.

Fluorination of arenes, aryl bromides, -alcohols, -triflates, and -boronic acid derivatives: In 2013, Larhed and co-workers [51] established a one-pot, two-step fluorination of aryl alcohols via aryl nonafluorobutylsulfonates. This transformation employed $\mathrm{Pd}_{2}(\mathrm{dba})_{3} / t$-BuBrettPhos and $\mathrm{CsF}$ to convert aryl alcohols to aryl fluorides at $180{ }^{\circ} \mathrm{C}$ under microwave conditions (Scheme 14). The proposed catalytic cycle of this aryl fluorination is also shown. Only reductive elimination was investigated by Larhed, because this reaction step is crucial for product formation and a successful outcome of the reaction.

In the same year, the Ritter group [52] reported a Pd-catalyzed fluorination of arylboronic acid derivatives via a $\mathrm{Pd}(\mathrm{II}) / \mathrm{Pd}(\mathrm{III})$ cycle (Scheme 15). A single-electron-transfer (SET) mechanism involving a well-defined Pd(III) intermediate has been proposed. First, a bis(terpyridyl)Pd(II) complex $\mathbf{B}$ is oxidized by Selectfluor with turnover-limiting to obtain $\mathrm{Pd}(\mathrm{III}) \mathbf{C}$ and a Selectfluor radical cation. Then, a transfer of a $\mathrm{F}^{\cdot}$ radical from the Selectfluor radical cation to an aryl trifluoroborate occurs, forming the $\mathrm{C}-\mathrm{F}$ bond and producing a delocalized radical. Finally, SET from the radical to $\mathbf{C}$ regenerates palladium species $\mathbf{B}$, and affords a delocalized cation which converts to<smiles>[R]CC(=O)Nc1cccc2cccnc12</smiles>

$\mathrm{R}=$ aryl, alkyl

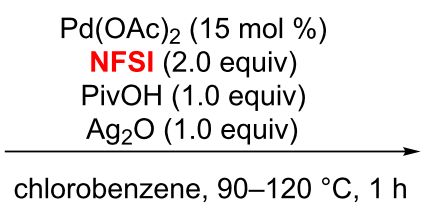

chlorobenzene, $90-120^{\circ} \mathrm{C}, 1 \mathrm{~h}$<smiles>[R]C(F)CC(=O)Nc1cccc2cccnc12</smiles>

20 examples $33-77 \%$

Scheme 12: Fluorination of $\mathrm{C}\left(\mathrm{sp}^{3}\right)-\mathrm{H}$ bonds at the $\beta$-position of carboxylic acids.
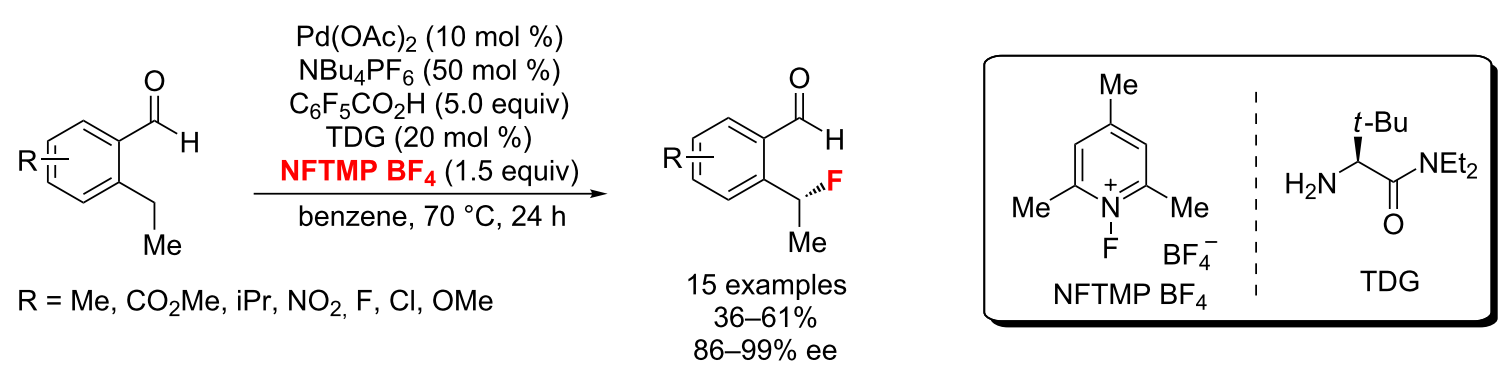

Scheme 13: Enantioselective benzylic C-H fluorination with a chiral transient directing group. 

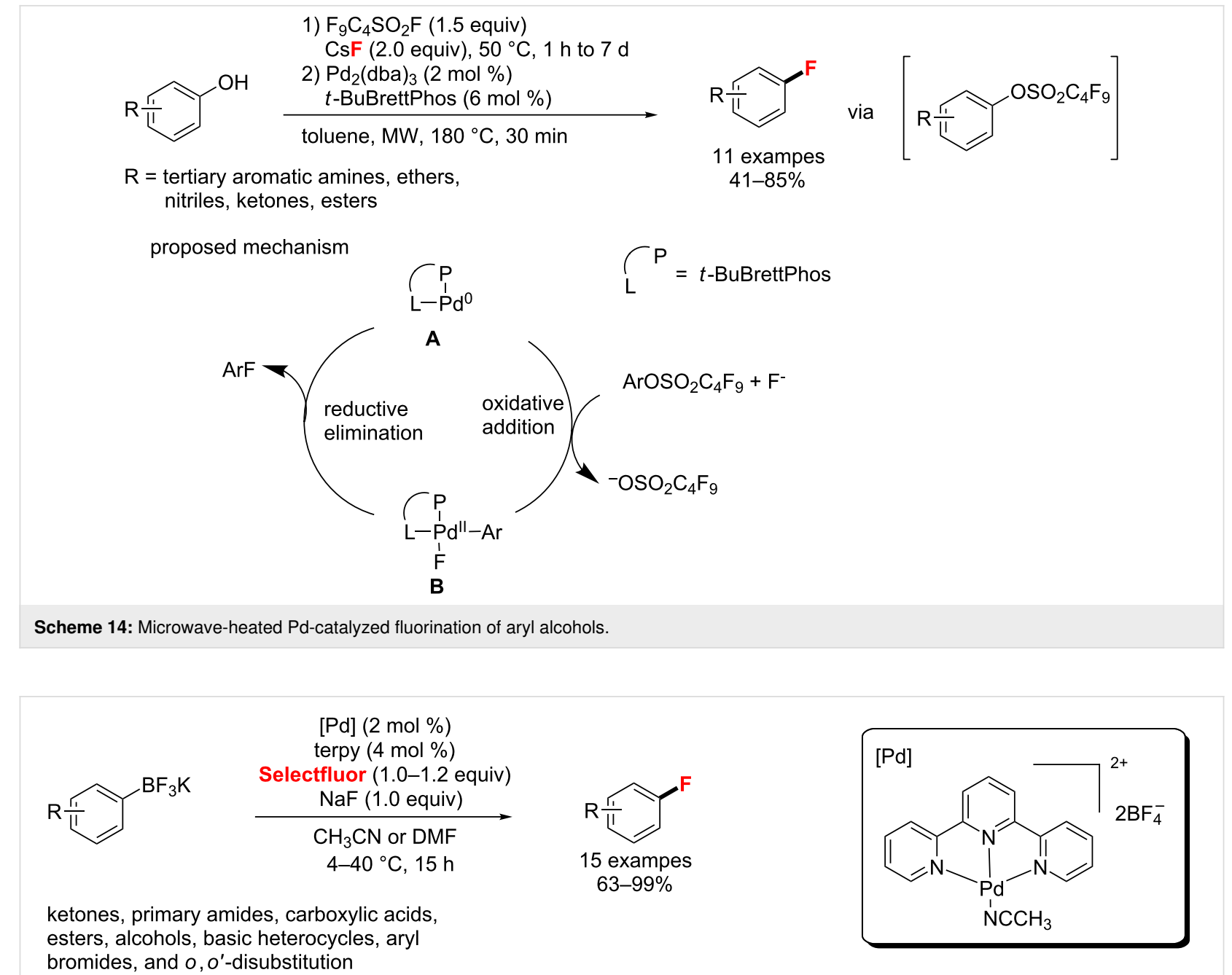

bromides, and $O, O^{\prime}$-disubstitution

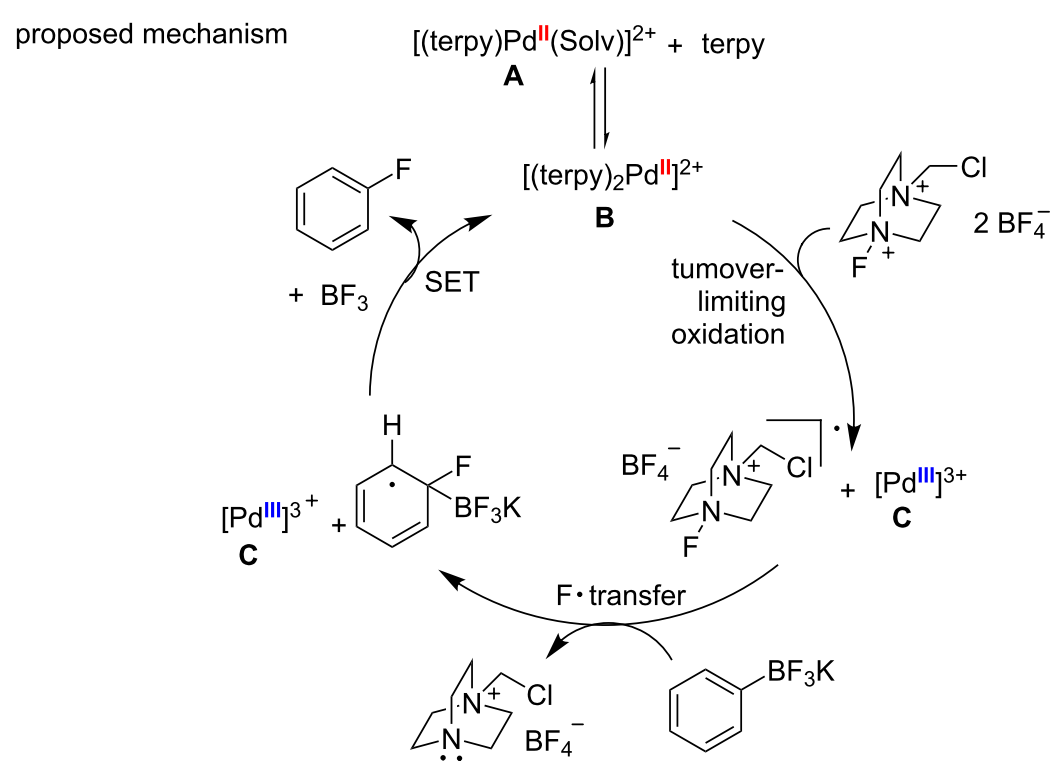

terpy = 2,2':6',2"-terpyridine; Solv = solvent (DMF or MeCN). 
the aryl fluoride with loss of $\mathrm{BF}_{3}$. Notably, the addition of $\mathrm{NaF}$ increases the yield of aryl fluoride by reacting with the generated $\mathrm{BF}_{3}$.

In 2013, Buchwald et al. [53] introduced an improved catalyst system involving $\mathrm{CsF}$ and the stable $\operatorname{Pd}(0)$ species $[(1,5-$ cyclooctadiene $\left.)\left(\mathrm{L}^{1} \cdot \mathrm{Pd}\right)_{2}\right]\left(\mathrm{L}^{1}=\right.$ AdBrettPhos $)$, which is a precatalyst for the fluorination of aryl triflates and heteroaryl triflates (Scheme 16a). Furthermore, aryl fluorides were provided in good to excellent yields with easy to separate byproducts. A year later, the same catalyst was employed for the nucleophilic fluorination of aryl bromides and iodides with $\mathrm{AgF}$ and KF [54]. Meanwhile, with a slight modification of the phosphine ligand, Buchwald developed a similar $\operatorname{Pd}(0)$ precatalyst
$\left[\mathrm{L}^{2} \mathrm{Pd}\right]_{2}(\mathrm{cod})$, which was used to fluorinate nitrogen-containing heteroaryl bromides (Scheme 16b).

In 2015, Buchwald and co-workers [55] explored a novel ligand for the Pd-catalyzed fluorination of (hetero)aryl triflates and bromides. The desired aryl fluorides were obtained with higher than 100:1 selectivity (Scheme 17).

More recently, Yamamoto and co-workers [56] described a palladium-catalyzed general method for aromatic $\mathrm{C}-\mathrm{H}$ fluorination with mild electrophilic fluorinating reagents at room temperature (Scheme 18). Notably, in this process, a reactive transition metal fluoride electrophile $\mathbf{B}$ is catalytically formed from A with Selectfluor or NFSI instead of an organometallic a

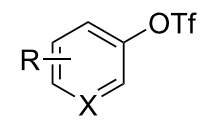

$$
\begin{aligned}
& \text { 1-3 mol \% }\left[\mathrm{L}^{1} \mathrm{Pd}\right]_{2}(\mathrm{cod}) \\
& \text { toluene, } 80-130^{\circ} \mathrm{C}, 14 \mathrm{~h}
\end{aligned}
$$

$$
\mathrm{X}=\mathrm{C}, \mathrm{N}
$$

aryl triflates derived from biologically active phenols heteroaryl and heterocycle-containing triflates

b<smiles>[R][X]c1ccc([X])cc1</smiles>

$$
1-2 \mathrm{~mol} \%\left[\mathrm{~L}^{1} \mathrm{Pd}\right]_{2}(\mathrm{cod})
$$

\section{0 equiv $\mathrm{AgF}, 0.5$ equiv $\mathrm{KF}$}

cyclohexane, $90-130^{\circ} \mathrm{C}, 14 \mathrm{~h}$

$\mathrm{X}=\mathrm{Br}$, I

$\mathrm{R}=\mathrm{Ph}, \mathrm{OMe}, \mathrm{CF}_{3}, \mathrm{SO}_{2} \mathrm{Me}, \mathrm{CN}, \mathrm{CO}_{2} \mathrm{Me}$

$\mathrm{SMe}, \mathrm{OBn}$, electron-rich amine, COMe, $\mathrm{COn}-\mathrm{Bu}, \mathrm{CONMe}_{2}$

$1-3 \mathrm{~mol} \%\left[\mathrm{~L}^{2} \mathrm{Pd}\right]_{2}(\mathrm{cod})$

HetAr-Br 2.0 equiv

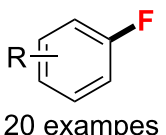

$$
30-92 \%
$$

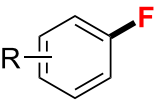

17 exampes $69-94 \%$

HetAr-F

13 exampes $51-96 \%$

Scheme 16: $C\left(\mathrm{sp}^{2}\right)-\mathrm{F}$ bond formation using precatalyst $[\mathrm{L} \cdot \mathrm{Pd}]_{2}(\mathrm{cod})$<smiles>[X]c1ccccc1</smiles>

$\mathrm{X}=\mathrm{OTf}$ or $\mathrm{Br}$
0.5-5 mol \% [L·Pd(cod)Pd.L], cy 3.0 equiv $\mathrm{CsF}(\mathrm{X}=\mathrm{OTf})$

$$
\begin{gathered}
\text { or } \\
2.0 \text { equiv } \mathrm{AgF}+0.5 \text { equiv } \mathrm{KF}(\mathrm{X}=\mathrm{Br}) \\
90-120^{\circ} \mathrm{C}, 17-28 \mathrm{~h}
\end{gathered}
$$<smiles>Fc1cccc[R]#1</smiles>

24 examples $51-96 \%$

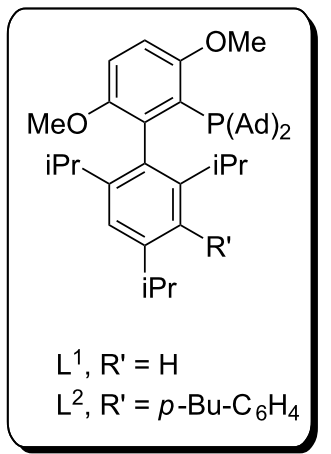

$L^{1}, R^{\prime}=H$

$\mathrm{L}^{2}, \mathrm{R}^{\prime}=p-\mathrm{Bu}-\mathrm{C}_{6} \mathrm{H}_{4}$

$\mathrm{R}$ = alkyl, aryl, heteroaryl, $\mathrm{CF}_{3}$, nitro, formyl, methyl ketone, redox active anthraquinone, sulfonamide/tertiary amine, flavone, quinoline, quinazoline, naproxen, diethylstilbesterol, tyrosine derivatives 


$$
\underset{\text { MeCN, } 25{ }^{\circ} \mathrm{C}, 8-36 \mathrm{~h}}{2.0 \text { equiv Selectfluor/NFSI }}
$$

$\mathrm{R}=$ nitriles, aryl bromides, chlorides, certain heterocycles, sulfonamides, ketones, amides, esters, carbamates, ethers, free hydroxy groups

proposed catalytic cycle for the fluorination of chlorobenzene
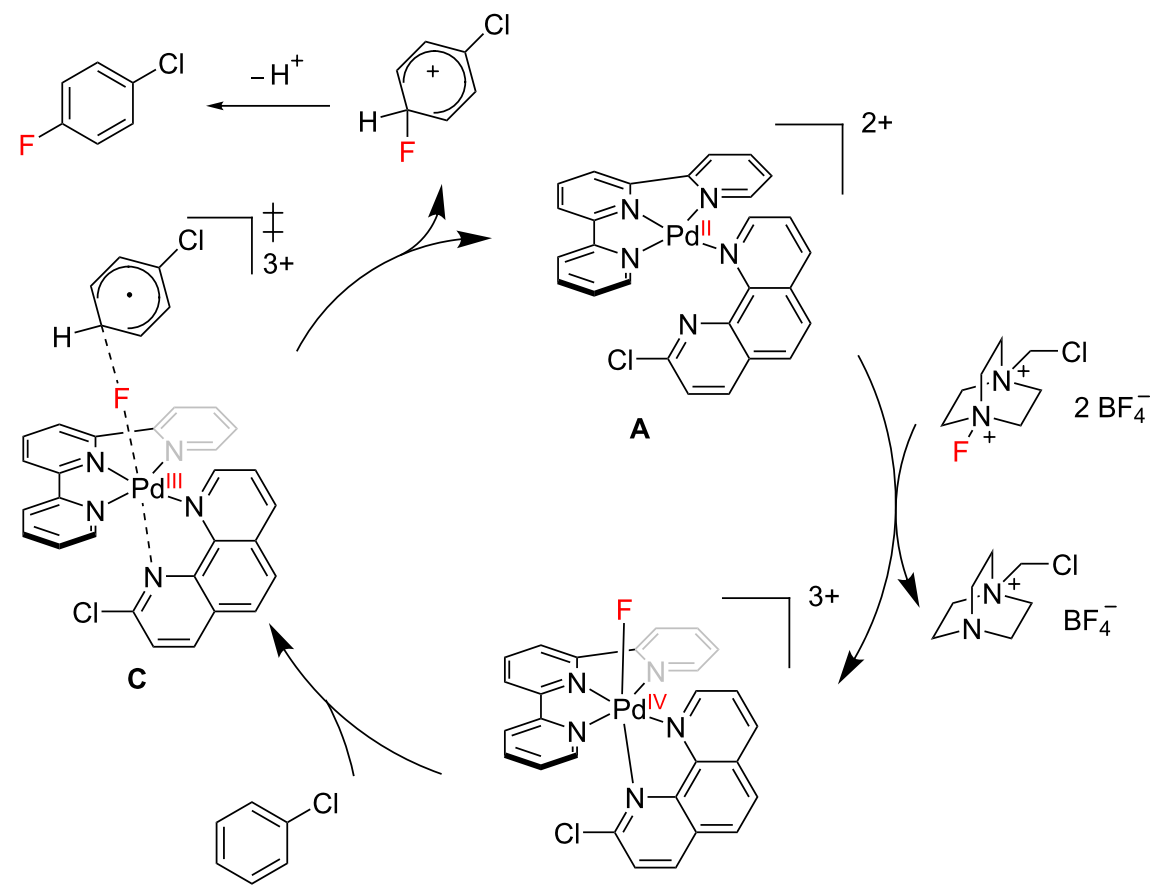

B

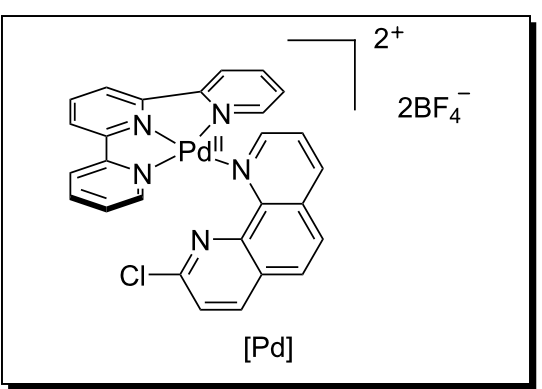

$[\mathrm{Pd}]$

Scheme 18: The Pd-catalyzed C-H fluorination of arenes with Selectfluor/NFSI.

intermediate as usual. Then, the activated Pd(IV)-F electrophile $\mathbf{B}$ would be capable of electrophilic fluorination of weakly nucleophilic arenes. This unusual mechanism of catalysis may provide a new idea to the catalysis of $\mathrm{C}-\mathrm{H}$ functionalization reactions.

Aryl C-H fluorination with various directing groups: With $\operatorname{Pd}(\mathrm{OTf})_{2}(\mathrm{MeCN})_{4}$ and $\mathrm{N}$-methyl-2-pyrrolidinone (NMP) used as the catalyst system, in 2011 the Yu group [57] described the ortho-fluorination of benzoic acid substrates with a directing group, an electron-deficient removable acidic amide (Scheme 19). With this method, both mono- and difluorinated benzoic acid derivatives can be selectively obtained in high yields.

In 2014, $\mathrm{Pu}$ and co-workers [58] devised the regioselective $\mathrm{Pd}\left(\mathrm{PPh}_{3}\right)_{4}$-catalyzed electrophilic ortho-fluorination of 2-aryl-

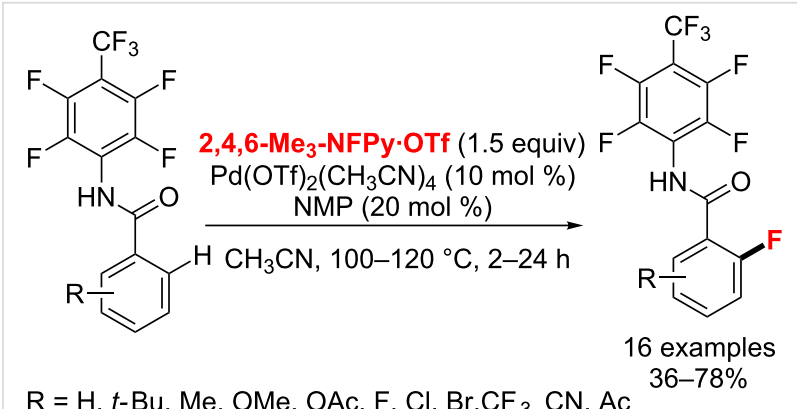

Scheme 19: $\mathrm{Pd}(\mathrm{II})$-catalyzed ortho-monofluorination protocol for benzoic acids.

benzothiazoles with NFSI and L-proline as the crucial promoter and the benzothiazoles as the directing groups (Scheme 20). This strategy plays an important role in the pharmaceutical and agrochemical industries. 

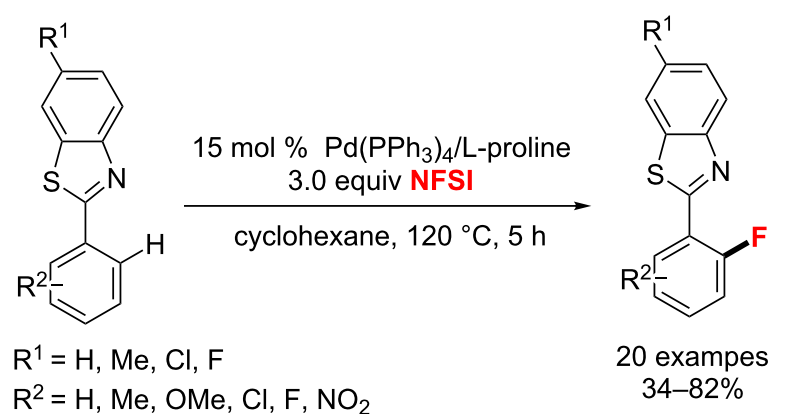

20 exampes $34-82 \%$

Scheme 20: $\mathrm{Pd}$-catalyzed $\mathrm{C}\left(\mathrm{sp}^{2}\right)-\mathrm{H}$ bond fluorination of 2-arylbenzothiazoles.

Meanwhile, Xu's group [59] used $O$-methyl oxime as the directing group for the Pd-catalyzed ortho-fluorination of aromatic and olefinic $\mathrm{C}\left(\mathrm{sp}^{2}\right)-\mathrm{H}$ bonds (Scheme $\left.21 \mathrm{a}\right)$. It is worth noting that a cheap and nontoxic nitrate was added as a highly efficient promoter in the presence of NFSI and $\operatorname{Pd}_{2}(\mathrm{dba})_{3}$. In addition, the authors proposed a reaction mechanism that involves

a $\mathrm{Pd}(\mathrm{II}) / \mathrm{Pd}(\mathrm{IV})$ catalytic cycle (Scheme $21 \mathrm{~b}$ ). At the early stage of this process, an in situ-generated cationic $\left[\mathrm{Pd}\left(\mathrm{NO}_{3}\right)\right]^{+}$species facilitates the $\mathrm{C}-\mathrm{H}$ bond activation to give intermediate $\mathbf{A}$. The $\mathrm{Pd}(\mathrm{II})(\mathbf{1 a})_{2}$ complex $\mathbf{B}$ is formed via further $\mathrm{C}-\mathrm{H}$ bond activation of another molecule 1a by the cyclopalladation(II) intermediate $\mathbf{A}$. Then, intermediate $\mathbf{B}$ undergoes oxidative addition by NFSI to give the highly reactive species F-Pd(IV)1a) $)_{2}^{-}$ $\mathrm{N}\left(\mathrm{SO}_{2} \mathrm{Ph}\right)_{2}(\mathbf{C})$, which produces the product $\mathbf{2 a}$ and reductive elimination intermediate $\mathbf{1 a}-\mathrm{Pd}(\mathrm{II})-\mathrm{N}\left(\mathrm{SO}_{2} \mathrm{Ph}\right)_{2}$ (D). Finally, intermediate $\mathbf{A}$ regenerates from intermediate $\mathbf{D}$ by aid of the catalytic amount of $\mathrm{HNO}_{3}$ released during the $\mathrm{C}-\mathrm{H}$ activation step.

In 2015, Zhao et al. [60] discovered a Pd(II)-catalyzed orthoselective C-H fluorination of oxalyl amide-protected benzylamines (Scheme 22). The yields were up to $95 \%$ with NFSI as the $\left[\mathrm{F}^{+}\right]$source and tert-amyl alcohol as the solvent.

In 2018, the Sorensen group [61] described a direct Pd-catalyzed ortho-C-H fluorination of benzaldehydes. Notably, these a)

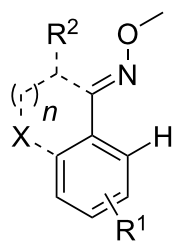

$1 \mathrm{a}$

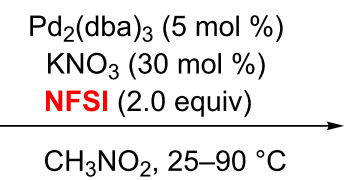

$\mathrm{CH}_{3} \mathrm{NO}_{2}, 25-90^{\circ} \mathrm{C}$<smiles>[R]C1=[Te]C(=NOC)C(=NOC)C1[R]</smiles>

$2 a$

27 examples up to $87 \%$ yield

$\mathrm{X}=\mathrm{CH}_{2}, \mathrm{O}$

$n=1,2$

$\mathrm{R}^{1}=\mathrm{H}, \mathrm{Me}, \mathrm{OMe}, \mathrm{OBn}, \mathrm{Ph}, \mathrm{Cl}, \mathrm{Br}, \mathrm{I}, \mathrm{CO}_{2} \mathrm{Me}, \mathrm{SO}_{2} \mathrm{Me}, \mathrm{NO}_{2}, \mathrm{CF}_{3}$

$\mathrm{R}^{2}=$ alkyl, $\mathrm{Ph}$

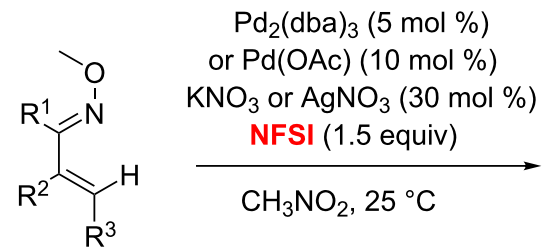

$\mathrm{R}^{1}=\mathrm{H}$, alkyl

$\mathrm{R}^{2}=$ alkyl, $\mathrm{Cl}, \mathrm{Br}, \mathrm{Ar}, \mathrm{OMe}$<smiles>[R]/C(F)=C(/[R])NOC</smiles>

$\mathrm{R}^{3}=\mathrm{H}, \mathrm{Ph}$

12 examples

up to $78 \%$ yield

b)

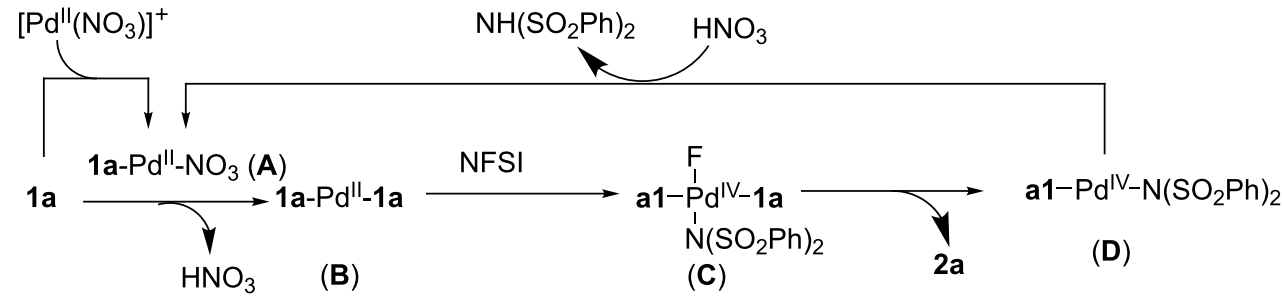


<smiles>[R]c1ccc(C([R])NC(=O)C(=O)NCCCCCCCCCC)cc1</smiles>

$\mathrm{Pd}(\mathrm{OAc})_{2}(5 \mathrm{~mol} \%)$

NFSI (3.0 equiv)

t-Amyl-OH, $80^{\circ} \mathrm{C}, 12 \mathrm{~h}$

$\mathrm{R}^{1}=\mathrm{H}, \mathrm{CH}_{3}, \mathrm{CH}_{2} \mathrm{OAc}$

$\mathrm{R}^{2}=\mathrm{OMe}, \mathrm{Me}, \mathrm{OCH}_{3}, \mathrm{Cl}, \mathrm{Br}, \mathrm{I}, \mathrm{F}, \mathrm{CF}_{3}$, vinyl

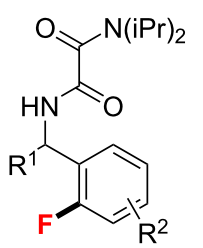

23 examples, up to $95 \%$ yield
Scheme 22: Fluorination of oxalyl amide-protected benzylamine derivatives.

transformations were achieved with orthanilic acids as new transient directing groups (TDGs) in DCE in the presence of air (Scheme 23). This approach employed 1-fluoro-2,4,6trimethylpyridinium salts as a bystanding $\mathrm{F}^{+}$oxidant or an electrophilic fluorinating reagent. A broad substrate scope and high functional group compatibility were observed.
In addition to the methods discussed above, there are some other methods for the aromatic $\mathrm{C}-\mathrm{H}$ fluorination using electrophilic fluorination reagents with various other directing groups [60,62-66]. Additionally, a diverse range of $N$-heterocycles, amides and motifs commonly encountered in medicinal chemistry were used as handles to direct $\mathrm{C}-\mathrm{H}$ fluorination for the synthesis of pharmaceutical drugs (Scheme 24) [25].

\section{Copper catalysis}

Despite the success of Pd-catalyzed fluorinations, the more widespread use of these technologies has been partially hampered by the high cost and toxicity associated with $\mathrm{Pd}$, in addition to the difficulty encountered when attempting to remove this metal from product mixtures. Therefore, cupper as low-cost, earth-abundant and readily available transition metal has emerged as a prevalent catalyst in a huge number of organic transformations. Similar to palladium complexes, copper complexes generally exist in four oxidation states, $\mathrm{Cu}(0), \mathrm{Cu}(\mathrm{I})$,<smiles>[R][X]1cccc(C=O)c1</smiles>

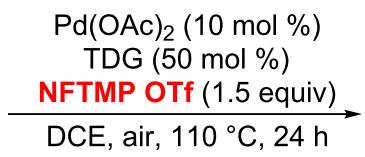

$\mathrm{R}=\mathrm{F}, \mathrm{Cl}, \mathrm{Br}, \mathrm{OMe}, \mathrm{Me}, \mathrm{NO}_{2}, \mathrm{CO}_{2} \mathrm{CH}_{3}$<smiles>O=Cc1cc[R7]cc1F</smiles>

30 examples $16-85 \%$

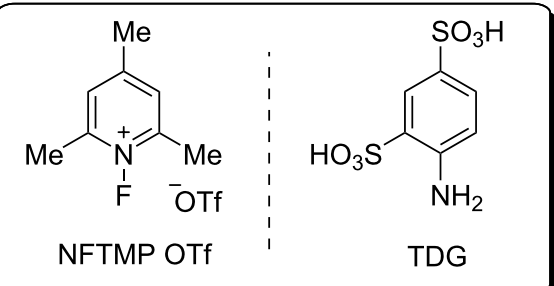

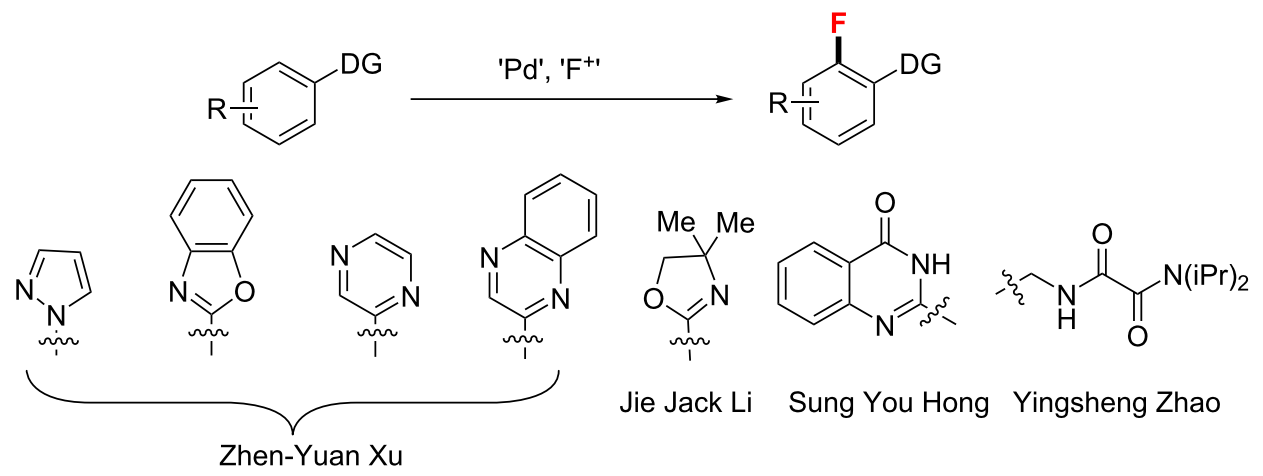

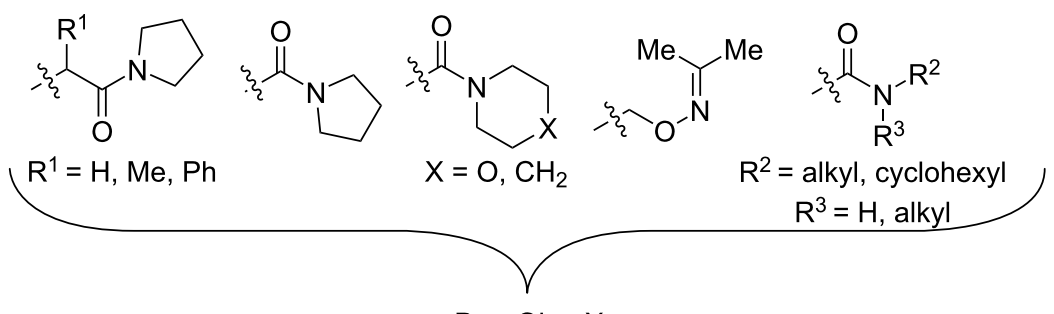

Dan-Qian Xu 
$\mathrm{Cu}(\mathrm{II})$, and $\mathrm{Cu}(\mathrm{III})$ and various fluorination reactions could be developed by different catalytic mechanisms.

Fluorination of inert $\mathrm{C}-\mathrm{H}$ bonds, alkyl bromides and -triflates: In a 2012 study, Lectka's group [67] disclosed the catalytic fluorination of a series of aliphatic, benzylic, and allylic substrates with moderate yields. In this case, the authors employed a multicomponent catalytic system, involving Selectfluor, the radical precursor $N$-hydroxyphthalimide (NHPI), an anionic phase-transfer catalyst $\left(\mathrm{KB}\left(\mathrm{C}_{6} \mathrm{~F}_{5}\right)_{4}\right)$, and a $\mathrm{Cu}(\mathrm{I})$ bisimine complex, to give the corresponding monofluorinated product (Scheme 25).
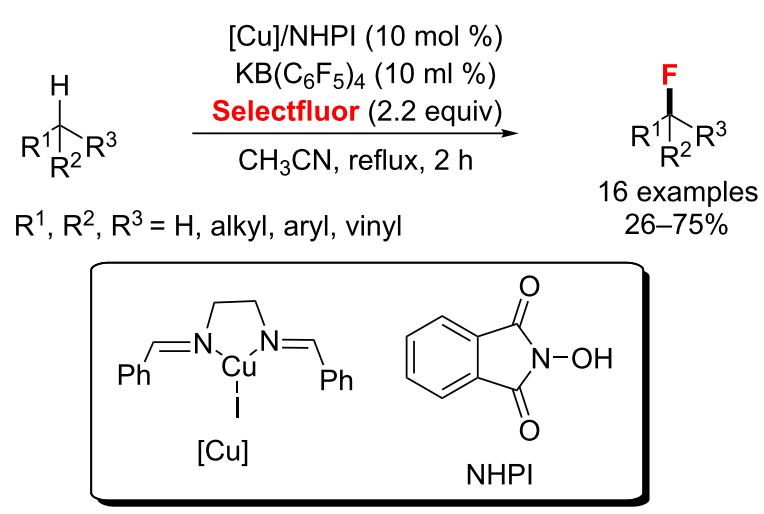

Scheme 25: Cu-catalyzed aliphatic, allylic, and benzylic fluorination.

One year later, Weng and co-workers [68] synthesized and characterized a new copper(I) fluoride complex ligated by a phenanthroline derivative. This complex was applied to the $\mathrm{S}_{\mathrm{N}} 2$ fluorination of primary and secondary alkyl bromides, producing the corresponding alkyl fluorides in $40-90 \%$ yield (Scheme 26).

$$
\begin{aligned}
& \stackrel{\mathrm{Br}}{\mathrm{R}^{1}} \stackrel{\left(\mathrm{Me}_{2} \text { phen }\right)_{2} \mathrm{Cu}\left(\mathrm{HF}_{2}\right)(1.5 \text { equiv })}{\mathrm{CH}_{3} \mathrm{CN}, 110^{\circ} \mathrm{C}, 15 \mathrm{~h}} \underset{\mathrm{R}^{1}}{\stackrel{\mathrm{F}}{\mathrm{R}^{2}}} \\
& \mathrm{R}^{1}, \mathrm{R}^{2}=\mathrm{H} \text {, alkyl, aryl }
\end{aligned}
$$

Scheme 26: Cu-catalyzed $\mathrm{S}_{\mathrm{N}} 2$ fluorination of primary and secondary alkyl bromides.
In 2014, the group of Lalic [69] developed a mild fluorination of alkyl triflates with potassium fluoride catalyzed by a phasetransfer copper catalyst (Scheme 27). Notably, with $10 \mathrm{~mol} \%$ of (IPr)CuOTf, full conversion can be accomplished in 10 minutes at $45{ }^{\circ} \mathrm{C}$.

Allylic fluorination: In 2013, there is an example of a coppercatalyzed fluorination of internal allylic bromides (Scheme 28). In Liu's study, this approach was achieved using $\mathrm{Et}_{3} \mathrm{~N} \cdot 3 \mathrm{HF}$ as the fluorine source with a high catalyst loading (20-30 mol \%) affording the products in $45-92 \%$ yield [70]. The heteroatomcontaining functional group $\left(\mathrm{R}^{1}\right)$ is necessary for good reactivity and regioselectivity.

$\mathrm{R}^{1}=$ alkyl-containing heteroatom functional group
$\mathrm{R}^{2}=$ alkyl, aryl, benzl
$\mathrm{X}=\mathrm{Br}, \mathrm{Cl}$
Scheme 28: Cu-catalyzed fluorination of allylic bromides and chlo-
rides.

$\boldsymbol{\alpha}$-Fluorination of acidic carbonyl compounds: In 2011, Shibatomi and co-workers [71] described the one-pot asymmetric gem-chlorofluorination of active methylene compounds by using a copper(II) complex with a chiral spiro 2-pyridyl monooxazoline ligand (SPYMOX). The corresponding $\alpha$-chloro- $\alpha$-fluoro- $\beta$-keto esters were isolated with up to $92 \%$ ee (Scheme 29a). This approach could be extended to asymmetric gem-chlorofluorination of $\beta$-ketophosphonates. Two years later, the same authors [72] demonstrated the highly enantioselective fluorination of $\alpha$-alkyl- $\beta$-keto esters and $\alpha$-alkylmalonates using the same catalyst system (Scheme 29b). Moreover, various cyclic and acyclic substrates were successfully fluorinated with high enantioselectivities.

In 2013, the Kesavan group [73] reported the use of tartrate-

\begin{tabular}{|c|c|c|c|c|c|}
\hline & $\begin{array}{c}\mathrm{Tf}_{2} \mathrm{O} \\
\text { 2,6-lutidine }\end{array}$ & OTf & $\begin{array}{l}\text { cat. (IPr)CuOTf }(2 \mathrm{~mol} \%) \\
\underset{\mathrm{KF}(3.0 \text { equiv) }}{\longrightarrow}\end{array}$ & . & 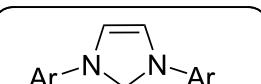 \\
\hline $\begin{array}{l}\mathrm{R}^{1} \mathrm{R} \\
\mathrm{R}^{1}, \mathrm{R}^{2}=\end{array}$ & $\begin{array}{l}\mathrm{CH}_{2} \mathrm{Cl}_{2},-78^{\circ} \mathrm{C}, 20 \mathrm{~min} \\
\text { alkyl, } \mathrm{CO}_{2} \mathrm{R}, \mathrm{CN}\end{array}$ & $\mathrm{R}^{1} \mathrm{R}^{2}$ & 1,4-dioxane, $45^{\circ} \mathrm{C}, 1 \mathrm{~h}$ & $\begin{array}{c}\mathrm{R}^{1} \mathrm{R}^{2} \\
19 \text { examples } \\
51-95 \%\end{array}$ & $\underset{\mathrm{IPr}}{\mathrm{IPr}=2,6-(\mathrm{PPr})_{2}-\mathrm{C}_{6} \mathrm{H}_{3}}$ \\
\hline
\end{tabular}
derived bidentate bisoxazoline- $\mathrm{Cu}(\mathrm{II})$ complexes for the enantioselective fluorination of aliphatic cyclic and acyclic $\beta$-ketoesters with up to $98 \%$ yields (Scheme 30 ). In this method, 
a)

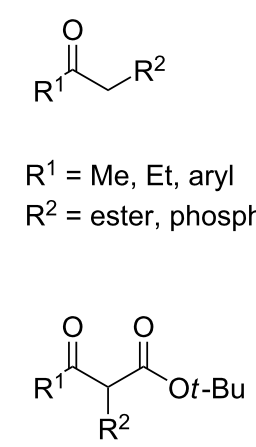

1) NCS (1.1 equiv), rt, $2 \mathrm{~h}$

2) NFSI (3.0 equiv), $40^{\circ} \mathrm{C}$ or $0{ }^{\circ} \mathrm{C}$

$\mathrm{L} / \mathrm{Cu}(\mathrm{OTf})_{2}(12 / 10 \mathrm{~mol} \%)$

$4 \AA \mathrm{MS}$, benzene, 4-70 h
Cle

12 examples

$52-92 \%$

$79-92 \%$ ee<smiles>[R]C(=O)C([R])(F)C(=O)OCC</smiles>

14 examples

$76-94 \%$

$87-99 \%$ ee

cyclic and acyclic substrates

At, $1-42 \mathrm{~h}$

$\mathrm{L} / \mathrm{Cu}(\mathrm{OTf})_{2}(36 / 30 \mathrm{~mol} \%)$

$\prod_{\mathrm{O}}^{\mathrm{MeO}} \underbrace{\mathrm{He}}_{\mathrm{O}} \mathrm{OR}$

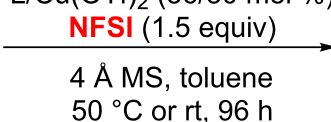

$\left.\prod_{O}^{M e O}\right|_{O} ^{\mathrm{Me}} \mathrm{OR}$

$\mathrm{R}=\mathrm{CH}(1 \text {-naphthyl })_{2}, 81 \%, 83 \%$ ee

$\mathrm{R}=t-\mathrm{Bu}, 74 \%, 71 \%$ ee

Scheme 29: Synthetic strategy for the fluorination of active methylene compounds.

Scheme 30: Fluorination of $\beta$-ketoesters using a tartrate-derived bidentate bisoxazoline-Cu(II) complex.

$(S, S)$-Nap- $(R, R)$-Box as the most suitable diastereomeric ligand forms a 5 -membered chelate with copper.

In the same year, an efficient and highly enantioselective fluorination of $\beta$-ketoesters catalyzed by diphenylamine-linked bis(thiazoline)-Cu(OTf $)_{2}$ complexes was reported by $\mathrm{Du}$ and co-worker (Scheme 31a) [74]. Che and co-workers [75] achieved a similar $\alpha$-fluorination of $\beta$-ketoesters and $N$-Bocoxindoles (Scheme 31b). Compared with Du's method, Che employed both $\mathrm{AgClO}_{4}$ and chiral iron(III)-salan complexes as the catalyst.
In 2016, the group of Nishikata [76] described a copper-catalyzed site-selective fluorination of $\alpha$-bromocarbonyl compounds using a copper/CsF catalyst system (Scheme 32). Tertiary alkyl fluorides could be generated by this fluorination through the assistance of an amide group. From the results, the catalytic cycle of this reaction includes: 1) copper salt induced generation of the alkyl radical species $\mathbf{B}$ from substrate $\mathbf{A}$ and 2) fluorination of the alkyl radical species $\mathbf{B}$ with $\mathrm{CuF}_{2}$, which is in situ-generated from the reaction of $\mathrm{CuXBr}$ and $\mathrm{CsF}$ with the aid of an amide group, gives the desired product and recyclable $\mathrm{CuF}$. 
a)<smiles>[R]C(=O)C1[Y]([H])c2cc([R])c([R])cc2C1=O</smiles>

$\mathrm{R}^{1}=\mathrm{OEt}, \mathrm{Et}, \mathrm{OBn}, \mathrm{OMe}, \mathrm{iPr}, t-\mathrm{Bu}, \mathrm{NH} n-\mathrm{Bu}, \mathrm{NHPh}, \mathrm{NHBn}$

$\mathrm{R}^{2}=\mathrm{H}, \mathrm{Me}, \mathrm{OMe}$

$\mathrm{R}^{3}=\mathrm{H}, \mathrm{Cl}, \mathrm{Br}, \mathrm{OMe}$

$n=1,2$

b)<smiles>[R17]OC(=O)C1[Y]c2c[R1]([H])ccc2C1=O</smiles>

$\mathrm{R}^{1}=t-\mathrm{Bu}, \mathrm{iPr}, \mathrm{Ad}$

$\mathrm{R}^{2}=\mathrm{H}, \mathrm{Cl}, \mathrm{F}, \mathrm{OMe}, \mathrm{Me}$

$n=1,2$<smiles>[R]c1ccc2c(c1)C([R])C(=O)N2[O+]</smiles>

Boc

$\mathrm{R}^{1}=\mathrm{Me}, \mathrm{Et}, t-\mathrm{Bu}, n-\mathrm{Pr}, \mathrm{Bn}, \mathrm{Ph}, p-\mathrm{MeC}_{6} \mathrm{H}_{4}, p-\mathrm{FC}_{6} \mathrm{H}_{4}$ $\mathrm{R}^{2}=\mathrm{H}, \mathrm{F}, \mathrm{OMe}, \mathrm{Me}$
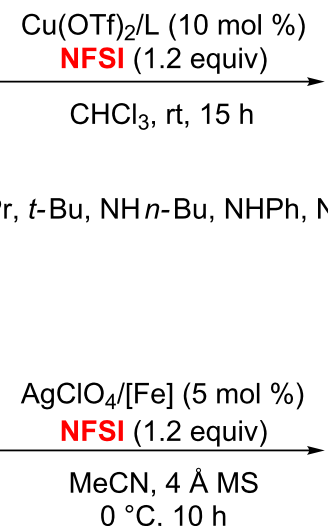

$\mathrm{AgClO}_{4} /[\mathrm{Fe}](5 \mathrm{~mol} \%)$ NFSI (1.2 equiv)

$\mathrm{Et}_{2} \mathrm{O}, 4 \AA \mathrm{MS}$

$0{ }^{\circ} \mathrm{C}, 3-10 \mathrm{~h}$<smiles>[R]CC(=O)C1(F)[Y6]c2cc([R])c([R4])cc2C1=O</smiles>

14 examples

$89-100 \%$

$73-99 \%$ ee<smiles>[R]OC(=O)C1(F)[Y20](=O)c2c[R1]([H])ccc2C1=O</smiles>

12 examples

$88-99 \%$

$46-97 \%$ ee<smiles>[R]c1ccc2c(c1)C([R1])(F)C(=O)N2C(=O)OCc1ccccc1</smiles>

11 examples

$82-94 \%$

$82-96 \%$ ee

Scheme 31: Highly enantioselective fluorination of $\beta$-ketoesters and $N$-Boc-oxindoles.<smiles>[R20]CCN=C(C#[R10])c1ccc(NC(=O)C([R])([R])Br)cc1</smiles>

$M=O, N$

$\mathrm{X}=\mathrm{Br}, \mathrm{Cl}, \mathrm{I}, \mathrm{OH}, \mathrm{OTs}, p-\mathrm{IC}_{6} \mathrm{H}_{4}, p-\mathrm{BrC}_{6} \mathrm{H}_{4}$

$\mathrm{R}^{1}, \mathrm{R}^{2}=$ alkyl

$\mathrm{R}(\mathrm{X})_{n}=$ primary or secondary alkyl halide moieties, tertiary alkyl-OH, alkyl-OTs

proposed mechanism<smiles>CC(C)(Br)C(=O)NCBr</smiles>

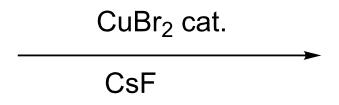<smiles>[2H]C(C)(F)C(=O)N[Al]</smiles>

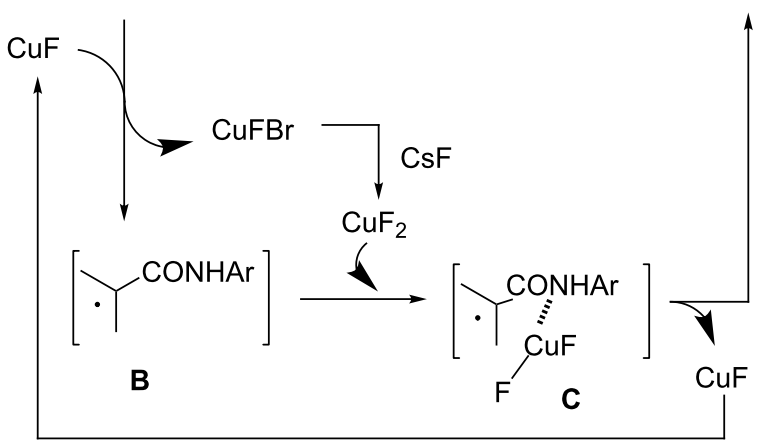

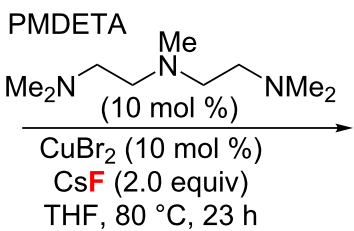

$\mathrm{CsF}(2.0$ equiv)<smiles>[R10]CCN=C([R])c1ccc(NC(=O)C([R])([R])F)cc1</smiles>

14 examples up to $80 \%$ yield 
$\mathbf{C}_{\mathrm{sp}}$ 2-H bond formation catalyzed by $\mathbf{C u}$ catalysts: In 2013, Sanford and co-workers [77] developed a simple and practical process for the nucleophilic fluorination of arylpotassium trifluoroborates. The reaction proceeds in $\mathrm{CH}_{3} \mathrm{CN}$ at $60{ }^{\circ} \mathrm{C}$ in the presence of $\mathrm{Cu}(\mathrm{OTf})_{2}$ as the catalyst and $\mathrm{KF}$ as the fluoride source (Scheme 33). A possible mechanism for this transformation is proposed in Scheme 33 below. Notably, $\mathrm{Cu}$ acts as both a mediator and an oxidizer in this reaction.
In the same year, Daugulis et al. [78] presented a Cu-catalyzed selective fluorination of benzoic acid derivatives and benzylamine derivatives assisted by an aminoquinoline auxiliary. With a CuI catalyst, $\mathrm{AgF}$ as fluoride source, $\mathrm{NMO}$ as oxidant, and DMF as solvent, they achieved the selective mono- or difluorination in high yields (Scheme 34). Notably, pyridine as an additive could prevent the decomposition of an amide substrate in a long-time reaction.
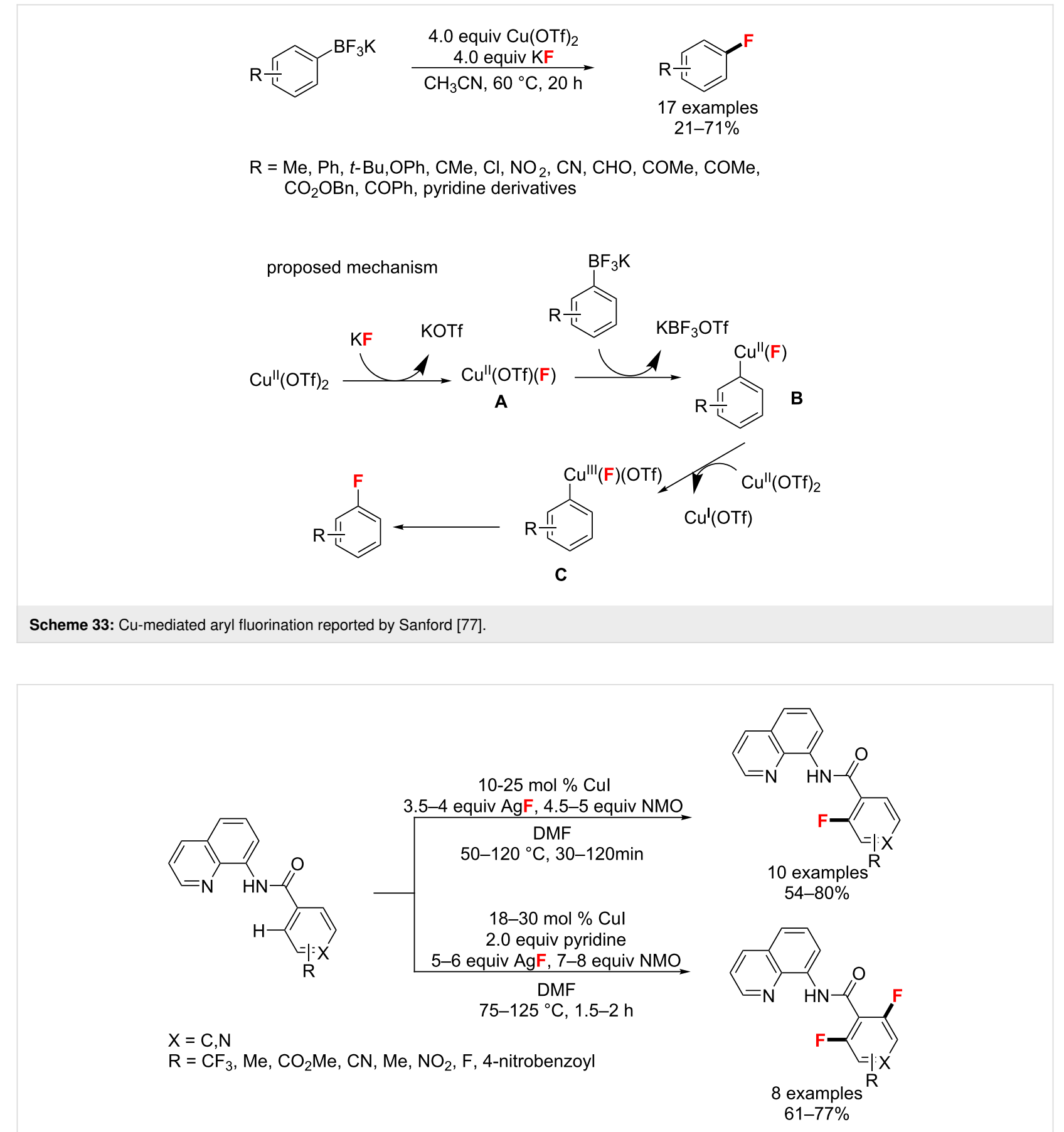

Scheme 34: Mono- or difluorination reactions of benzoic acid derivatives. 
Meanwhile, the group of Sanford [79] presented the nucleophilic fluorination of diaryliodonium salts with KF through a $\mathrm{Cu}(\mathrm{I} / \mathrm{III})$ catalytic cycle mechanism. This procedure preferentially fluorinates the smaller aromatic ligand on iodine(III). Also, the addition of $\mathrm{Cu}(\mathrm{OTf})_{2}$ and 18 -crown- 6 promoted the fluorination effectively. Finally, excellent yields, fast rate, high selectivity, and a broad substrate scope were observed by the authors (Scheme 35). The proposed mechanism is as follows: ligand exchange of the active $\mathrm{Cu}(\mathrm{I})$ catalyst $\mathbf{A}$, which is generated via either reduction by the solvent or disproportionation of the precatalyst $\mathrm{Cu}(\mathrm{II})(\mathrm{OTf})_{2}$, provides $\mathrm{Cu}(\mathrm{I})-\mathrm{F}(\mathbf{B})$. Then, oxidation of $\mathrm{Cu}(\mathrm{I})-\mathrm{F}(\mathbf{B})$ by the diaryliodonium reagent forms $\mathrm{Cu}(\mathrm{III})-$ aryl intermediate $\mathbf{C}$. Subsequently, a reductive elimination of intermediate $\mathbf{C}$ provides a putative $\pi$-complex $\mathbf{D}$, which then releases the desired aryl-F product and regenerates the $\mathrm{CuI}$ catalyst $\mathbf{A}$.

Subsequently, the Cu-catalyzed fluorination of 2-pyridylaryl bromides was achieved by Liu and co-workers [80] through a $\mathrm{Cu}(\mathrm{I} / \mathrm{III})$ catalytic cycle as well (Scheme 36 ). This method is based on the aid of an important pyridyl directing group and the final aryl C-F bond is formed after the reductive elimination of $\mathrm{ArCu}(\mathrm{III})-\mathrm{F}$ species.

\section{Other catalysts}

Other transition metals, including $\mathrm{Co}, \mathrm{Ni}, \mathrm{Fe}, \mathrm{Ag}, \mathrm{Ir}, \mathrm{Mn}$, etc., have received more and more attention.

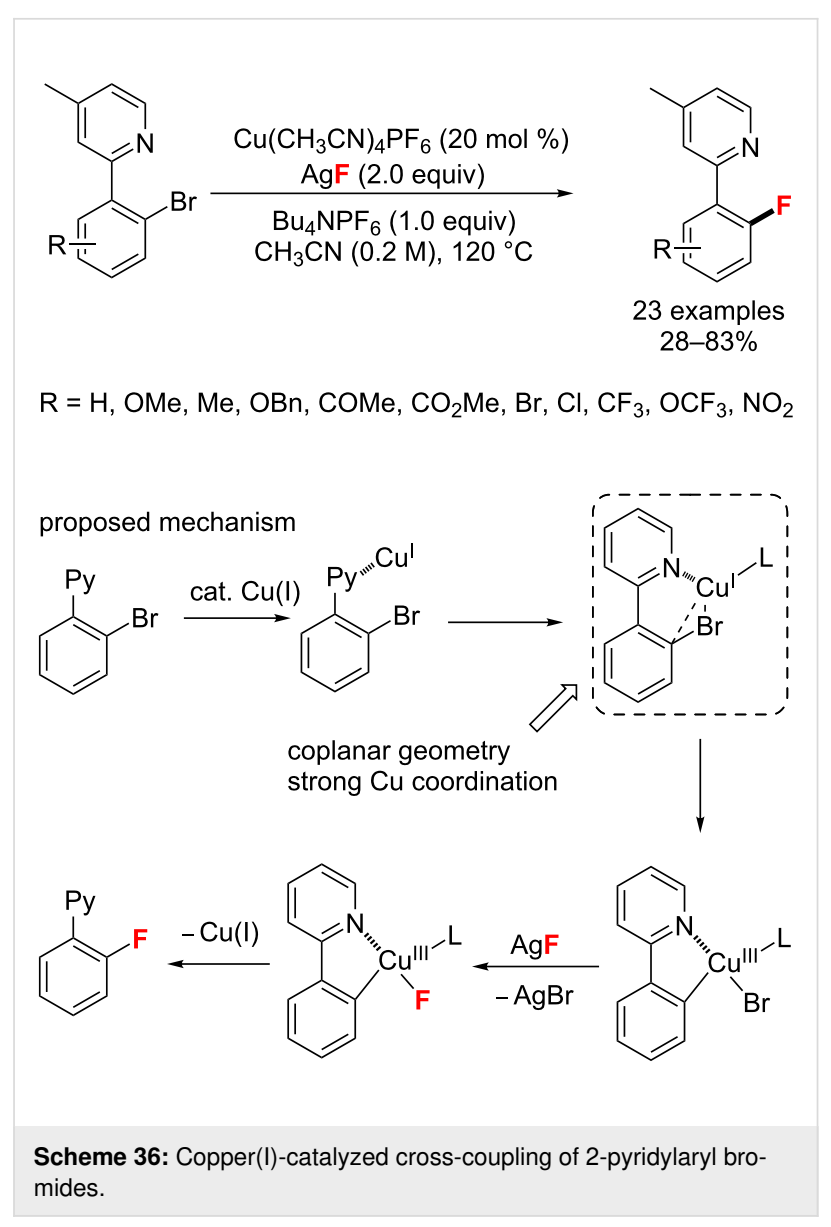

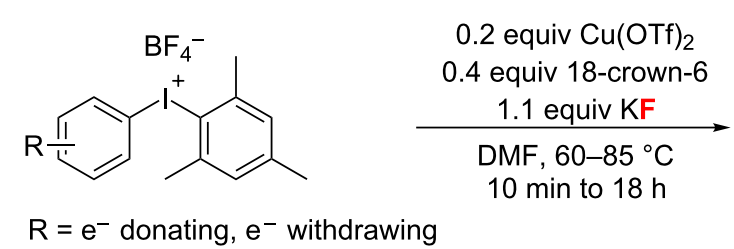

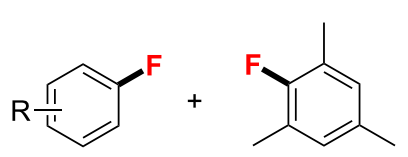

26 examples, 33-99\%

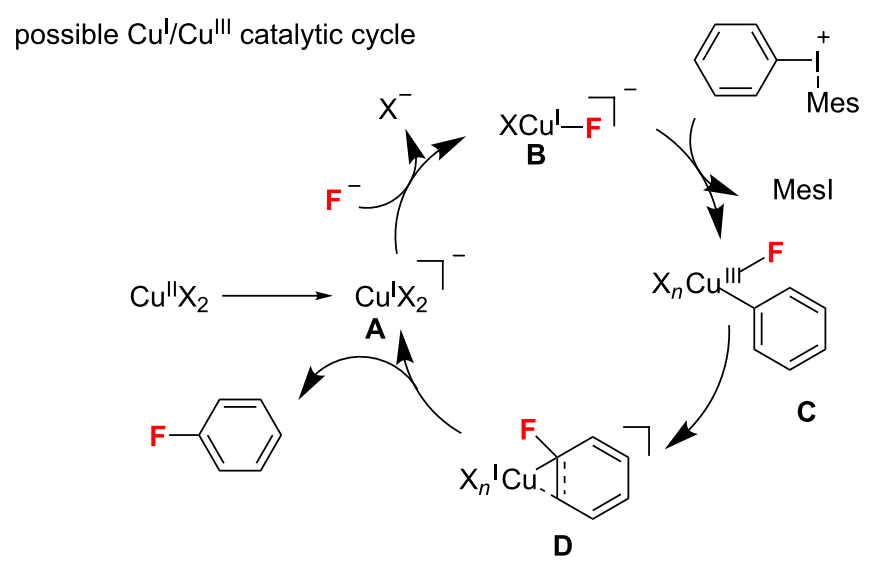

Scheme 35: Cu-catalyzed fluorination of diaryliodonium salts with KF. 
Aliphatic and benzylic C-H fluorination and decarboxylative fluorination: In 2012, a silver-catalyzed radical decarboxylative fluorination of aliphatic carboxylic acids in aqueous solution was provided by $\mathrm{Li}$ and co-workers (Scheme 37) [81] The corresponding alkyl fluorides were produced in $47-95 \%$ yield under mild conditions. Additionally, the authors proposed a mechanism involving a $\mathrm{Ag}(\mathrm{III})$-mediated SET followed by a fluorine transfer.

Subsequently, the group of Groves [82] developed two manganese catalysts for the fluorination of $\mathrm{C}\left(\mathrm{sp}^{3}\right)-\mathrm{H}$ bonds (Scheme 38). On the one hand, they employed a manganese

$$
\mathrm{R}_{\mathrm{R}^{2}}^{\mathrm{CO}_{2} \mathrm{H}} \mathrm{R}^{3}
$$

$$
\begin{aligned}
& \underset{\text { Selectfluor (2.0 equiv) }}{\stackrel{\text { acetone } / \mathrm{H}_{2} \mathrm{O} 1: 1 \text { or } \mathrm{H}_{2} \mathrm{O}}{\longrightarrow}} \\
& \text { rt or } 45^{\circ} \mathrm{C} \text { or } 55^{\circ} \mathrm{C}, 1-10 \mathrm{~h}
\end{aligned}
$$$$
\text { cat. } \mathrm{AgNO}_{3}(20 \mathrm{~mol} \%)
$$

$R^{1}, R^{2}, R^{3}=H$, alkyl, OR, $N R_{2}$

$$
{ }_{\mathrm{R}^{1}}^{\mathrm{F}} \mathrm{R}_{\mathrm{R}^{3}}
$$

27 examples $47-95 \%$

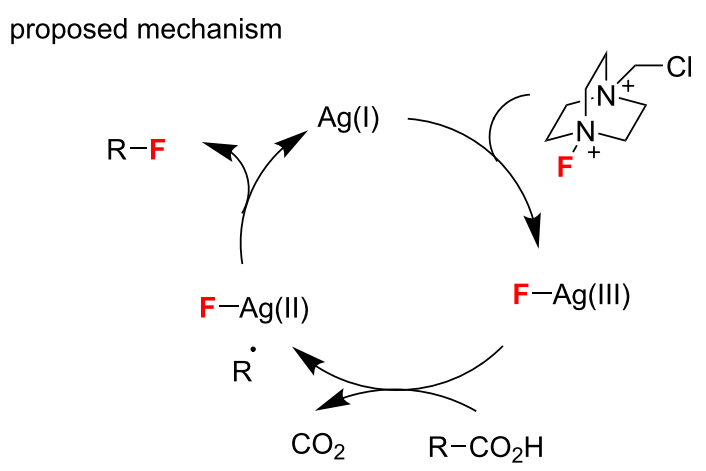

Scheme 37: $\mathrm{AgNO}_{3}$-catalyzed decarboxylative fluorination of aliphatic carboxylic acids.

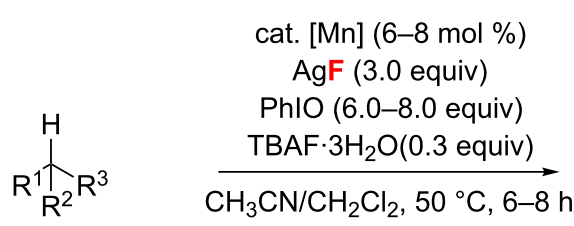

$R^{1}, R^{2}, R^{3}=H$, alkyl<smiles>[R]C(C)c1cc[R1]cc1</smiles>
benzylic substrates

$$
\begin{aligned}
& \mathrm{CH}_{3} \mathrm{CN}, 50^{\circ} \mathrm{C}, 6-9 \mathrm{~h} \\
& \mathrm{Mn} \text { (salen)Cl (20 mol \%) } \\
& \text { PhIO (6.0-9.0 equiv) } \\
& \text { TREAT.HF ( } 1.5 \text { equiv) }
\end{aligned}
$$<smiles>[R]C([1H])c1cc[R1]cc1</smiles>

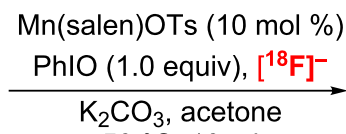
$50^{\circ} \mathrm{C}, 10 \mathrm{~min}$

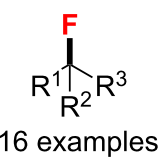

$30-57 \%$<smiles>[R]C(F)c1cc[R1]cc1</smiles>

16 examples, $44-70 \%$<smiles></smiles>

30 examples, $22-72 \%$ RCC
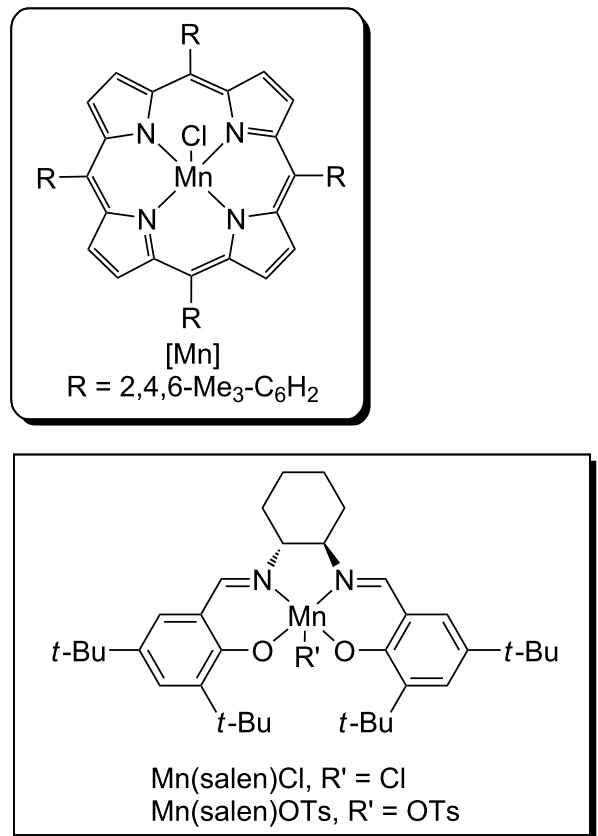
porphyrin to catalyze the oxidative aliphatic $\mathrm{C}-\mathrm{H}$ fluorination with iodosylbenzene (PhIO) as a stoichiometric oxidant. A variety of substrates, including simple hydrocarbons, substituted cyclic molecules, terpenoids, and steroid derivatives, were selectively fluorinated at some otherwise inaccessible sites, however, in low to moderate yields. On the other hand, the same group [83] developed $\mathrm{Mn}$ (salen) $\mathrm{Cl}$ as a catalyst for the direct $\mathrm{C}-\mathrm{H}$ fluorination at benzylic positions with a nucleophilic fluorine source. Notably, Groves adapted the method for the ${ }^{18} \mathrm{~F}$-radiofluorination of benzylic and aliphatic $\mathrm{C}-\mathrm{H}$ bonds using no-carrier-added $\left[{ }^{18} \mathrm{~F}\right]$-fluoride with $\mathrm{Mn}$ (salen)OTs [84]

In 2013, Lectka's group $[85,86]$ reported an iron-catalyzed $\mathrm{C}\left(\mathrm{sp}^{3}\right)-\mathrm{H}$ fluorination of benzylic substrates with or without an electron-withdrawing group (EWG) in the presence of Selectfluor (Scheme 39). Notably, an EWG beta to the benzylic position is efficient for an excellent selectivity of the benzylic fluorination.
Moreover, Gouverneur and co-workers [87] established the decarboxylative fluorination of $\alpha, \alpha$-difluoro- and $\alpha$-fluoroarylacetic acids with a wide functional group compatibility in the presence of $\mathrm{AgNO}_{3}$ as catalyst in good yields (Scheme 40). Further, this approach was efficiently applied to the preparation of $\left[{ }^{18} \mathrm{~F}\right]$-labelled tri- and difluoromethylarenes using $\left[{ }^{18} \mathrm{~F}\right]$ Selectfluor bis(triflate).

In 2014, Chen and co-workers [88] described a selective direct $\mathrm{C}\left(\mathrm{sp}^{3}\right)-\mathrm{H}$ fluorination catalyzed by a commercially available vanadium(III) oxide with Selectfluor in good yields (Scheme 41). It is noteworthy that the catalyst and the byproduct H-TEDA could be removed easily by filtration.

A simple $\mathrm{AgNO}_{3}$-catalyzed synthesis of alkyl fluorides through radical deboronofluorination of alkyl boronates and boronic acids in acidic aqueous solution was also developed by $\mathrm{Li}$ and co-workers in 2014 [89]. This method features

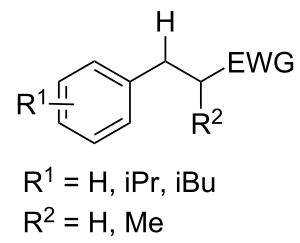
$10 \mathrm{~mol} \% \mathrm{Fe}(\mathrm{acac})_{2}$ Selectfluor ( 2.2 equiv)

$\mathrm{MeCN}, \mathrm{rt},>24 \mathrm{~h}$ $\mathrm{R}^{2}=\mathrm{H}, \mathrm{Me}$<smiles></smiles>

Scheme 39: Iron(II)-promoted C-H fluorination of benzylic substrates.
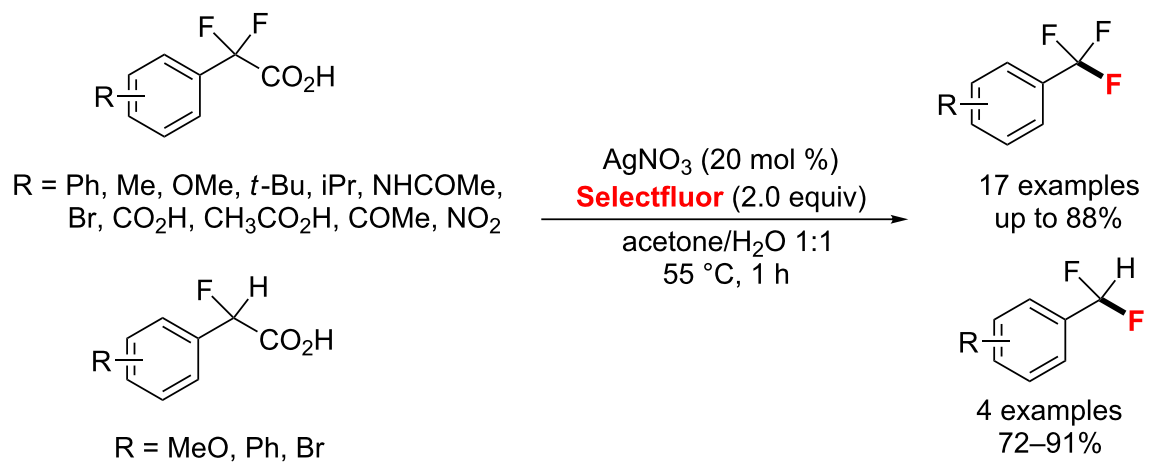

Scheme 40: Ag-catalyzed fluorodecarboxylation of carboxylic acids.

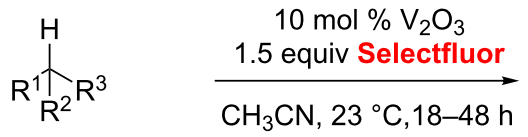

$\mathrm{R}^{1}, \mathrm{R}^{2}, \mathrm{R}^{3}=\mathrm{H}$, alkyl, aryl

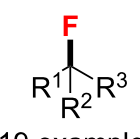

19 examples $12-85 \%$ NMR

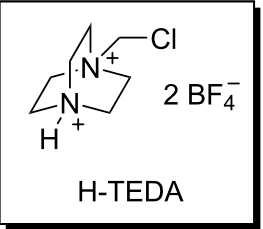


good yields and a wide functional group compatibility (Scheme 42).

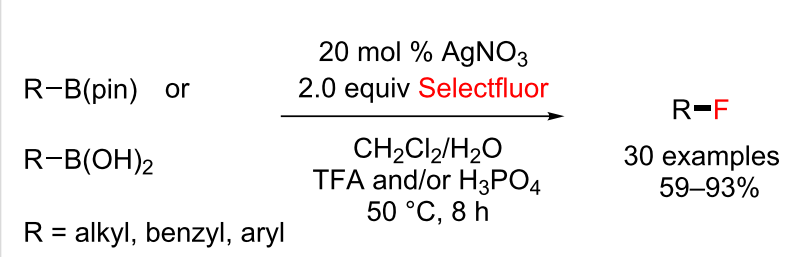

Scheme 42: $\mathrm{AgNO}_{3}$-catalyzed radical deboronofluorination of alkylboronates and boronic acids.

Recently, the group of Van Humbeck [90] reported a selective and mild method for the $\mathrm{C}-\mathrm{H}$ fluorination of azaheterocycles with Selectfluor at room temperature. In this case, a new radical mechanism was proposed that electron transfer from the heterocyclic substrate to Selectfluor eventually generates a benzylic radical, leading to the desired $\mathrm{C}-\mathrm{F}$ bond formation. The excellent selectivity of the desired fluorinated product was obtained without additives. In addition, a catalytic amount of iron(III) complex $\left[\mathrm{FeCl}_{4}\right]\left[\mathrm{FeCl}_{2}(\mathrm{dmf})_{3}\right]$ was found to improve the yields in some cases (Scheme 43).

With an $\mathrm{Fe}$ (II)-catalyzed orchestrated redox process, an alkoxyl radical-guided strategy for the site-selective fluorination of unactivated methylene and methine $\mathrm{C}-\mathrm{H}$ bonds was published by Liu and co-workers in 2018 (Scheme 44) [91]. The fluorination of various primary, secondary, and tertiary hydroperoxides was achieved in moderate to excellent yields, with the hydroperoxide functional group acting as a precursor of an alkoxy radical to control site-selective carbon-centered radical formation.

Allylic fluorination: In 2011, the group of Nguyen [92] developed the nucleophilic fluorination of allylic trichloroacetimidates, as shown in Scheme 45a. Cyclooctadiene iridium chloride dimer, $[\mathrm{IrCl}(\mathrm{COD})]_{2}$, was an effective catalyst to promote this fluorination with $\mathrm{Et}_{3} \mathrm{~N} \cdot 3 \mathrm{HF}$, forming allylic fluorides in

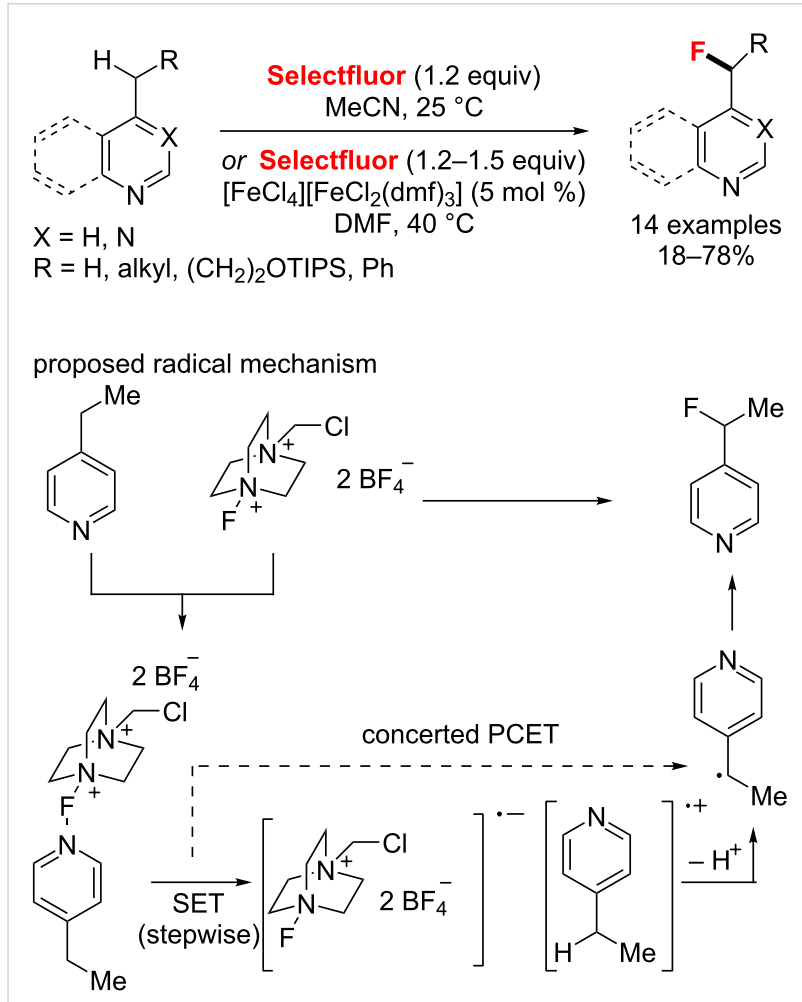

Scheme 43: Selective heterobenzylic $\mathrm{C}-\mathrm{H}$ fluorination with Selectfluor reported by Van Humbeck.

moderate to good yields. This facile method shows a good regioselectivity to gain the branched isomer within $1 \mathrm{~h}$. Later in 2017, they described a similar method for the asymmetric fluorination of racemic allylic trichloroacetimidates utilizing a chiral bicyclo[3.3.0] octadiene-ligated iridium complex (Scheme 45b) [93]. This reaction proceeded under mild conditions with an extremely broad substrate scope, as well as excellent branched-to-linear ratios and enantioselectivities.

In 2013, Gouverneur and co-workers [94] demonstrated the regio and stereocontrolled fluorination of allylic carbonates with $[\operatorname{Ir}(\mathrm{COD}) \mathrm{Cl}]_{2}$ as the catalyst and $\operatorname{TBAF}(t-\mathrm{BuOH})_{4}$ as the fluoride source to produce branched and linear allylic fluorides

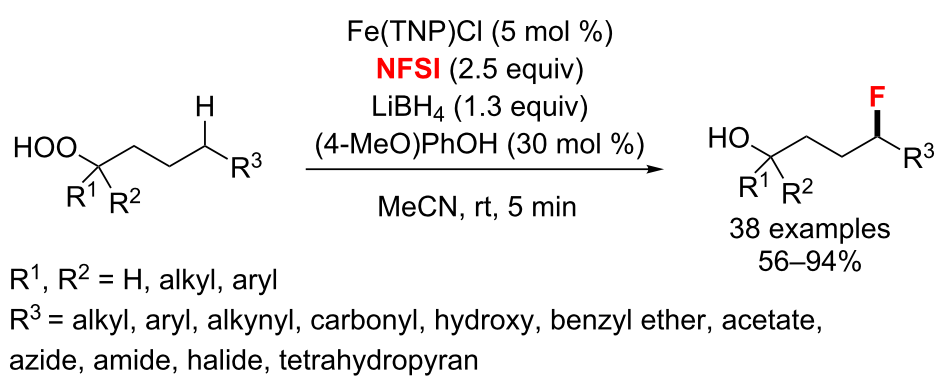

Scheme 44: Fe(II)-catalyzed site-selective fluorination guided by an alkoxyl radical. 
a)<smiles>[R1][C@H](C=C)OC(=N)C([R])([R])Cl</smiles>

$\mathrm{R}^{1}=$ alkyl

$\mathrm{R}^{2}=\mathrm{H}, \mathrm{CH}_{3}$

b)

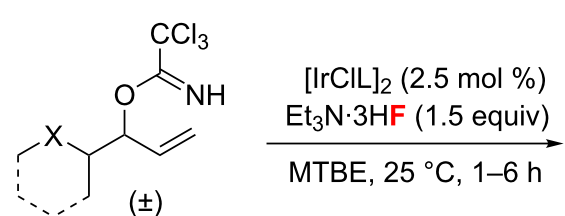

allylic trichloroacetimidates bearing $\alpha$-branching, $\alpha$-linear, $\beta$-oxygen, and $\beta$-nitrogen substituents
$\left[\mathrm{Ir}(\mathrm{cod}) \mathrm{Cl}_{2}(5 \mathrm{~mol} \%)\right.$
$\mathrm{Et}_{3} \mathrm{~N} \cdot 3 \mathrm{HF}(3.0$ equiv $)$<smiles>[R][R1]([R])C=C</smiles>

12 examples, $64-91 \%$ branched/linear $>10: 1$<smiles>[X]C1CCCCC1C=C</smiles>

52 examples up to $97 \%$ ee up to $99: 1 \mathrm{dr}$

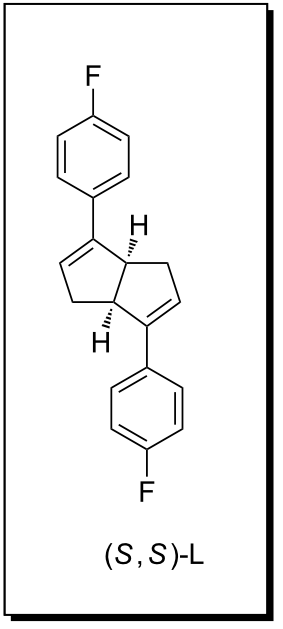

Scheme 45: Fluorination of allylic trichloroacetimidates reported by Nguyen et al.

(Scheme 46). Remarkably, this was the first example to afford (Z)-allyl fluorides ( $Z: E$ ratio $>20: 1)$.

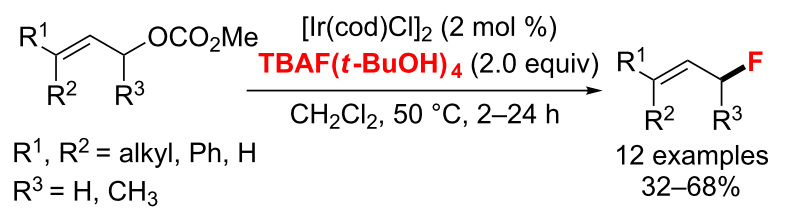

Scheme 46: Iridium-catalyzed fluorination of allylic carbonates with $\operatorname{TBAF}(t-\mathrm{BuOH})_{4}$.

In 2015, Nguyen et al. [95] explored the asymmetric fluorination of racemic, secondary allylic trichloroacetimidates with $\mathrm{Et}_{3} \mathrm{~N} \cdot 3 \mathrm{HF}$ using a chiral-diene-ligated Ir complex (Scheme 47). This process proceeded under mild conditions with excellent enantioselectivity and yields, a broad substrate scope, as well as a wide range of functional group compatibility. Notably, this strategy overcomes the challenges associated with the forma- tion of secondary allylic fluorides bearing $\alpha$-linear substituents, providing complete regio and stereocontrolled acrylic allylic fluorides.

Fluorination of acidic carbonyl compounds: In 2010, Itoh and co-workers [96] demonstrated the asymmetric fluorination of cyclic and acyclic $\beta$-ketoesters by using a catalytic amount of $\mathrm{Co}(\mathrm{acac})_{2}$ with $(R, R)$-Jacobsen's salen ligand (Scheme 48). The $\alpha$-fluorinated products were thus obtained with good enantioselectivity.

In the same year, Kim's group [97] accomplished an efficient enantioselective electrophilic $\alpha$-fluorination of various $\alpha$-chloro- $\beta$-ketoesters catalyzed by chiral nickel complexes with good enantioselectivity (up to $99 \%$ ee). Notably, the chiral nickel-diamine complexes are air and moisture-stable (Scheme 49).

In 2011, two nickel-catalyzed protocols for the enantioselective $\alpha$-fluorination of $\beta$-ketoesters were reported separately. In van

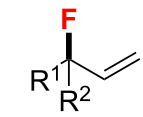

12 examples up to $90 \%$ yield up to $99 \%$ ee

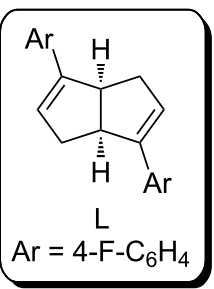




\section{$\mathrm{Co}(\mathrm{acac})_{2}(10 \mathrm{~mol} \%)$}<smiles>[R]C(=O)C([R])C([R])=O</smiles>

$(R, R)$-Jacobsen's salen ligand $(10 \mathrm{~mol} \%)$ NFSI ( 1.4 equiv)

$\mathrm{Et}_{2} \mathrm{O}$, rt or -20 or $0^{\circ} \mathrm{C}, 12 \mathrm{~h}$<smiles>[R]OC(=O)C([R])(F)C([R])=O</smiles>

$R^{1}, R^{2}=$ five, six or seven-membered rings, $M e$

7 examples

$64-75 \%$

$\mathrm{R}^{3}=\mathrm{Me}, \mathrm{Et}, t-\mathrm{Bu}$

$71-90 \%$ ee

Scheme 48: Cobalt-catalyzed $\alpha$-fluorination of $\beta$-ketoesters<smiles>[R]C(=O)C(Cl)C(=O)OCC</smiles>

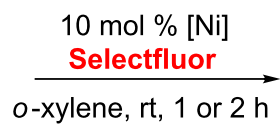

$\mathrm{R}=p-\mathrm{MeC}_{6} \mathrm{H}_{4}, \mathrm{Ph}, p-\mathrm{CF}_{3} \mathrm{C}_{6} \mathrm{H}_{4}, p-\mathrm{BrC}_{6} \mathrm{H}_{4}, 3-\mathrm{ClC}_{6} \mathrm{H}_{4}$, 2-naphthyl, Me

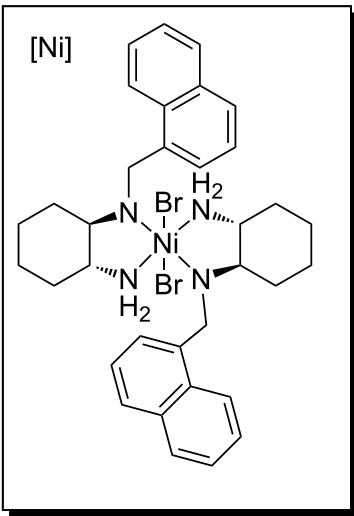

Scheme 49: Nickel-catalyzed $\alpha$-fluorination of various $\alpha$-chloro- $\beta$-ketoesters
Leeuwen's reaction, SPANamine derivatives were synthesized and applied as chiral ligands in the asymmetric $\alpha$-fluorination of $\beta$-ketoesters (Scheme 50a) [98]. Meanwhile, to achieve this transformation, Gade and co-workers [99] developed a new class of chiral tridentate $\mathrm{N}$-donor pincer ligands, bis(oxazolinylmethylidene)isoindolines. They obtained the desired products a)<smiles>[R]OC(=O)C1Cc2ccccc2C1=O</smiles>

$\mathrm{R}=\mathrm{Et}, t-\mathrm{Bu}$

R
$\mathrm{NiCl}_{2}(10 \mathrm{~mol} \%)$

SPANamine (11 mol \%) NFSI

$\mathrm{CH}_{2} \mathrm{Cl}_{2}$, rt, $3 \mathrm{~h}$

Ni( $\left.\mathrm{ClO}_{4}\right)_{2} \cdot 6 \mathrm{H}_{2} \mathrm{O}(10 \mathrm{~mol} \%)$ ligand (12 $\mathrm{mol} \%)$ NFSI

$4 \AA \mathrm{MS}, \mathrm{Et}_{2} \mathrm{O}, \mathrm{rt}, 6 \mathrm{~h}$

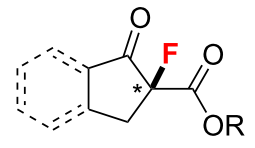

4 examples

$66-100 \%$

$9-63 \%$ ee

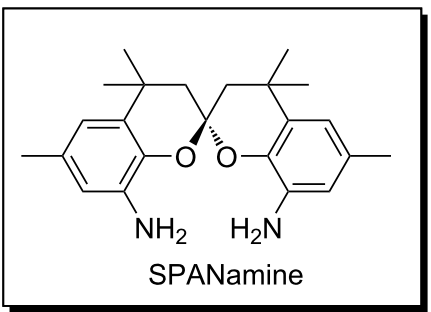

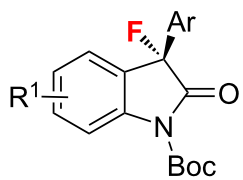

$95-99 \%$ ee<smiles>[R][R]1ccc2c(c1)C(=O)C(C(=O)OCC)(C(=O)OCC)C2</smiles>

92-97\% ee

$\mathrm{R}^{1}=\mathrm{H}, \mathrm{F}, \mathrm{Br}, \mathrm{Me}, \mathrm{MeO}, \mathrm{CF}_{3}$

$\mathrm{R}^{2}=\mathrm{H}, \mathrm{Br}, \mathrm{MeO}$ 
under mild conditions with excellent enantioselectivities (up to $>99 \%$ ee) and good yields (Scheme 50b).

Also, Feng et al. [100] developed a new method for the highly enantioselective fluorination of $\mathrm{N}-\mathrm{H}$-free 3-substituted oxindoles catalyzed by a $\mathrm{Sc}(\mathrm{III}) / N, N^{\prime}$-dioxide complex. A series of 3-aryl- and 3-alkyl-3-fluoro-2-oxindoles were obtained in excellent yields and enantioselectivities (89-99\% ee) with NFSI under basic conditions (Scheme 51).<smiles>[R]C1C(=O)Nc2ccccc21</smiles>

$$
\begin{gathered}
\mathrm{L}-\mathrm{Sc}(\mathrm{OTf})_{3}(5-10 \mathrm{~mol} \%) \\
\mathrm{NFSI}(1.2 \text { equiv }) \\
\underset{\mathrm{Na}_{2} \mathrm{CO}_{3}(120 \mathrm{~mol} \%)}{\stackrel{\mathrm{CHCl}_{3}, 0{ }^{\circ} \mathrm{C}, 20 \mathrm{~h}}{\longrightarrow}}
\end{gathered}
$$

$\mathrm{R}^{1}=$ alkyl, aryl

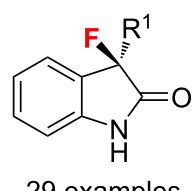

29 examples $80-98 \%$ $89-99 \%$ ee
Scheme 51: Scandium(III)-catalyzed asymmetric C-H fluorination of unprotected 3-substituted oxindoles.

In 2016, a mild, amide-directed fluorination of benzylic, allylic, and unactivated $\mathrm{C}-\mathrm{H}$ bonds was described by the Cook group [101]. By the use of the iron(II) triflate $\left(\mathrm{Fe}(\mathrm{OTf})_{2}\right)$ as catalyst, the desired fluorides were finally obtained through a F-transfer of a short-lived radical intermediate ( $N$-fluoro-2-methylbenzamides) in up to $93 \%$ yield (Scheme 52).

$\mathrm{C}_{\mathrm{sp}} \mathbf{2}-\mathrm{H}$ bond formation catalyzed by Ag catalysts: In 2010, the Ritter group [102] firstly reported a Ag-catalyzed fluorination of arylstannane derivatives with the electrophilic fluorination reagent F-TEDA-PF 6 (Scheme 53). Also, the reaction was applied to late-stage fluorination of small molecules. However, this method uses toxic arylstannanes as starting materials and requires an additional synthetic step from the triflate or halide to the stannanes.

\section{Trifluoromethylation}

Transition-metal-catalyzed trifluoromethylation reactions have made great progress in the joint efforts of organic fluorination

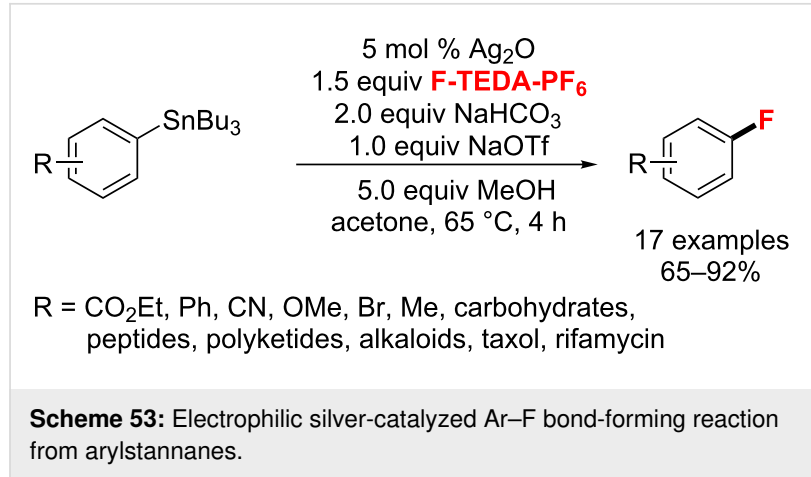

scientists and metalorganic chemists over the past decade. Introducing trifluoromethyl groups into organic molecules can significantly alter their properties, such as their metabolic stability, lipophilicity, and the ability to penetrate the blood-brain barrier. Similar to fluorination, trifluoromethylation can also be achieved by three reaction types: nucleophilic, electrophilic and radical trifluoromethylation.

In recent years, many novel trifluoromethylation reagents, such as cationic, anionic and radical $\mathrm{CF}_{3}$ sources have been discovered and offer manifold choices to effect electrophilic, nucleophilic and radical trifluoromethylation [103] (Figure 1). The selection of the trifluoromethylation reagent has become the main factor in the optimization of these reactions. With a suitable trifluoromethylation reagent, a wide range of substrates are directly converted to the desired trifluoromethylated products. Several reviews [104-110] have been published on this subject, while this part mainly discusses trifluoromethylation reactions catalyzed by metals. However, there are only a few methods available for the $\mathrm{C}\left(\mathrm{sp}^{3}\right)-\mathrm{CF}_{3}$ bond formation and this transformation still needs further examination.

\section{$\mathrm{C}\left(\mathrm{sp}^{3}\right)-\mathrm{CF}_{3}$ bond formation}

Copper catalysis: In 2011, two $\mathrm{Cu}(\mathrm{I})$-catalyzed allylic trifluoromethylation reactions of terminal olefins have been developed independently by the groups of Buchwald [111] and Wang [112] (Scheme 54). Under similar mild conditions using Togni's reagent II, the desired allyl- $\mathrm{CF}_{3}$ products were ob-

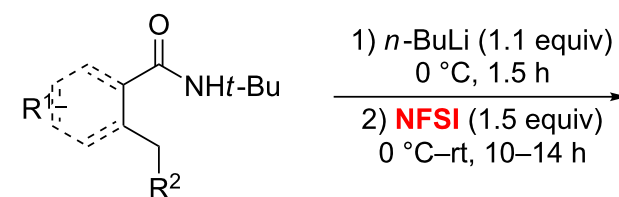

$\mathrm{R}^{1}=\mathrm{H}, \mathrm{Me}$, internal and terminal alkynes and alkenes, Bpin, CONHt-Bu $\mathrm{R}^{2}=\mathrm{H}$, alkyl<smiles>[R]Cc1cc[R1]cc1C(=O)N(C)CC</smiles>

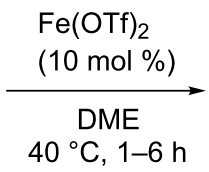<smiles></smiles>

21 examples $32-93 \%$ 
a) $\mathrm{CF}_{3}{ }^{-}$source

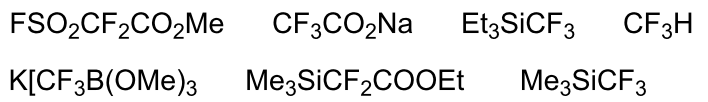

b) $\mathrm{CF}_{3}{ }^{+}$source<smiles>FC(F)(F)c1cccc2c3ccccc3[s+](C(F)(F)F)c12</smiles><smiles></smiles><smiles>CC1(C)OC(C(F)(F)F)c2ccccc21</smiles><smiles>O=C1OI(C(F)(F)F)c2ccccc21</smiles>

Umemoto's reagent

Togni's reagent I Togni's reagent II<smiles>FC(F)(F)C1OC(C(F)(F)F)(C(F)(F)F)c2ccccc21</smiles><smiles>C[N+](C)(C(F)(F)Br)S(=O)(=O)c1ccccc1</smiles>

c) $\mathrm{CF}_{3} \cdot$ source

$\mathrm{Zn}\left(\mathrm{SO}_{2} \mathrm{CF}_{3}\right)_{2} \quad \mathrm{NaSO}_{2} \mathrm{CF}_{3} \quad \mathrm{CF}_{3}$

$\mathrm{AgCF}_{3} \quad \mathrm{CuCF}_{3} \quad \mathrm{CF}_{3} \mathrm{SO}_{2} \mathrm{Cl}$

Figure 1: Nucleophilic, electrophilic and radical $\mathrm{CF}_{3}$ sources.<smiles>[R]C/C=C\[CH-]</smiles>

$\mathrm{R}=\mathrm{alkyl}, \mathrm{aryl}$

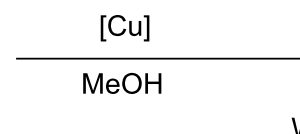

Wang: 15 examples, $44-97 \%$

Buchwald: 13 examples, $54-80 \%$

Wang: 2 (1-2.0 equiv), $\mathrm{CuCl}(10 \mathrm{~mol} \%), 70^{\circ} \mathrm{C}, 10 \mathrm{~min}$ or $1 \mathrm{~h}$

Buchwald: 2 (1.0 equiv), [Cu( $\left.\left.\mathrm{CH}_{3} \mathrm{CN}\right)_{4}\right]\left(\mathrm{PF}_{6}\right)(15 \mathrm{~mol} \%), 0{ }^{\circ} \mathrm{C}-\mathrm{rt}, 24 \mathrm{~h}$

Scheme 54: $\mathrm{Cu}(\mathrm{I})$-catalyzed allylic trifluoromethylation of unactivated terminal olefins.

tained and the methods well tolerated a variety of functional groups (e.g., esters, epoxides, amides, alcohols, or aldehydes). Moreover, the thermodynamically favored $E$-olefin was generated with high stereoselectivity in good yields.

In 2012, two different groups [113,114] individually reported the direct trifluoromethylation of allylsilanes under very similar conditions. These processes furnished various branched cyclic and acyclic allylic $\mathrm{CF}_{3}$ products using copper as the catalyst (Scheme 55).

Subsequently, an enantioselective trifluoromethylation of cyclic $\beta$-ketoesters with commercially available trifluoromethylating reagents was reported by Gade and co-workers using a Cu-boxmi catalyst [115]. Under mild conditions, both five and six-membered ring $\beta$-ketoesters were converted to the corre- sponding products in high yields and enantioselectivities (Scheme 56).

In 2018, the first example for the copper-catalyzed stereospecific trifluoromethylation of secondary propargyl sulfonates was described by the group of Zhang [116]. The resulting chiral trifluoromethylated alkynes were acquired with high regioselectivity and stereospecificity (ees up to $>99 \%$ ). Furthermore, this reaction showed a broad substrate scope, as well as excellent functional-group compatibility (Scheme 57). A possible mechanism was proposed: firstly, trifluoromethylcopper complex A, generated from $\mathrm{CuCN}$ with $\mathrm{TMSCF}_{3}$, undergoes oxidative addition with a secondary propargyl sulfonate to give a configuration-inversed propargyl-Cu(III) species $\mathrm{B}$. Then, the reductive elimination of $\mathrm{B}$ affords the final product with overall inversion of the configuration. 


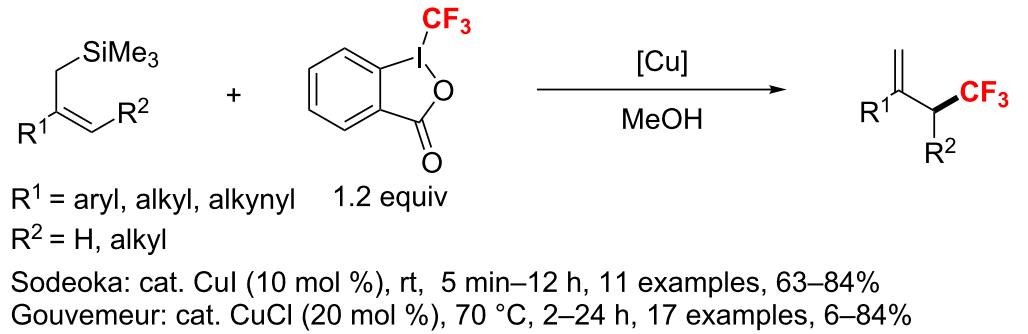

Scheme 55: Direct copper-catalyzed trifluoromethylation of allylsilanes.

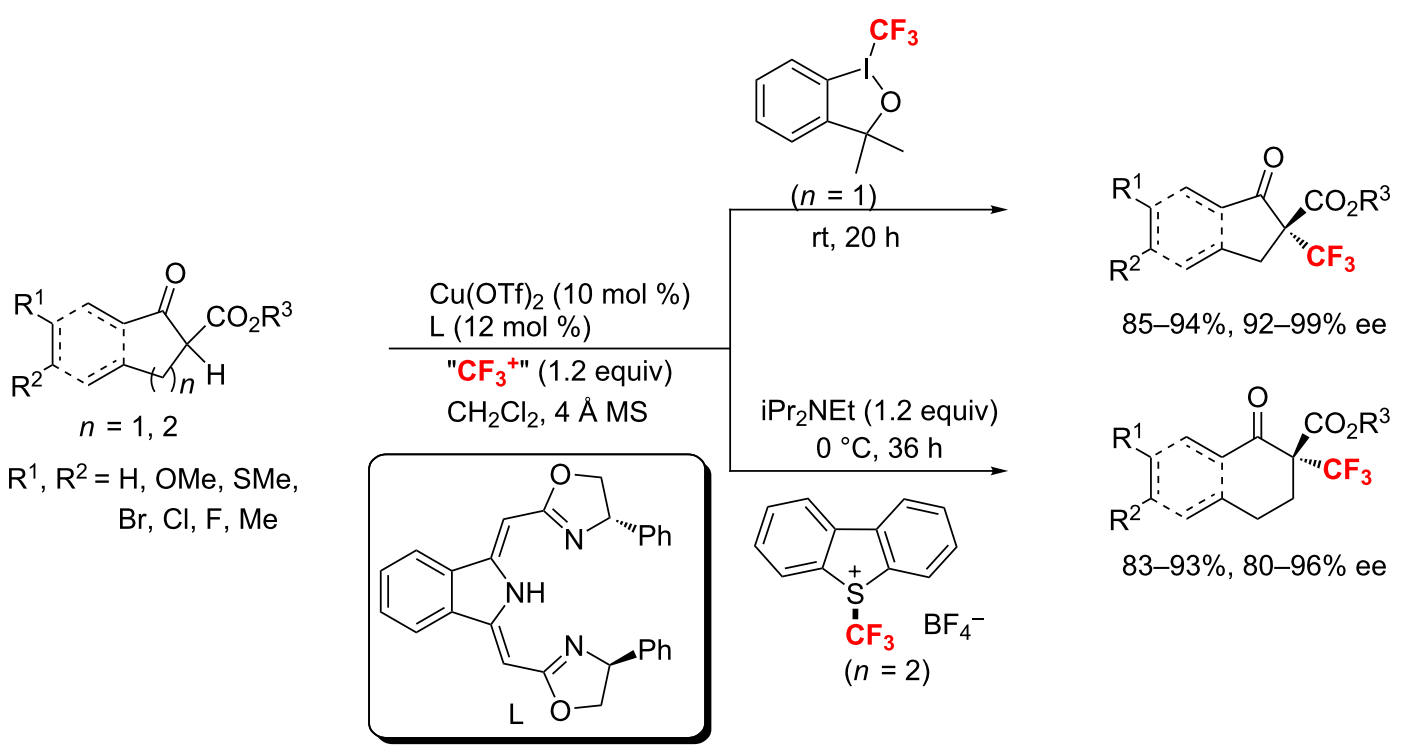

Scheme 56: Cupper-catalyzed enantioselective trifluoromethylation of five and six-membered ring $\beta$-ketoesters.

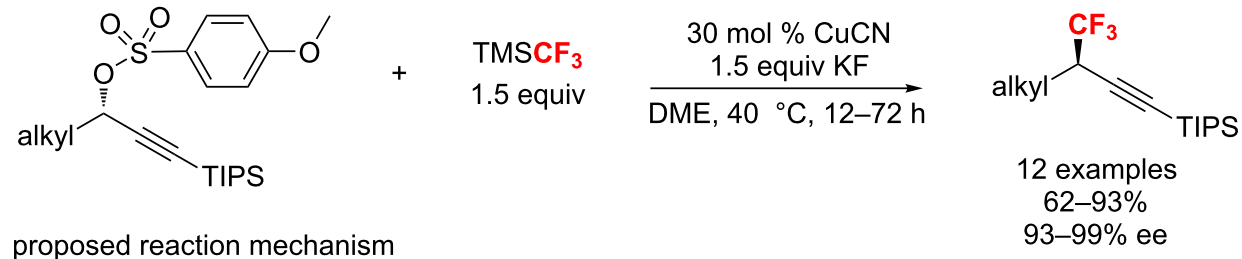

$\mathrm{TMSCF}_{3}$

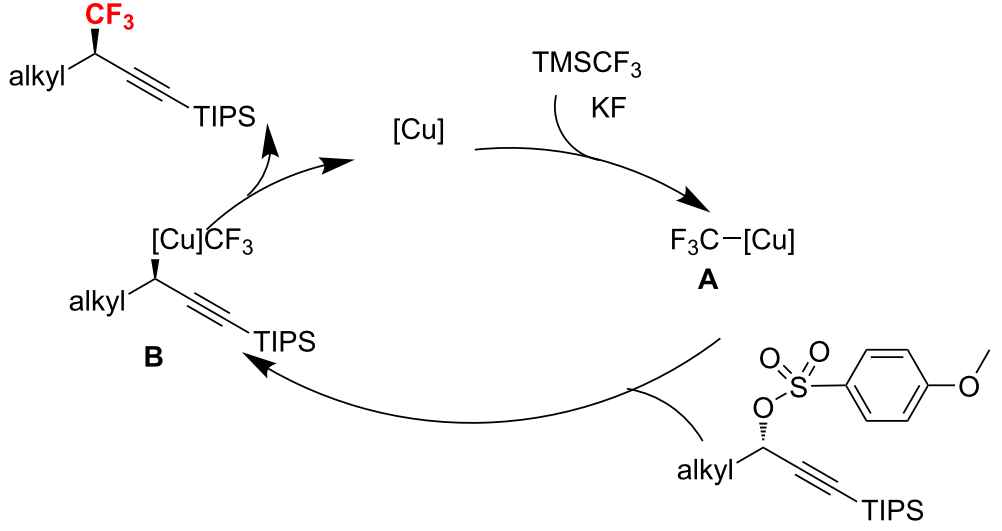

Scheme 57: Cu-catalyzed highly stereoselective trifluoromethylation of secondary propargyl sulfonates. 
Recently, Li and co-workers [117] explored a simple and facile method to access $\delta$-trifluoromethylated carboxamides and sulfonamides through a copper-catalyzed 1,5-hydrogen atom transfer (Scheme 58).

Other catalysts: In 2013, Gouverneur and co-workers [118] described a photoredox-based catalytic approach to afford enantioenriched branched allylic $\mathrm{CF}_{3}$ products from allylsilanes using $\left[\mathrm{Ru}(\mathrm{bpy})_{3}\right] \mathrm{Cl}_{2}$ (Scheme 59). Herein, the silyl group in the substrate plays an important role in controlling the regioselectivity of the trifluoromethylation reaction.

Later in 2017, Li's group [119] described a practical protocol for the decarboxylative trifluoromethylation of various primary and secondary aliphatic carboxylic acids. With $\mathrm{AgNO}_{3}$ as a catalyst, (bpy) $\mathrm{Cu}\left(\mathrm{CF}_{3}\right)_{3}$ (bpy $=2,2$ '-bipyridine) as a $\mathrm{CF}_{3}$ source and $\mathrm{K}_{2} \mathrm{~S}_{2} \mathrm{O}_{8}$ as an oxidant, aliphatic carboxylic acids were converted to the corresponding trifluoromethylated products in good yields (Scheme 60). Also, mechanistic studies, a radical clock experiment, revealed the intermediacy of ${ }^{-} \mathrm{Cu}\left(\mathrm{CF}_{3}\right)_{3} \mathrm{Me}$, which undergoes reductive elimination and subsequent oxidation to give the active species $\mathrm{Cu}\left(\mathrm{CF}_{3}\right)_{2}$. Meanwhile, aliphatic carboxylic acids give the corresponding alkyl radicals via $\mathrm{Ag}(\mathrm{II})$-mediated oxidative decarboxylation. Then, $\mathrm{Cu}\left(\mathrm{CF}_{3}\right)_{2}$ provides a $\mathrm{CF}_{3}$ group to alkyl radicals to obtain the final product.

Very recently, MacMillan et al. [120] discovered an efficient approach to the decarboxylative trifluoromethylation of aliphatic carboxylic acids via the combination of photoredox and

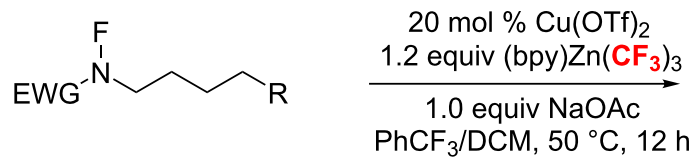

$\mathrm{EWG}=\mathrm{ArSO}_{2}, \operatorname{ArC}(\mathrm{O})$

$\mathrm{R}=\mathrm{Me}, \mathrm{Et}, \mathrm{CH}_{2} \mathrm{CO}_{2} \mathrm{Me}, \mathrm{CO}_{2} \mathrm{Me}, \mathrm{H}$, natural product or drug derivatives<smiles>[R]C(CCCN(F)O[Na])C(F)(F)F</smiles>

21 examples $33-75 \%$

Scheme 58: Remote $\mathrm{C}\left(\mathrm{sp}^{3}\right)-\mathrm{H}$ trifluoromethylation of carboxamides and sulfonamides.

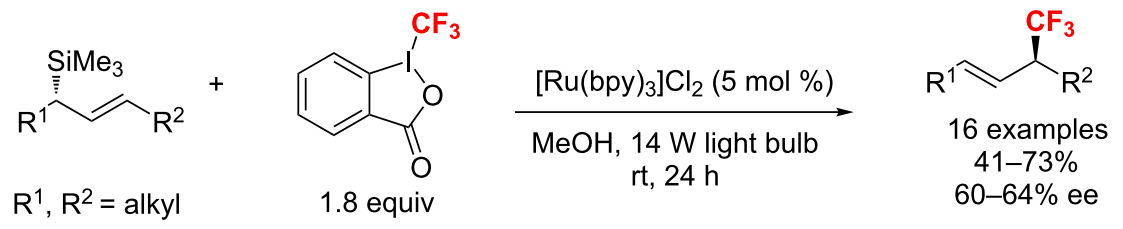

Scheme 59: Trifluoromethylation of allylsilanes with photoredox catalysis.

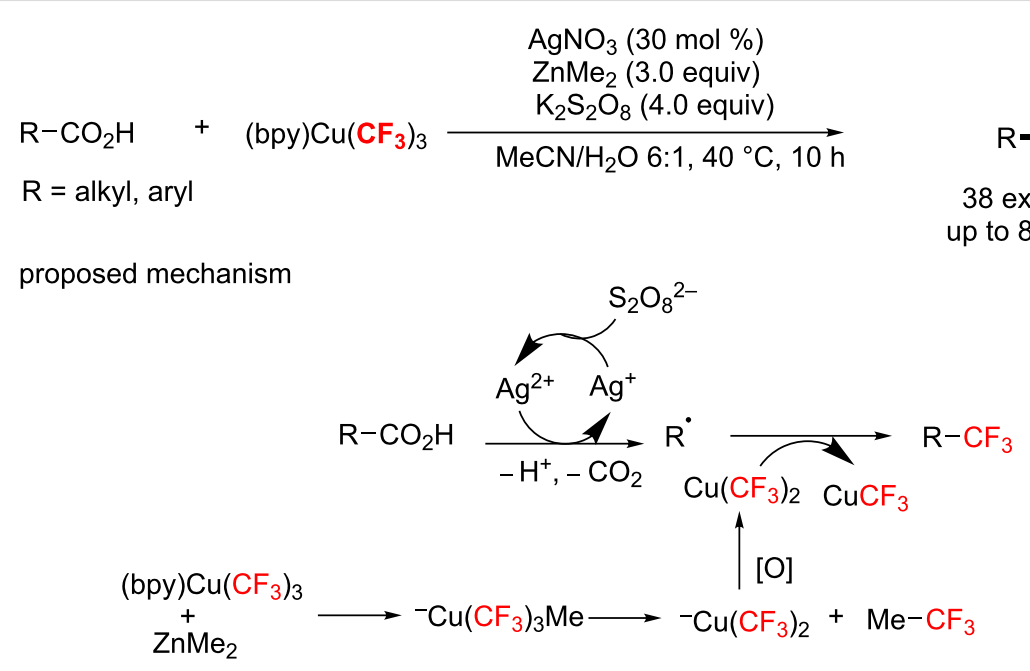

Scheme 60: Ag-catalyzed decarboxylative trifluoromethylation of aliphatic carboxylic acids in aqueous $\mathrm{CH}_{3} \mathrm{CN}$. 
copper catalysis (Scheme 61). The method tolerates a myriad of primary, secondary and tertiary carboxylic acids and provides the corresponding $\mathrm{CF}_{3}$ analogue in good to excellent yields. Details of the proposed dual copper-photoredox cycle are shown in Scheme 61. The Ir(III) photocatalyst $\operatorname{Ir}\left[\mathrm{dF}_{(}\left(\mathrm{CF}_{3}\right) \mathrm{ppy}_{2}\left(4,4^{\prime}-\mathrm{dCF}_{3}\right.\right.$ bpy $) \mathrm{PF}_{6}(\mathbf{1})$ undergoes photoexcitation with visible light to form the highly oxidizing excited state Ir(III) 2. Then, SET from copper carboxylate 4, derived from carboxylic acid $\mathbf{3}$ with the $\mathrm{Cu}(\mathrm{II})$ catalyst to $\operatorname{Ir}(\mathrm{III}) \mathbf{2}$ provides
$\mathrm{Cu}(\mathrm{III})$ carboxylate 5 , or in the dissociated form, a carboxyl radical and $\mathrm{Cu}$ (II) complex $\mathbf{6}$, along with reduced $\mathrm{Ir}$ (II) photocatalyst 7. The resulting carboxyl radical extrudes $\mathrm{CO}_{2}$ and sequentially recombines to generate $\mathrm{Cu}$ (III) species $\mathbf{9}$. At this stage, SET from 7 to 9 closes the photoredox catalytic cycle and produces an alkylcopper(II) species 10. Under the addition of Togni's reagent I (11), species 10 affords the final alkyl- $\mathrm{CF}_{3}$ product and complex $\mathbf{1 3}$, which is used for ligand exchange with 3.<smiles>O=C(O)C1CCCCC1</smiles>

carboxylic acid<smiles>CC1(C)OC(C(F)(F)F)c2ccccc21</smiles>

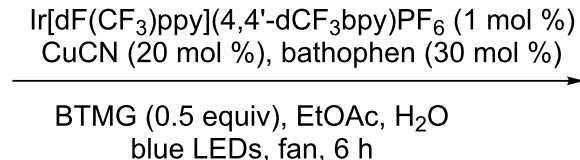

blue LEDs, fan, $6 \mathrm{~h}$<smiles>FC(F)(F)C1CCCCC1</smiles>

31 examples $30-93 \%$

proposed dual copper-photoredox cycle

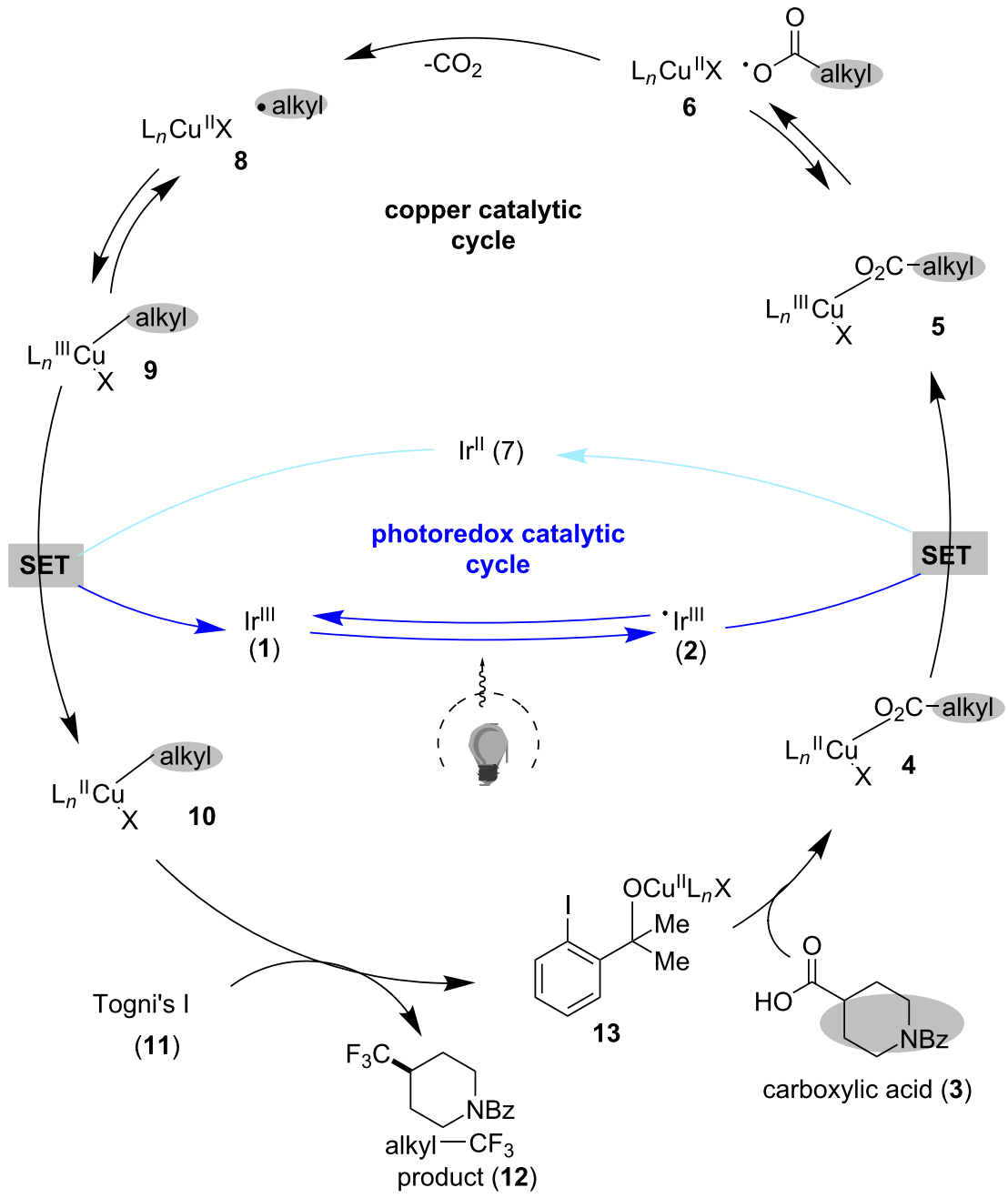

Scheme 61: Decarboxylative trifluoromethylation of aliphatic carboxylic acids via combined photoredox and copper catalysis. 


\section{$\mathrm{C}\left(\mathrm{sp}^{2}\right)-\mathrm{CF}_{3}$ bond formation}

Palladium-catalyzed trifluoromethylation of aryl and vinyl compounds: In 2010, Watson and co-workers [121] developed the first Pd-catalyzed trifluoromethylation of aryl/heterocyclic chlorides with the $\mathrm{CF}_{3}$ source $\mathrm{TESCF}_{3}$ (TES, triethylsilyl), which proceeded following a classical $\mathrm{Pd}(0) / \mathrm{Pd}(\mathrm{II})$ catalytic cycle (Scheme 62). Also, the reaction tolerates a variety of functional groups, such as esters, amides, ethers, nitriles, etc., and therefore provides a new way for late-stage modifications.

In the same year, Yu's group [122] reported a Pd(II)-catalyzed $\mathrm{C}-\mathrm{H}$ trifluoromethylation of arenes with an electrophilic trifluoromethylation reagent using diverse heterocyclic directing groups. Notably, the presence of trifluoroacetic acid (TFA) is crucial for the $\mathrm{Ar}-\mathrm{CF}_{3}$ bond formation and $\mathrm{Cu}(\mathrm{OAc})_{2}$ can increase the catalytic turnover (Scheme 63). Based on three different modes of the ArPd(II) species reaction with nucleophiles, electrophiles and highly oxidizing reagents, three possible reaction pathways (A, B and C, respectively) are envisaged, that can follow the $\mathrm{C}-\mathrm{H}$ activation event to the trifluoromethylated products, as described in Scheme 63. In this case, the specific catalytic mechanism remains to be studied.
In 2011, the group of Liu [123] accomplished a Pd(II)-catalyzed oxidative trifluoromethylation of indoles with $\mathrm{TMSCF}_{3}$ and $\mathrm{PhI}(\mathrm{OAc})_{2}$ at room temperature (Scheme 64). Through reductive elimination from the (Ar) $\mathrm{Pd}(\mathrm{IV})-\mathrm{CF}_{3}$ intermediate, the aryl $\mathrm{C}-\mathrm{CF}_{3}$ bond is generated. Notably, the bidentate nitrogen-containing ligand is crucial to the achievement of this process.

In the same year, Buchwald et al. [124] discovered a palladiumcatalyzed trifluoromethylation of vinyl triflates and nonaflates (Scheme 65). A variety of trifluoromethylated cyclohexenes were obtained using a catalyst system, which was composed of $\mathrm{Pd}(\mathrm{dba})_{2}$ or $[(\mathrm{allyl}) \mathrm{PdCl}]_{2}$ and the monodentate biaryl phosphine ligand $t$-BuXPhos. Also, $\mathrm{TMSCF}_{3}$ and $\mathrm{KF}$ were more suitable to the trifluoromethylation of triflate electrophiles, while the use of $\mathrm{TESCF}_{3}$ and $\mathrm{RbF}$ gave better results for nonaflate electrophiles.

Subsequently, the Yu [15,125] and Shi group [126] independently reported the palladium-catalyzed ortho-trifluoromethylation of an aromatic C-H bond with Umemoto's trifluoromethylation reagent. Notably, $\mathrm{Cu}$ (II) salts were crucial for forming the

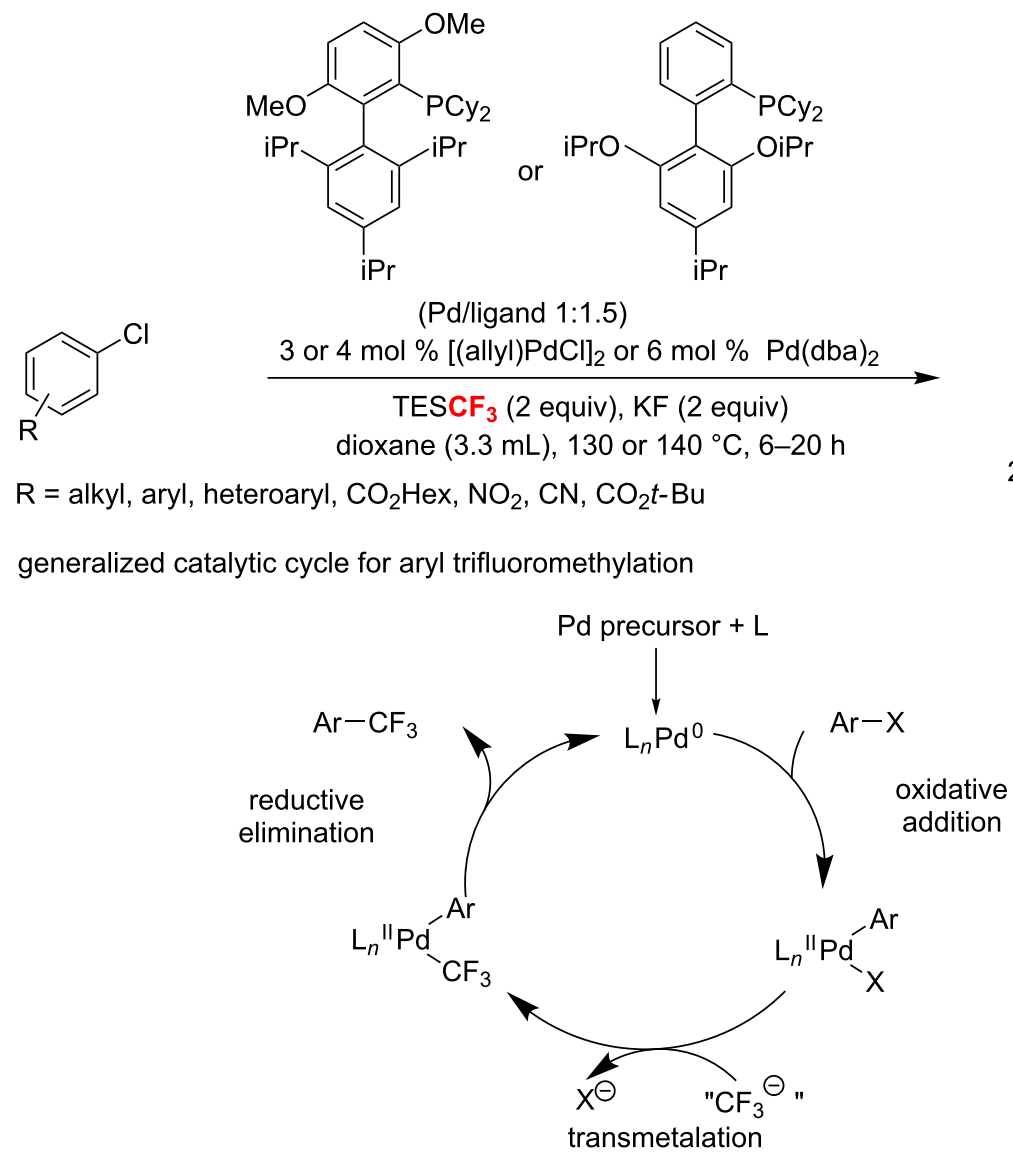

Scheme 62: Palladium-catalyzed $\mathrm{Ar}-\mathrm{CF}_{3}$ bond-forming reaction. 


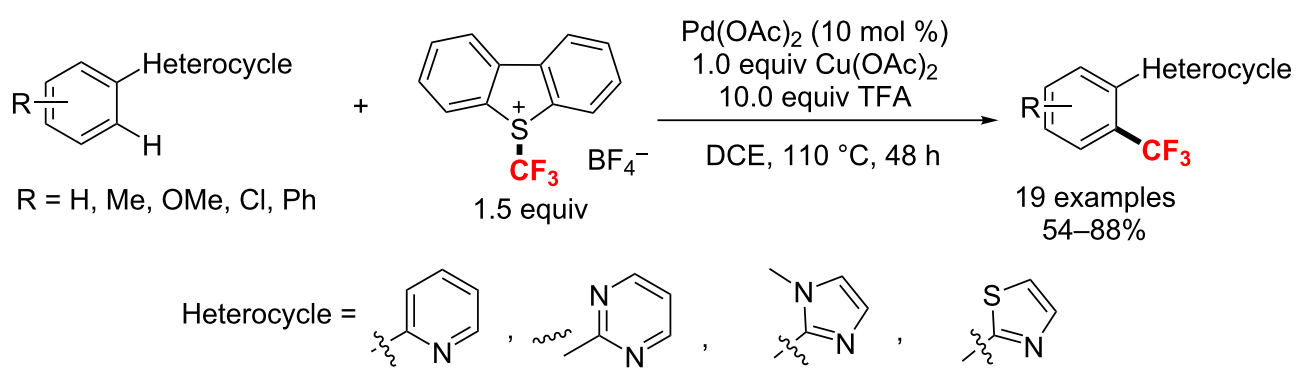

plausible reaction pathways for trifluoromethylation

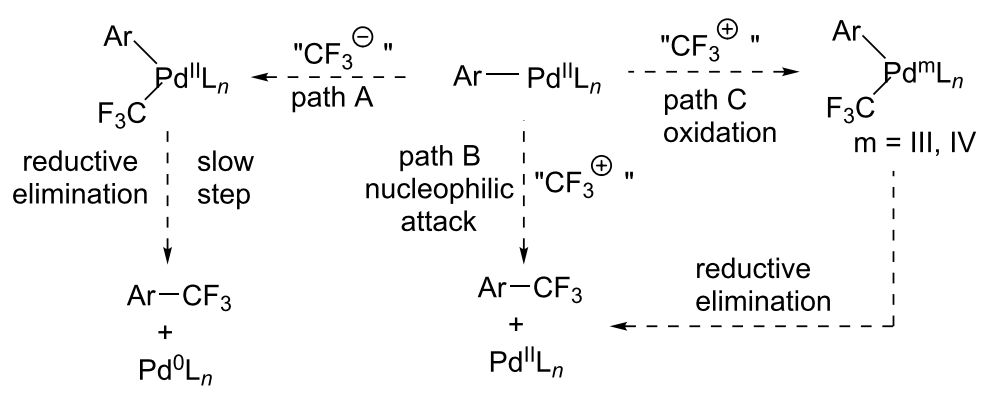

Scheme 63: Palladium-catalyzed trifluoromethylation of arenes with diverse heterocyclic directing groups.

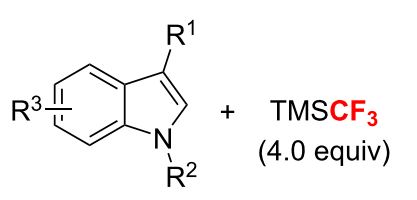

$\mathrm{R}^{1}=\mathrm{H}, \mathrm{OMe}, \mathrm{Me}, \mathrm{Cl}, \mathrm{Br}, \mathrm{CO}_{2} \mathrm{Me}$

$\mathrm{R}^{2}=\mathrm{Me}, \mathrm{Et}, \mathrm{Bn}, n-\mathrm{Bu}, \mathrm{Ph}, \mathrm{SEM}, \mathrm{Ts}$

$\mathrm{R}^{3}=$ alkyl, $\mathrm{CO}_{2} \mathrm{Me}, \mathrm{CF}_{3}$
$\mathrm{Pd}(\mathrm{OAc})_{2}(10 \mathrm{~mol} \%) / \mathrm{L}(15 \mathrm{~mol} \%)$

$$
\mathrm{Phl}(\mathrm{OAc})_{2} \text { (2.0 equiv) }
$$$$
\text { CsF (4.0 equiv) }
$$

TEMPO ( 0.5 equiv)

$\mathrm{CH}_{3} \mathrm{CN}, \mathrm{rt}$

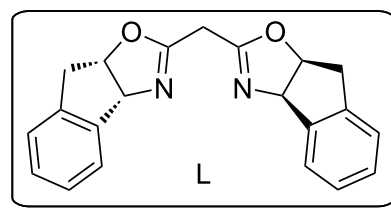

22 examples

$33-83 \%$

Scheme 64: Pd-catalyzed trifluoromethylation of indoles as reported by Liu.

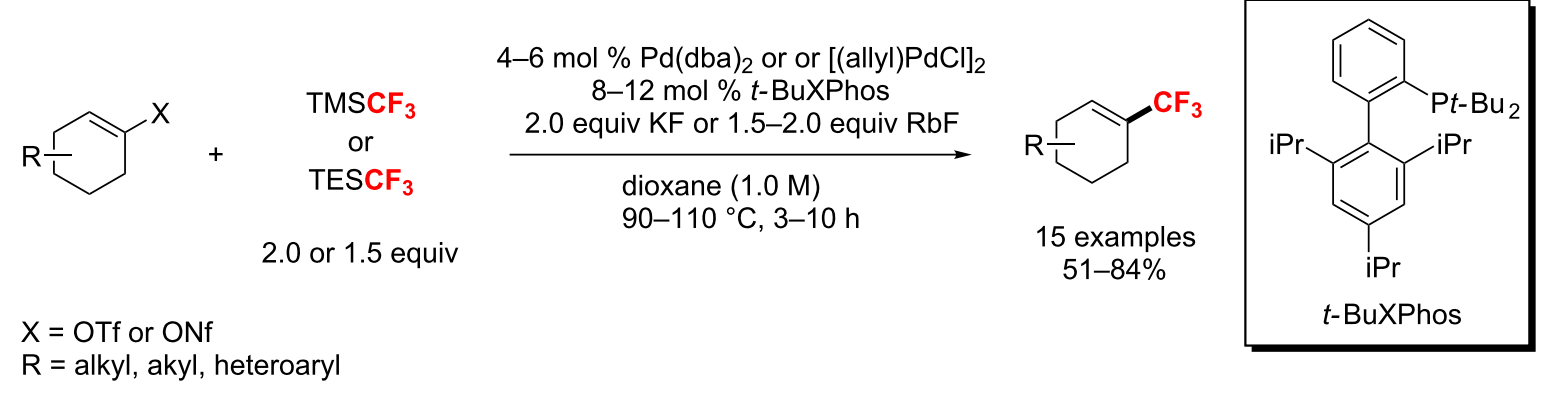

Scheme 65: Pd-catalyzed trifluoromethylation of vinyl triflates and vinyl nonaflates.

aryl- $\mathrm{CF}_{3}$ bonds. In Yu's study, benzamides and benzylamines were well trifluoromethylated via a $\mathrm{Pd}(\mathrm{II}) / \mathrm{Pd}(\mathrm{IV})$ catalytic cycle with the addition of TFA (and $\mathrm{Ag}_{2} \mathrm{O}$ ) (Scheme 66a). With an acetamido group as a directing group, Shi developed an efficient method to access ortho- $\mathrm{CF}_{3}$ acetanilides and anilines (Scheme 66b). 
a)<smiles>NC(=O)c1cc#[R]cc1</smiles>

$\mathrm{Ar}=\left(4-\mathrm{CF}_{3}\right) \mathrm{C}_{8} \mathrm{~F}_{4}$

$\mathrm{R}=\mathrm{Me}, \mathrm{OMe}, t-\mathrm{Bu}, \mathrm{Ph}, \mathrm{F}, \mathrm{Cl}, \mathrm{Br}, \mathrm{CO}_{2} \mathrm{Me}, \mathrm{CF}_{3}$<smiles>[R]NCC1=CC=C[R1]C=C1</smiles>

$\mathrm{R}^{1}=\mathrm{Me}, \mathrm{H}, \mathrm{OMe}, \mathrm{Cl}, \mathrm{Ph}$ $\mathrm{R}^{2}=\mathrm{H}$, alkyl
$\mathrm{Pd}(\mathrm{OAc})_{2}(10 \mathrm{~mol} \%)$

$L$ (15.0 equiv)

$\mathrm{Cu}(\mathrm{OAc})_{2}$ (2.0 equiv)

TFA (10 equiv)

DCE, $130{ }^{\circ} \mathrm{C}, 48 \mathrm{~h}$

$\mathrm{CF}_{3} \quad \mathrm{OTf}^{-}$

(1.5 equiv)<smiles></smiles>

19 examples

$32-94 \%$

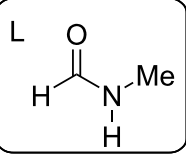

$\mathrm{Pd}(\mathrm{OAc})_{2}(10 \mathrm{~mol} \%)$

$\mathrm{Ag}_{2} \mathrm{O}(15 \mathrm{~mol} \%)$,

$\mathrm{Cu}(\mathrm{OAc})_{2}$ (2.0 equiv), TFA (5.0 equiv) $\mathrm{ClCH}_{2} \mathrm{CH}_{2} \mathrm{Cl} / \mathrm{H}_{2} \mathrm{O}, 130{ }^{\circ} \mathrm{C}, 12 \mathrm{~h}$

then, $\mathrm{Boc}_{2} \mathrm{O}$ (3.0 equiv), $\mathrm{NaOH}$ (50 equiv) 1,4-dioxane $/ \mathrm{H}_{2} \mathrm{O}, 25^{\circ} \mathrm{C}, 12 \mathrm{~h}$

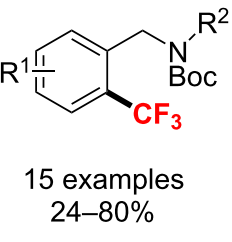

15 examples $24-80 \%$ b)<smiles>[R]C(=O)NC1=CC=[R1]#CC=C1</smiles><smiles>[13CH3][Si]1c2ccccc2-c2ccccc21</smiles>

(1.5 equiv)

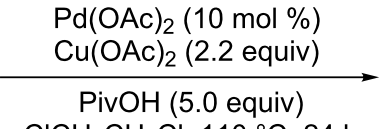

$\mathrm{ClCH}_{2} \mathrm{CH}_{2} \mathrm{Cl}, 110^{\circ} \mathrm{C}, 24 \mathrm{~h}$

$\mathrm{R}^{1}=\mathrm{Me}, \mathrm{H}, t-\mathrm{Bu}, \mathrm{OMe}, \mathrm{F}, \mathrm{Cl}, \mathrm{Br}, \mathrm{I}, \mathrm{Ph}, \mathrm{CO}_{2} \mathrm{Me}, \mathrm{CO}_{2} \mathrm{Et}, \mathrm{COPh}, \mathrm{COMe}, \mathrm{OAc}, \mathrm{CF}_{3}$ $\mathrm{R}^{2}=\mathrm{Me}, t-\mathrm{Bu}, \mathrm{Ph}$
(1.5 equiv)
22 examples up to $83 \%$ yield

Scheme 66: $\mathrm{Pd}(\mathrm{II})$-catalyzed ortho-trifluoromethylation of aromatic $\mathrm{C}-\mathrm{H}$ bonds.

Recently, Wang and co-workers [127] reported a visible-lightinduced Pd-catalyzed ortho-trifluoromethylation of acetanilides. Without the need of an external photocatalyst and additive, various $\mathrm{N}$-substituted anilides and acetanilides were obtained efficiently at room temperature in air. The strategy features good yields, broad functional group tolerance and high regioselectivity (Scheme 67).

Copper-catalyzed trifluoromethylation of aryl- and alkenylboronic acids: In 2011, Liu and Shen [128] developed a CuI-catalyzed method for the trifluoromethylation of aryl- and alkenylboronic acids with Togni's reagent
(Scheme 68). A range of different substrates gave the corresponding trifluoromethylated (hetero)arenes in good to excellent yields.

Also, in 2012, Beller and co-workers [129] described a coppercatalyzed trifluoromethylation of aryl- and vinylboronic acids with the generation of $\mathrm{CF}_{3}$-radicals at room temperature. The mild reaction conditions allowed a wide variety of functional groups to be tolerated, though a large quantity of TBHP was required (Scheme 69). Notably, the authors proposed two mechanistic pathways for this trifluoromethylation reaction. The difference between path $\mathrm{A}$ and path $\mathrm{B}$ is that the sequence of<smiles>[R]C(=O)Nc1cc[R17]cc1[Na]</smiles>

$\mathrm{R}^{1}=$ alkyl, aryl, Ot-Bu

$\mathrm{R}^{1}=\mathrm{Me}, \mathrm{R}^{2}=$ alkyl, $\mathrm{Ph}$, halogen, $\mathrm{CN}, \mathrm{OCF}_{3}, \mathrm{COMe} \mathrm{CO}_{2} \mathrm{Me}, \mathrm{CO}_{2} \mathrm{Et}, \mathrm{OMe}, \mathrm{NHCOMe}$ cat. $\mathrm{Pd}(\mathrm{OAc})_{2}(5 \mathrm{~mol} \%)$ DMSO, air, $25^{\circ} \mathrm{C}, 20 \mathrm{~h}$

blue LED (410-415 nm) no external photocatalyst<smiles>[R]C(=O)Nc1cc[R17]cc1C(F)(F)F</smiles>

35 examples up to $88 \%$ yiled 
<smiles>CO[Hg]c1[X]:[R]cc1</smiles><smiles>CC1(C)OC(C(F)(F)F)c2ccccc21</smiles>

1.2 equiv
$5 \mathrm{~mol} \% \mathrm{Cul}$ $\frac{10 \mathrm{~mol} \% \mathrm{~L}}{2.0 \text { equiv } \mathrm{K}_{2} \mathrm{CO}_{3}}$ Diglyme, $35^{\circ} \mathrm{C}, 14 \mathrm{~h}$ 14 examples 50-95\%

$\mathrm{R}=$ aryl, alkyl, ether, ester, amide<smiles></smiles>

$\mathrm{R}=\mathrm{Ph}, \mathrm{Me}, \mathrm{Cl}, \mathrm{OMe}$<smiles>CC1(C)OC(C(F)(F)F)c2ccccc21</smiles>

1.2 equiv
$5 \mathrm{~mol} \% \mathrm{Cul}$ $\underset{2.0 \text { equiv } \mathrm{K}_{2} \mathrm{CO}_{3}}{\stackrel{10 \mathrm{~mol}}{\longrightarrow}}$ Diglyme, $35^{\circ} \mathrm{C}, 24 \mathrm{~h}$<smiles>[R][R]1ccc(C=CC(F)(F)F)cc1C=Cc1cccc(C(F)(F)F)c1</smiles>

Scheme 68: Cul-catalyzed trifluoromethylation of aryl- and alkenylboronic acids.<smiles>[R]Oc1ccc(OC)cc1</smiles>

$$
\begin{array}{r}
\mathrm{R}=\mathrm{OMe}, \mathrm{Me}, \mathrm{OBn}, \mathrm{OTBS}, \\
\mathrm{SMe}, \mathrm{NMe}_{2}, \mathrm{Ph}, \mathrm{I}, \mathrm{Br}, \mathrm{Cl}
\end{array}
$$<smiles>[R]O/C=C/c1ccc([R])cc1</smiles>

$\mathrm{R}=\mathrm{OMe}, \mathrm{Me}, \mathrm{H}, \mathrm{Ph}, \mathrm{F}, \mathrm{Br}, \mathrm{Cl}, \mathrm{CF}_{3}$<smiles>FC(F)(F)C1=CC[R]C=C1</smiles>

17 examples $34-74 \%$<smiles>[R]c1ccc(/C=C/C(F)(F)F)cc1</smiles>
$\mathrm{Cu}(\mathrm{OAc})_{2}(20 \mathrm{~mol} \%)$ imidazole (24 $\mathrm{mol} \%)$ $t$-BuOOH (16.1 equiv) 2,4,6-collidine (2.0 equiv)

$\mathrm{NH}_{4} \mathrm{Cl}$ (2.4 equiv) $\mathrm{DCM} / \mathrm{H}_{2} \mathrm{O}$, rt, air, $6 \mathrm{~h}$

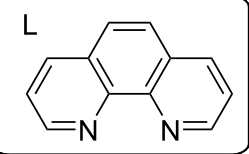

proposed reaction mechanism
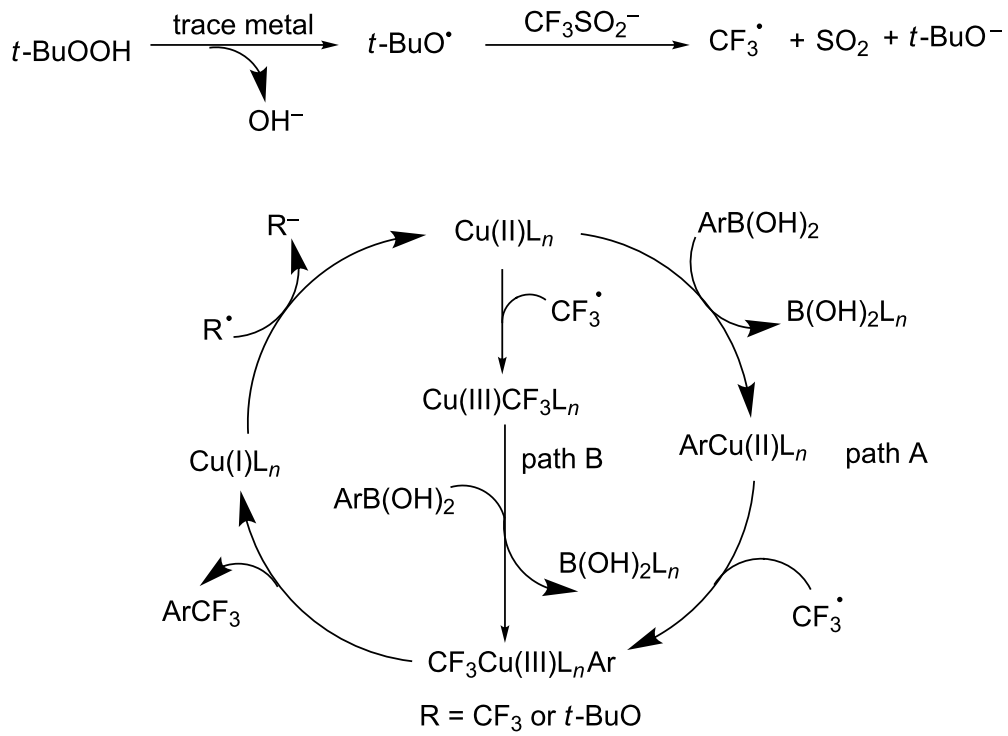

Scheme 69: Cu-catalyzed trifluoromethylation of aryl- and vinylboronic acids.

$\mathrm{CF}_{3}$ radicals and aryl- and vinylboronic acids is reversed. In addition, the $\mathrm{CF}_{3}$ radical is generated from the reaction of TBHP with $\mathrm{NaSO}_{2} \mathrm{CF}_{3}$.
Copper-catalyzed trifluoromethylation of alkenes: The method described by $\mathrm{Hu}$ [130] was applied to the trifluoromethylation of a wide range of $\alpha, \beta$-unsaturated carboxylic acids 
through $\mathrm{CuF}_{2}$-catalyzed decarboxylative fluoroalkylation with high yields and excellent $E / Z$ ratio (Scheme 70).

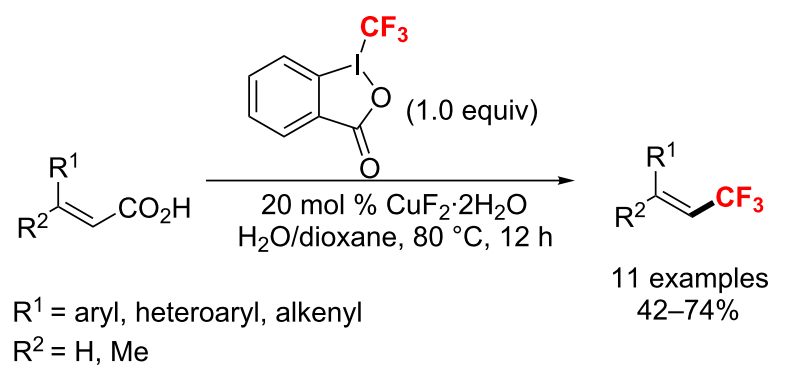

Scheme 70: Copper-catalyzed trifluoromethylation of $\alpha, \beta$-unsaturated carboxylic acids.

Additionally, a copper(I)-catalyzed trifluoromethylation of alkenes was disclosed by Sodeoka and co-workers in 2012 [131]. The reaction was carried out with Togni's reagent as the $\mathrm{CF}_{3}$ source and $\mathrm{TsOH}$ as a Brønsted acid in $\mathrm{CH}_{2} \mathrm{Cl}_{2}$ at $40{ }^{\circ} \mathrm{C}$ (Scheme 71). Notably, trifluoromethylstyrenes were formed through further transformations of the oxytrifluoromethylated products with high efficiency.

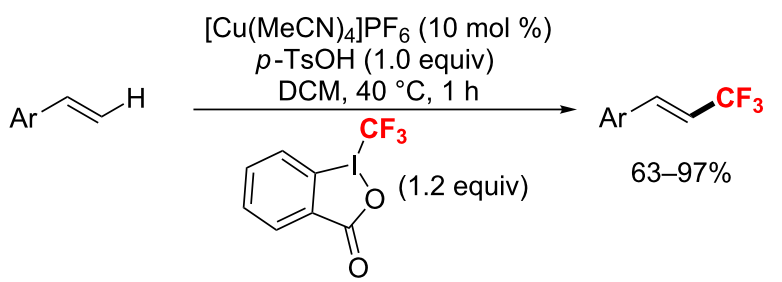

Ar $=$ phenyl, $\mathrm{N}$-protected aniline, heteroaryl, dienes

Scheme 71: Formation of $\mathrm{C}\left(\mathrm{sp}^{2}\right)-\mathrm{CF}_{3}$ bond catalyzed by copper(I) complex.
In the same year, Loh's group [132] used the same copper catalyst and Togni's reagent to achieve the trifluoromethylation of enamides in good yields at room temperature (Scheme 72a). Meanwhile, this reaction exhibited excellent stereoselectivity towards the $E$-isomer. One year later, the same group [133] extended this approach to the directing-group-assisted copper-catalyzed trifluoromethylation of electron-deficient alkenes (Scheme 72b). Moreover, $\alpha$-aryl and $\alpha$-alkyl-substituted acrylate derivatives could be used as substrates to form the $\mathrm{C}\left(\mathrm{sp}^{2}\right)-\mathrm{CF}_{3}$ bond with a complete $Z$-selectivity. A radical species participated in the reaction's catalytic cycle.

In 2013, the group of Liu [134] described a copper-catalyzed decarboxylative trifluoromethylation of $\alpha, \beta$-unsaturated carboxylic acids with $\mathrm{CF}_{3} \mathrm{SO}_{2} \mathrm{Na}$. This method was applied to a wide range of $\alpha, \beta$-unsaturated carboxylic acids. Meanwhile, a similar radical process for the difluoromethylation of arylsubstituted acrylic acids was also achieved by Liu and co-workers. The $\mathrm{HCF}_{2}$-substituted $E$-alkenes were finally obtained with iron catalysis and zinc difluoromethanesulfinate $\left(\left(\mathrm{CF}_{2} \mathrm{HSO}_{2}\right)_{2} \mathrm{Zn}\right.$, Baran reagent $)$. Also, the authors proved that the formation of the $\mathrm{C}_{\mathrm{vinyl}}-\mathrm{CF}_{3} / \mathrm{C}_{\mathrm{vinyl}}-\mathrm{CF}_{2} \mathrm{H}$ bonds followed a radical addition-elimination process (Scheme 73).

Subsequently, Bouyssi and co-workers [135-137] used Togni's reagent to conduct the trifluoromethylation of (hetero)aromatic aldehydes or corresponding $N, N$-dialkylhydrazones with $\mathrm{CuCl}$ as the catalyst at room temperature (Scheme 74 ). These reactions showed a broad substrate scope and good functional group compatibility with up to $99 \%$ yield.

In 2013, a simple and effective copper-catalyzed approach for the construction of $\mathrm{C}_{\mathrm{vinyl}}-\mathrm{CF}_{3}$ bonds without using pre-functionalized substrates was reported by Xiao et al. (Scheme 75) [138]. The process proceeded smoothly to give the trifluoromethylated alkenes in good to excellent yields via a radical mechanism. a)<smiles>[R]/C(N)=C/[3H]</smiles>

$\mathrm{R}=\operatorname{aryl}$

b)

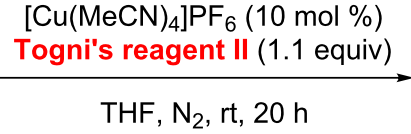

THF, $\mathrm{N}_{2}, \mathrm{rt}, 20 \mathrm{~h}$

$$
\mathrm{R}=\text { aryl, alkyl }
$$

\section{$\mathrm{CuCl}(10 \mathrm{~mol} \%)$ \\ $\underset{\text { DMSO, } \mathrm{N}_{2}, 80{ }^{\circ} \mathrm{C}, 20 \mathrm{~h}}{\stackrel{\text { Togni's reagent II (1.1 equiv) }}{\longrightarrow}}$ \\ $\underset{\text { DMSO, } \mathrm{N}_{2}, 80{ }^{\circ} \mathrm{C}, 20 \mathrm{~h}}{\stackrel{\text { Togni's reagent II (1.1 equiv) }}{\longrightarrow}}$}

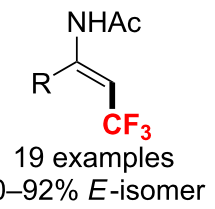<smiles>[R]C(=CC(F)(F)F)C(=O)N[Sb]</smiles>

18 examples 60-97\% Z-isomer 


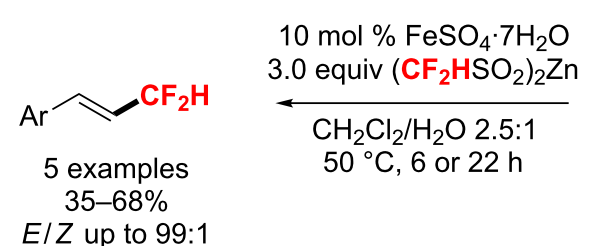

$10 \mathrm{~mol} \% \mathrm{FeSO}_{4} \cdot 7 \mathrm{H}_{2} \mathrm{O}$

$\mathrm{Ar} \curvearrowright \mathrm{COOH}$

$10 \mathrm{~mol} \% \mathrm{CuSO}_{4} \cdot 6 \mathrm{H}_{2} \mathrm{O}$

3.0 equiv $\mathrm{CF}_{3} \mathrm{SO}_{2} \mathrm{Na}$

$\mathrm{CH}_{2} \mathrm{Cl}_{2} / \mathrm{H}_{2} \mathrm{O} 2.5: 1$
$50{ }^{\circ} \mathrm{C}, 5-21 \mathrm{~h}$

$\mathrm{Ar} \curvearrowright \mathrm{CF}_{3}$

24 examples

$41-85 \%$

$E / Z$ up to $99: 1$

Scheme 73: Copper and iron-catalyzed decarboxylative tri- and difluoromethylation.

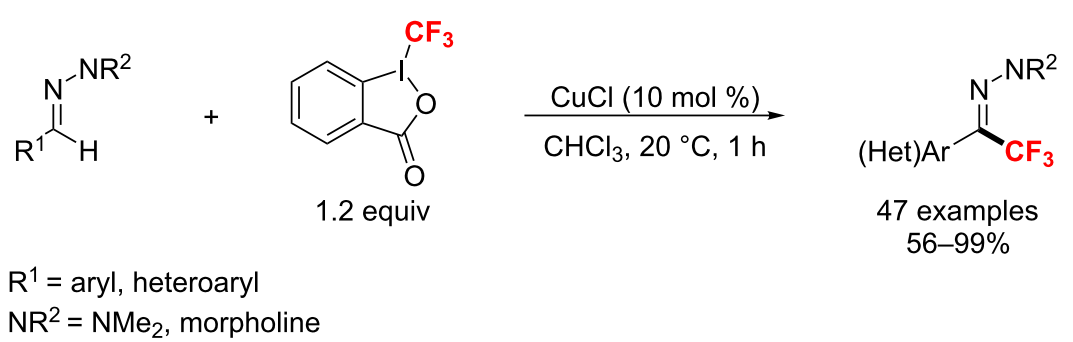

Scheme 74: Cu-catalyzed trifluoromethylation of hydrazones developed by Bouyssi.

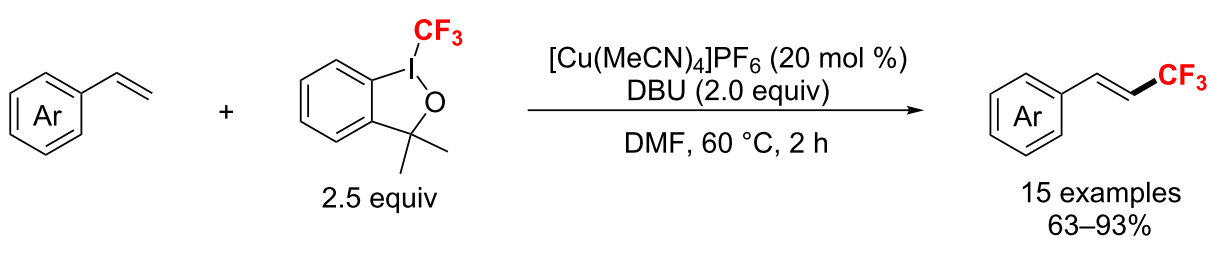

$\mathrm{Ar}=$ electron-rich and electron-poor (hetero)arenes

Scheme 75: $\mathrm{Cu}(\mathrm{I})$-catalyzed trifluoromethylation of terminal alkenes.

Additionally, Duan and co-workers [139] discovered a copper/ silver-catalyzed decarboxylative trifluoromethylation of $\alpha, \beta$ unsaturated carboxylic acids with $\mathrm{CF}_{3} \mathrm{SO}_{2} \mathrm{Na}$. This reaction proceeded efficiently for a wide range of alkyl and aryl-substituted $\alpha, \beta$-unsaturated carboxylic acids derivatives with excellent $E / Z$ selectivity (Scheme 76). It's worth mentioning that the addition of $\mathrm{Ag}_{2} \mathrm{CO}_{3}$ additives was crucial for promoting the decarboxylation of $\alpha, \beta$-unsaturated carboxylic acids.

In 2014, a $\mathrm{Cu}(\mathrm{I} / \mathrm{II})$-catalyzed $\alpha$-trifluoromethylation of $\alpha, \beta$ unsaturated carbonyl compounds were unfolded by the Bi group
(Scheme 77) [140]. The reaction was applied to a broad range of carbonyl compounds, including enones, $\alpha, \beta$-unsaturated esters, thioesters, and amides. Notably, the authors obtained products with stable $E$-configuration through a SET process.

In 2017, Loh and co-workers [141] introduced a $\mathrm{Cu}(\mathrm{I} / \mathrm{II})$-catalyzed $\mathrm{C}_{\mathrm{vinyl}}-\mathrm{H}$ trifluoromethylation of a variety of styrene derivatives. This process was achieved by using 1-methylimidazole (NMI) as ligand and tetrabutylammonium iodide (TBAI) as an additive (Scheme 78). Mechanistic studies revealed that this reaction probably proceeds through a radical pathway.<smiles>[R]/C(=C\C(=O)O)c1cc[R1]cc1</smiles>

$\mathrm{R}^{1}=\mathrm{H}, \mathrm{Me}, \mathrm{Ph}$

$\mathrm{R}^{2}=\mathrm{OMe}, \mathrm{Me}, \mathrm{Cl}, \mathrm{Br}, \mathrm{Me}, \mathrm{Cl}, \mathrm{H}, \mathrm{OH}$
$\mathrm{CuCl}(20 \mathrm{~mol} \%)$

$\mathrm{CF}_{3} \mathrm{SO}_{2} \mathrm{Na}$ (3.0 equiv)

$\mathrm{Ag}_{2} \mathrm{CO}_{3}$ (0.6 equiv)

$t$-BuOOH (5.0 equiv)

DCE, $70^{\circ} \mathrm{C}, 24 \mathrm{~h}$<smiles>[R1]C(=CC(F)(F)F)c1c[R1]ccc1</smiles>

13 examples $48-72 \%$ 


$$
\begin{aligned}
& \text { Cul }(10 \mathrm{~mol} \%) \\
& \mathrm{DMF}^{1} \mathrm{~N}_{2}, 80^{\circ} \mathrm{C}, 10 \mathrm{~h} \\
& \mathrm{R}^{2}=\text { aryl, ketone }
\end{aligned}
$$

Scheme 77: Copper-catalyzed direct alkenyl C-H trifluoromethylation.

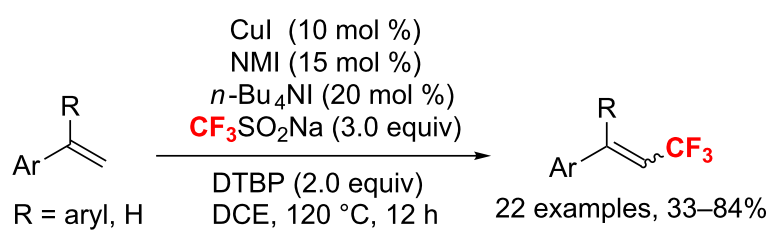

Scheme 78: Copper(I/II)-catalyzed direct trifluoromethylation of styrene derivatives.

Copper-catalyzed trifluoromethylation of arenes and heteroarenes: In 2013, Xi et al. [142] reported a CuCl-catalyzed direct trifluoromethylation of $\mathrm{sp}^{2} \mathrm{C}-\mathrm{H}$ bonds with Togni reagent (Scheme 79). Also, phenyl, thiophene, and pyridine derivatives achieved regioselectively trifluoromethylation with
$N$-pival-amide as a directing group. The authors also proposed a possible radical pathway for this reaction. The final trifluoromethylated compounds were generated from pivalamido arenes and heteroarenes with the $\mathrm{CF}_{3}$ radical through a $\mathrm{Cu}(\mathrm{I} / \mathrm{II})$ catalytic cycle.

In 2013, the Szabó [143] and Wang group [144] described the copper-mediated $\mathrm{C}-\mathrm{H}$ trifluoromethylation of quinones with Togni's reagent. Szabó utilized a stoichiometric amount of $\mathrm{CuCN}$ combined with catalytic bis(pinacolato)diboron, whereas Wang applied a stoichiometric amount of CuI. Notably, both groups proved a mechanism involving the formation of a $\mathrm{CF}_{3}$ radical with copper(I) acting as a one-electron reducing agent (Scheme 80).

With catalytic cupric acetate and TBHP, the group of Tang [145] developed a green strategy for the trifluoromethylation of imidazoheterocycles with a recyclable mixed medium of 1-butyl-3-methylimidazolium tetrafluoroborate $\left([\mathrm{Bmim}] \mathrm{BF}_{4}\right)$ and water (Scheme 81). By following this method, diverse trifluoromethylated imidazoheterocycles were obtained in up to $80 \%$ yield. The method features a green and recyclable solvent, mild reaction conditions (room temperature) and excellent functional group tolerance. In this instance, the copper catalyst may only promote the generation of the tert-butoxyl radical from TBHP. The oxidation of the intermediate A with $t$-BuOOH<smiles>[R]C1=c2[R]cc(NC(=O)C(C)(C)C)cc2C=CC=C1</smiles>

$\mathrm{R}=\mathrm{H}$, alkyl, halogen, ether, $\mathrm{CO}_{2} \mathrm{Et}$

$\mathrm{X}=\mathrm{CH}, \mathrm{S}, \mathrm{N}$

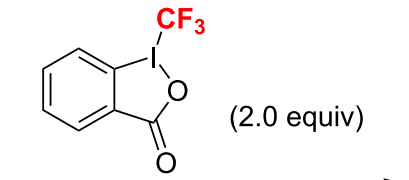

$\mathrm{CuCl}(20 \mathrm{~mol} \%)$ $t$-BuOH, $\mathrm{N}_{2}, 30-120^{\circ} \mathrm{C}, 24 \mathrm{~h}$

13 examples

$40-70 \%$

Scheme 79: Regioselective trifluoromethylation of pivalamido arenes and heteroarenes.<smiles>[R]C1=CC(=O)c2ccccc2C1=O</smiles>

$\mathrm{R}=$ alkyl, aryl, $\mathrm{OMe}, \mathrm{Cl}, \mathrm{Br}, \mathrm{NMePh}$<smiles>[R]C1=C(C(F)(F)F)C(=O)c2ccccc2C1=O</smiles>

15 examples, $49-89 \%$ (A)

15 examples, $33-83 \%$ (B)

Szabó (A): Togni's reagent (1.5 equiv), $\mathrm{B}_{2} \mathrm{Pin}_{2}(5 \mathrm{~mol} \%), \mathrm{CuCN}$ (1.0 equiv), $\mathrm{CDCl}_{3}, \mathrm{rt}, 18 \mathrm{~h}$

Wang (B): Togni's reagent (2.0 equiv), Cul $(20 \mathrm{~mol} \%), t-\mathrm{BuOH} / \mathrm{DCM} 1: 1,55^{\circ} \mathrm{C}, 12 \mathrm{~h}$ 
produces a carbocation $\mathrm{B}$, followed by an oxidative dehydrogenation process to afford the target product.

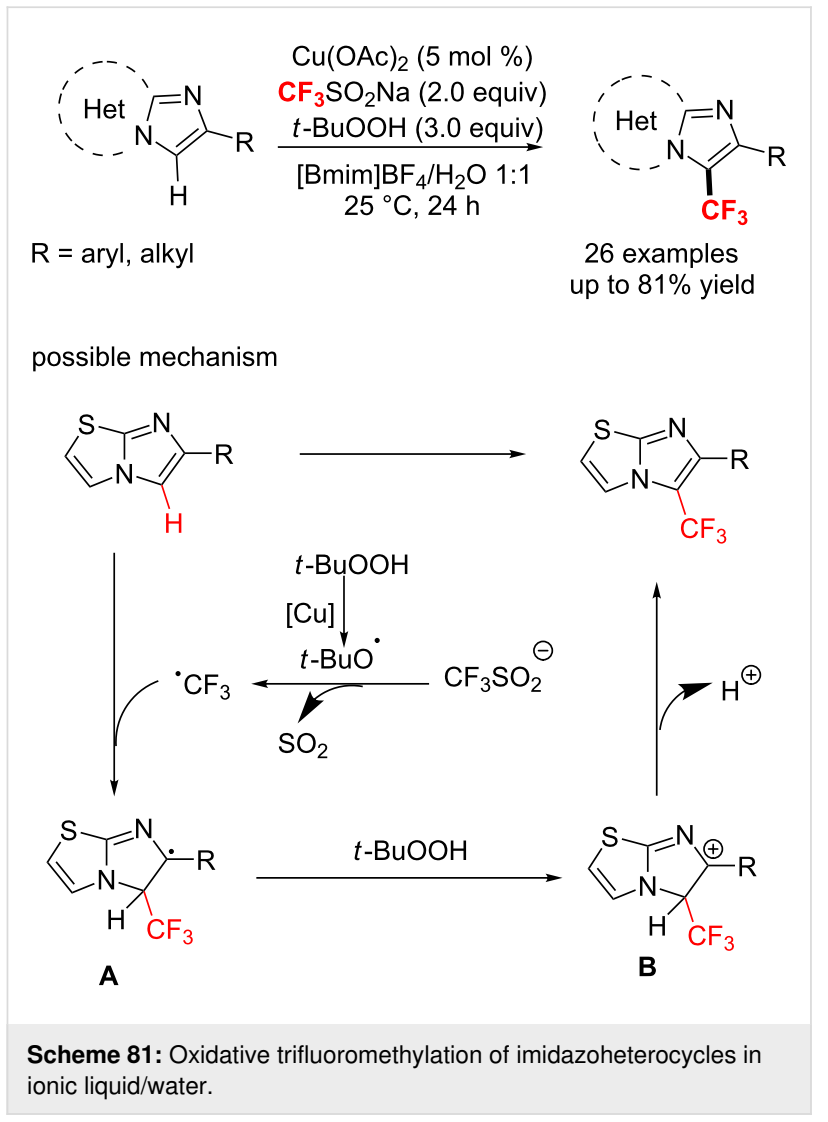

Also in 2015, Li and co-workers [146] developed a mild and fast $\mathrm{Cu}(\mathrm{I} / \mathrm{II})$-catalyzed trifluoromethylation procedure to obtain 3-trifluoromethylcoumarins. The reaction was carried out with a $\mathrm{CuCl} / \mathrm{CF}_{3} \mathrm{SO}_{2} \mathrm{Na} / \mathrm{TBHP}$ system under continuous-flow condi- tions, affording the corresponding products with wide substrate tolerance in moderate to good yields (Scheme 82).
Scheme 82: A mild and fast continuous-flow trifluoromethylation of coumarins using a $\mathrm{Cul} / \mathrm{CF}_{3} \mathrm{SO}_{2} \mathrm{Na} / \mathrm{TBHP}$ system.

After one year, the group of Cai [147] presented a $\mathrm{Cu}$ (II)-catalyzed 8-amido chelation-induced regioselective C5-trifluoromethylation of quinolines (Scheme $83 \mathrm{a}$ ). With $\mathrm{CuBr}_{2}$ as a catalyst and azobisisobutyronitrile (AIBN) as an oxidant, a wide range of functional groups were well tolerated to provide the products in moderate to excellent yields. Simultaneously, Zhang and co-workers [148] described a similar, milder regioselective $\mathrm{C}-\mathrm{H}$ trifluoromethylation of 8 -aminoquinolines by using a chitosan-based heterogeneous copper catalyst $\left(\mathrm{CS} @ \mathrm{Cu}(\mathrm{OAc})_{2}\right.$, $\mathrm{CS}=$ chitosan) (Scheme 83b).

Recently, a picolinamide (PA)-directed method for the Cu-catalyzed trifluoromethylation of anilines was described by the group of Zhang [149]. The trifluoromethyl group was installed at the ortho position of the substrate, yielding 2-(trifluoromethyl)aniline derivatives in moderate to good yields (Scheme 84). Notably, the directing group could be recovered a)<smiles>[R]C(=O)Nc1cccc2cccnc12</smiles>

$\mathrm{R}=$ alkyl, (het)aryl

b)<smiles>[R]C(=O)Nc1cccc2cccnc12</smiles>

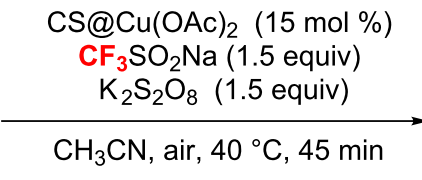

$\mathrm{R}^{1}$ = alkyl, (het)aryl

$\mathrm{R}^{2}=\mathrm{H}, \mathrm{OMe}$
$\mathrm{CuBr}_{2}(10 \mathrm{~mol} \%)$ $\mathrm{CF}_{3} \mathrm{SO}_{2} \mathrm{Na}$ (2.0 equiv) AIBN (1.2 equiv)

$\mathrm{CH}_{3} \mathrm{CN}$, air, $120^{\circ} \mathrm{C}, 12 \mathrm{~h}$<smiles>[R]C(=O)Nc1ccc(C(F)(F)F)c2cccnc12</smiles>

18 examples, $53-91 \%$<smiles>[R]C=C(c1cccnc1NC([R])=O)C(F)(F)F</smiles>

20 examples, $51-92 \%$ 


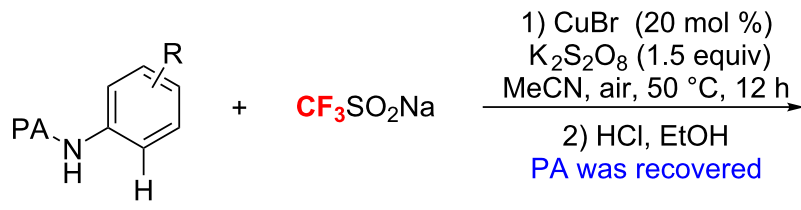

$\mathrm{R}=\mathrm{I}, \mathrm{Br}, \mathrm{Cl}, \mathrm{F}, \mathrm{CN}, \mathrm{NO}_{2}, \mathrm{Me}, \mathrm{CF}_{3}, \mathrm{CN}$<smiles>[R]c1ccc(N)c(C(F)(F)F)c1</smiles><smiles>O=C(O)c1ccccc1</smiles>

16 examples $18-69 \%$

Scheme 84: PA-directed copper-catalyzed trifluoromethylation of anilines.

in excellent yields and this approach provided a new way for the efficient synthesis of floctafenine via a single-electrontransfer mechanism.

Vinyl $\mathrm{C}-\mathrm{CF}_{3}$ bond formation using $\mathrm{Fe}$, Ir, $\mathrm{Ru}$, and $\mathrm{Ag}$ catalysts: In 2012, Buchwald and co-workers [150] unfolded an iron(II)-catalyzed trifluoromethylation of potassium vinyltrifluoroborates at room temperature (Scheme 85 ). With this approach, 2-arylvinyl substrates, in particular, furnished the products in good yields and excellent $E / Z$ ratios $(E / Z>95.5 \%)$.

Also, Cho and co-workers [151] reported a direct method for an alkenyl trifluoromethylation employing a Ru photocatalyst. The method used $\mathrm{CF}_{3} \mathrm{I}$ as a $\mathrm{CF}_{3}$ radical source and 1,8 diazabicyclo[5.4.0]undec-7-ene (DBU) as the base (Scheme 86). Under these mild reaction conditions, the trifluoromethylation of a wide range of alkenes shows high functional-group tolerance with a low catalyst loading. Moreover, compared with other alkenes, this process works especially well for terminal alkenes.

In 2013, Akita's group [152] developed a radical-mediated trifluoromethylation of vinyltrifluoroborates promoted by the photoredox catalyst $\left[\mathrm{Ru}(\mathrm{bpy})_{3}\right]\left(\mathrm{PF}_{6}\right)_{2}$ under visible light irradiation (Scheme 87a). The trifluoromethylated alkenes were obtained in up to $95 \%$ yield. One year later, the same group [153] presented a procedure for trifluoromethylation of multisubstituted alkenes with a different $\mathrm{CF}_{3}$ source, Umemoto's reagent (Scheme 87b). Additionally, this reaction could be extended to double trifluoromethylation.

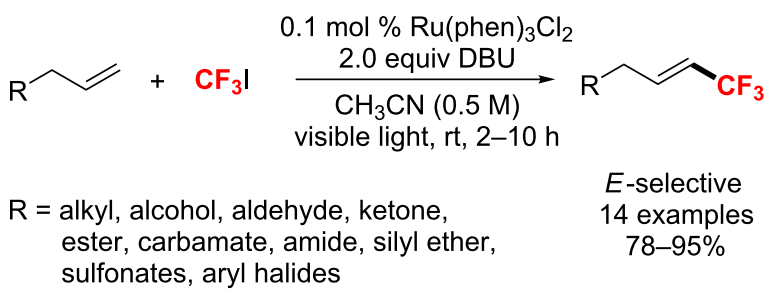

E-selective 14 examples $78-95 \%$

Scheme 86: Alkenyl trifluoromethylation catalyzed by $\mathrm{Ru}(\text { phen })_{3} \mathrm{Cl}_{2}$ as photocatalyst.

In 2014, a visible-light-induced decarboxylative trifluoromethylation of $\alpha, \beta$-unsaturated carboxylic acids by using $\left[\operatorname{Ir}(\mathrm{ppy})_{3}\right]$ as a photoredox catalyst was explored by Zhu and co-workers (Scheme 88) [154]. Notably, this procedure employed only $1 \mathrm{~mol} \%$ catalyst loading to achieve an excellent reactivity and $E / Z$ stereoselectivity at room temperature.

In 2016, Duan and co-workers [155] disclosed a Ag(I)-catalyzed denitration/trifluoromethylation of $\beta$-nitrostyrenes with $\mathrm{CF}_{3} \mathrm{SO}_{2} \mathrm{Na}$, which employed a large excess of di-tert-butyl peroxide (DTBP) as the oxidant and tetrabutylammonium iodide (TBAI) as phase-transfer catalyst (Scheme 89). Notably, only $(E)$-isomers of the products were obtained in moderate to high yields.

Various transition-metal-catalyzed direct $\mathbf{C}-\mathbf{H}$ bond trifluoromethylation of arenes and heteroarenes: In 2011, the group of MacMillan [156] reported a simple approach for the direct trifluoromethylation of unactivated arenes and

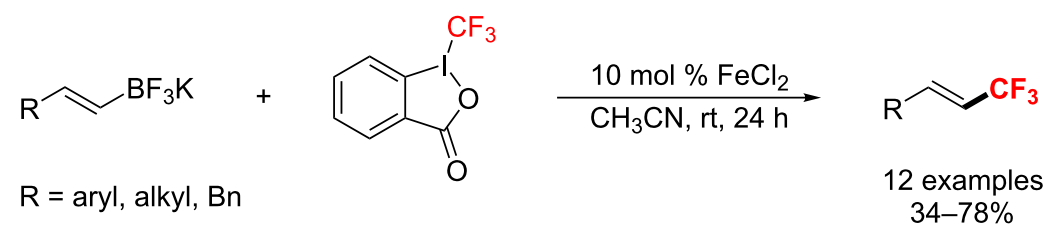

Scheme 85: Trifluoromethylation of potassium vinyltrifluoroborates catalyzed by $\mathrm{Fe}(\mathrm{II})$. 
a)<smiles>[R]C=CBr</smiles>

b)<smiles>[R]C=C([R])[R]</smiles>

$\mathrm{R}^{1}, \mathrm{R}^{2}=$ aryl $\mathrm{R}^{3}=$ aryl, $\mathrm{H}$<smiles>O=C1OC(C(F)(F)F)c2ccccc21</smiles>

$1.1-1.2$ equiv<smiles>[R]C=C[C-]</smiles>

21 examples $56-88 \%$

Scheme 87: Ru-catalyzed trifluoromethylation of alkenes by Akita's group.<smiles>[R][R]([R])=CC(=O)O</smiles>

$\mathrm{R}^{1}=\mathrm{H}, \mathrm{Me}$

$R^{2}=$ aryl

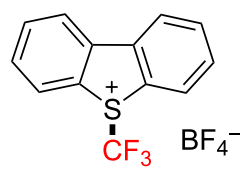

1.2 equiv

\section{$5 \mathrm{~mol} \%\left[\mathrm{Ru}(\mathrm{bpy})_{3}\right]\left(\mathrm{PF}_{6}\right)_{2}$ \\ $\mathrm{CH}_{3} \mathrm{OH}, \mathrm{rt}, 5 \mathrm{~h}$ \\ $3 \mathrm{~W}$ blue LEDs}<smiles></smiles>

13 examples $37-82 \%$
DMSO, rt, 2 h $425 \mathrm{~nm}$ blue LEDs<smiles>O=[N+]([O-])/C=C/c1c[R]ccc1</smiles>

$\mathrm{AgNO}_{3}(15 \mathrm{~mol} \%)$

TBAI $(20 \mathrm{~mol} \%)$

$\mathrm{CF}_{3} \mathrm{SO}_{2} \mathrm{Na}$ (3 equiv)

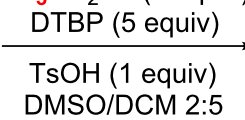

$70{ }^{\circ} \mathrm{C}, 24 \mathrm{~h}$

$\mathrm{R}=$ alkyl, $\mathrm{CO}_{2} \mathrm{Me}, \mathrm{OMe}, \mathrm{Me}$,

$\mathrm{Cl}, \mathrm{Br}, \mathrm{Ph}, \mathrm{CN}, \mathrm{NO}_{2}$

Scheme 89: $\mathrm{Ag}(\mathrm{I})$-catalyzed denitrative trifluoromethylation of $\beta$-nitrostyrenes.

heteroarenes through a radical-mediated mechanism (Scheme 90). Under exposure to $26 \mathrm{~W}$ fluorescent light, this process proceeded well in the presence of triflyl chloride and different photocatalysts depending on the substrate's nature, i.e., $\mathrm{Ru}$ (phen $)_{3} \mathrm{Cl}_{2}$ for 5 -membered heterocycles, $\operatorname{Ir}(\mathrm{Fppy})_{3}$ for 6-membered arenes and heterocycles. It is worth mentioning, that triflyl chloride provides a cheap and easy to handle $\mathrm{CF}_{3}$ source.

A mild and simple electrophilic trifluoromethylation of various aromatic and heteroaromatic compounds was disclosed by the Togni group [157] in 2012. The authors used methyltrioxorhe-
$1 \mathrm{~mol} \% \operatorname{Ir}(\mathrm{ppy})_{3}$ $\frac{2.0 \text { equiv } \mathrm{CH}_{3} \mathrm{COONa}}{\text { rt, } 18-24 \mathrm{~h}}$ $35 \mathrm{~W}$ fluorescent light<smiles>[R]C([R])=CC(F)(F)F</smiles>

24 examples $59-87 \%$ 


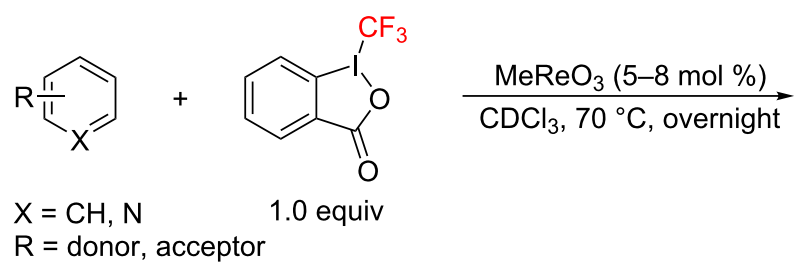

$$
\begin{aligned}
& \mathrm{R} \frac{1}{\mathrm{~L}} \underset{\mathrm{X}}{\mathrm{j}} \mathrm{CF}_{3} \\
& 34 \text { examples } \\
& 13-77 \%{ }^{19} \mathrm{~F} \text { NMR yield }
\end{aligned}
$$

Scheme 91: Rhenium (MTO)-catalyzed direct trifluoromethylation of aromatic substrates.

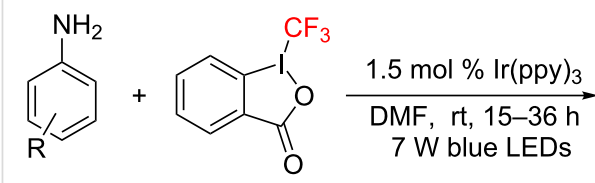

$\mathrm{R}=$ donor, acceptor

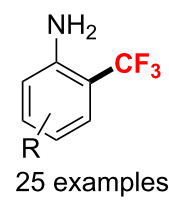
$38-81 \%$

Scheme 92: Trifluoromethylation of unprotected anilines under $\left[\operatorname{lr}(\mathrm{ppy})_{3}\right]$ catalyst.

In 2015, the group of Hajra [159] described a method for the direct trifluoromethylation of imidazopyridines and other imidazoheterocycles. The $\mathrm{CF}_{3} \mathrm{SO}_{2} \mathrm{Na} / t$ - $\mathrm{BuOOH} / \mathrm{Ag}$ system enables accomplishing the reaction at room temperature under ambient air (Scheme 93).

A direct trifluoromethylation of (hetero)arenes in the presence of only $0.1 \mathrm{~mol} \%\left[\mathrm{Ru}(\mathrm{bpy})_{3}\right] \mathrm{Cl}_{2}$ as catalyst was reported by the Stephenson group in 2016 [160]. Notably, the authors utilized pyridine $N$-oxide derivatives in concert with trifluoroacetic anhydride to facilitate this process (Scheme 94). Moreover, the method has been successfully extended on a kilogram scale.

One year later Mizuno's group [161] introduced a direct C-H trifluoromethylation of (hetero)arenes with $\mathrm{O}_{2}$ as the terminal oxidant in the presence of catalytic amounts of phosphovanadomolybdic acids (Scheme 95). The reaction tolerated diverse (hetero)arenes to afford the corresponding trifluoromethylated products via a radical pathway in $26-92 \%$ yields.

In 2017, Zhang and co-workers [162] were the first who reported a nickel(II)-catalyzed and picolinamide-assisted site-<smiles></smiles>

$\mathrm{R}=\mathrm{H}, \mathrm{Me}, \mathrm{Cl}, \mathrm{Br}$
$\mathrm{AgNO}_{3}(20 \mathrm{~mol} \%)$

TBHP (20 mol \%) $\mathrm{CF}_{3} \mathrm{SO}_{2} \mathrm{Na}$ (2.0 equiv)

DMSO, air, rt, $12 \mathrm{~h}$<smiles></smiles>

17 examples, $63-78 \%$

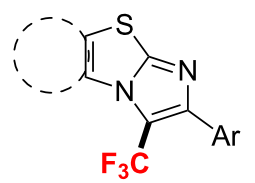

3 examples, $68-71 \%$

Scheme 93: Oxidative trifluoromethylation of imidazopyridines and imidazoheterocycles.

$$
\mathrm{Ar}^{\mathrm{H}}
$$

(hetero)arenes with electron-rich groups<smiles></smiles>

$\mathrm{X}=\mathrm{C}, \mathrm{N}, \mathrm{O}, \mathrm{S}$

$\mathrm{R}^{1}=\mathrm{H}, \mathrm{COMe}, \mathrm{CO}_{2} \mathrm{Me}, \mathrm{COCF}_{3}$, MIDA-protected boronate esters

$\mathrm{R}^{2}=\mathrm{Boc}, \mathrm{Ph}, \mathrm{Me}$
$\mathrm{Ru}(\mathrm{bpy})_{3} \mathrm{Cl}_{2}(0.1 \mathrm{~mol} \%)$ 4-Ph-pyridine $\mathrm{N}$-oxide (1.0-4.0 equiv) $\left(\mathrm{F}_{3} \mathrm{CCO}\right)_{2} \mathrm{O}$ (1.1-4.1 equiv)

$\mathrm{MeCN}, 35^{\circ} \mathrm{C}$, blue light

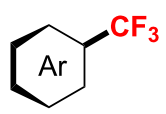

or<smiles></smiles>

16 examples $32-79 \%$ 


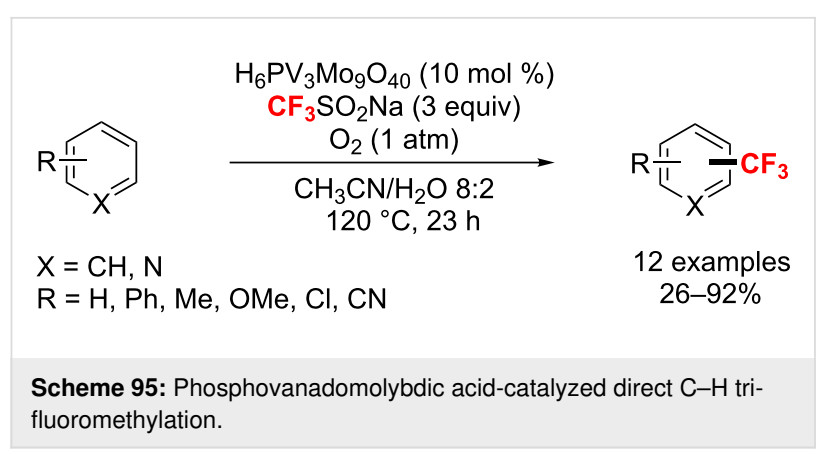

selective $\mathrm{C}-\mathrm{H}$ bond trifluoromethylation of arylamines in water (Scheme 96a). This strategy displays several advantages: 1) inexpensive nickel catalyst, 2) recyclable catalyst, 3) aqueous phase reaction, and 4) high site selectivity. Only one year later, the group of Xia optimized this approach and established a convenient, oxidant-free protocol for the ortho-trifluoromethylation of arylamine under ultraviolet irradiation (Scheme 96b) [163].

In 2018, Wu and co-workers [164] introduced a one-step strategy for the synthesis of trifluoromethylated free anilines using Togni's reagent using a nickel-catalyzed C-H trifluoromethylation. Moreover, free anilines with a variety of functional groups were trifluoromethylated under the mild reaction conditions in up to $90 \%$ yield (Scheme 97).

\section{$\mathrm{C}(\mathrm{sp})-\mathrm{CF}_{3}$ bond formation}

In 2010, Qing's group [165] reported the first example of a copper-mediated trifluoromethylation of terminal alkynes. Notably, the reaction was carried out with nucleophilic (trifluoromethyl)trimethylsilane $\left(\mathrm{Me}_{3} \mathrm{SiCF}_{3}\right)$ as a $\mathrm{CF}_{3}$ source under

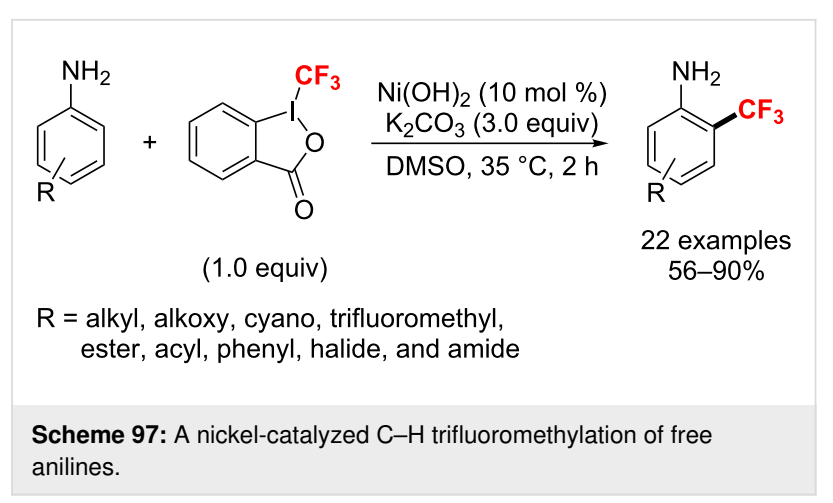

air atmosphere (Scheme 98a). Moreover, this protocol was compatible with various terminal alkynes, such as aromatic and aliphatic alkynes, affording the trifluoromethylated alkynes in 47-91\% yields. Subsequently, Qing [166] developed an efficient catalytic trifluoromethylation by adding terminal alkynes and $\mathrm{Me}_{3} \mathrm{SiCF}_{3}$ slowly with a syringe pump. Two years later, the same group [167] presented an improved $\mathrm{Cu}$-mediated oxidative trifluoromethylation of aryl and heteroaryl terminal alkynes. In the latter case, the trifluoromethylation proceeded at room temperature by using $\mathrm{Ag}_{2} \mathrm{CO}_{3}$ as an oxidant with a significantly lower amount of $\mathrm{TMSCF}_{3}$ (Scheme 98b).

In 2012, Huang et al. [168] reported a process for trifluoromethylation of terminal alkynes with Togni's reagent in DCM at room temperature (Scheme 99a). The trifluoromethylated acetylenes were obtained with up to $98 \%$ yield via a $\mathrm{Cu}(\mathrm{I} / \mathrm{III})$ catalytic cycle with $\mathrm{CF}_{3}{ }^{+}$. As an extension of their work, this group [169] developed the trifluoromethylation of alkynyltrifluoroborates to form trifluoromethylated acetylenes under similar conditions without the addition of bases (Scheme 99b). a<smiles>[R]c1cccc(NC(=O)c2ccccn2)c1</smiles>

$\mathrm{R}=$ alkyl, $\mathrm{H}, \mathrm{Cl}, \mathrm{Br}, \mathrm{I}, \mathrm{F}, \mathrm{CN}, \mathrm{NO}_{2}$

b

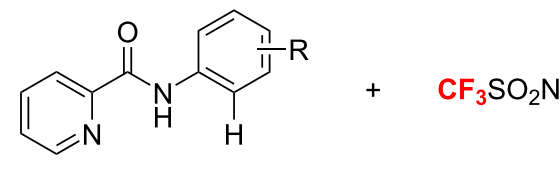

$\mathrm{R}=\mathrm{H}, \mathrm{Me}, \mathrm{Cl}, \mathrm{Br}, \mathrm{I}, \mathrm{F}, \mathrm{CN}, \mathrm{NO}_{2}$

$$
\frac{\begin{array}{c}
\mathrm{NiSO}_{4} \cdot 6 \mathrm{H}_{2} \mathrm{O}(10 \mathrm{~mol} \%) \\
\mathrm{K}_{2} \mathrm{~S}_{2} \mathrm{O}_{8}(3 \text { equiv })
\end{array}}{\mathrm{H}_{2} \mathrm{O}, 50^{\circ} \mathrm{C}, 12 \mathrm{~h} \text {, air }}
$$<smiles>[R]c1cccc(NC(=O)c2ccccn2)c1C(F)(F)F</smiles>

17 examples up to $72 \%$ yield

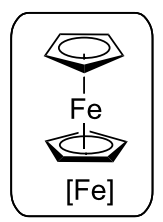

[Fe] 


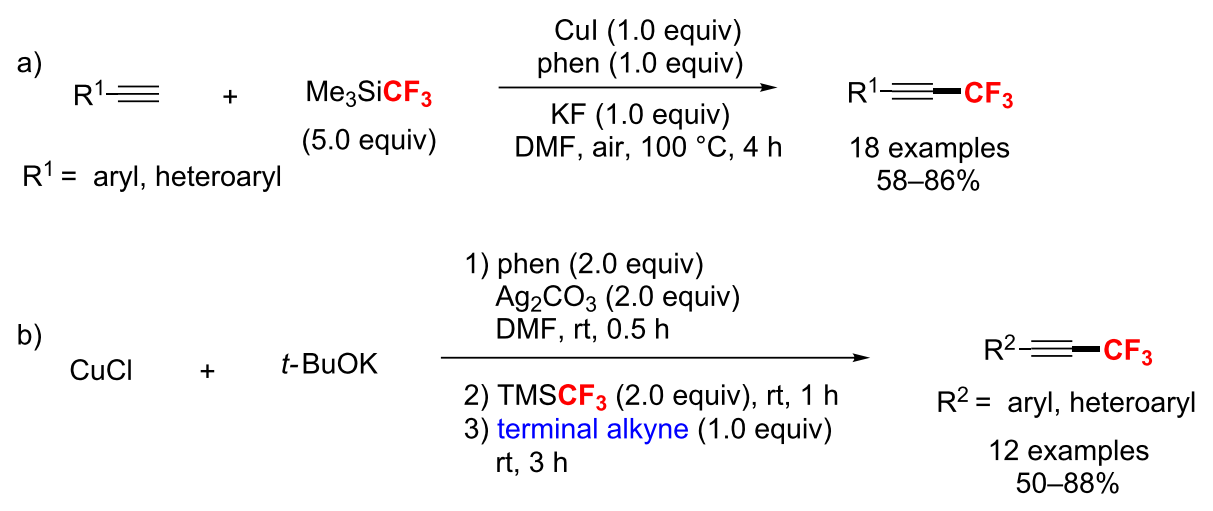

Scheme 98: Cu-mediated trifluoromethylation of terminal alkynes reported by Qing.

a)

$$
\begin{aligned}
& \mathrm{R}=\mathrm{H} \\
& \mathrm{R}=\text { aryl, heteroaryl, benzyl }
\end{aligned}
$$

b)<smiles></smiles>

$\mathrm{R}=$ aryl, alkyl<smiles>CC1(C)OC(C)(C)c2ccccc21</smiles>

Cul $(20 \mathrm{~mol} \%)$ phen $(40 \mathrm{~mol} \%)$ $\mathrm{KHCO}_{3}$ (2.0 equiv) $\mathrm{DCM}, \mathrm{rt}, 24 \mathrm{~h}$

$$
\mathrm{R}-\mathrm{CF}_{3}
$$$$
70-96 \%
$$

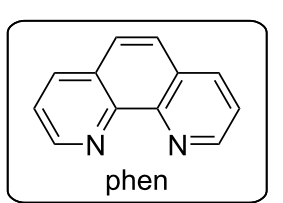<smiles>CC1(C)OC(C(F)(F)F)c2ccccc21</smiles>

(1.2 equiv)

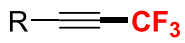

12 examples $47-88 \%$

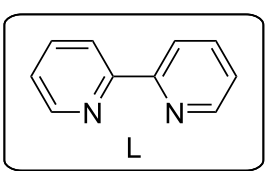

proposed mechanism

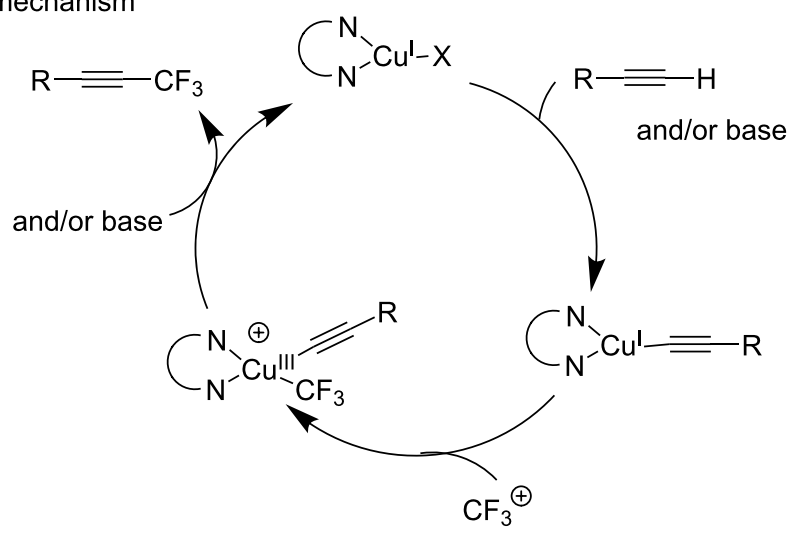

Scheme 99: Huang's C(sp)-H trifluoromethylation using Togni's reagent.

In the same year, the groups of Guo [170] and Xiao [171] also developed a copper(I)-catalyzed trifluoromethylation of terminal alkynes with Umemoto's reagent as an electrophilic $\mathrm{CF}_{3}$ source (Scheme 100a). Compared with the reaction conditions reported by Guo, Xiao's method was carried out at higher tem- perature, using similar copper(I) catalysts, but with different ligands (Scheme 100b).

In 2014, the trifluoromethylation of aromatic alkynes through visible-light photoredox catalysis was described by Cho and 


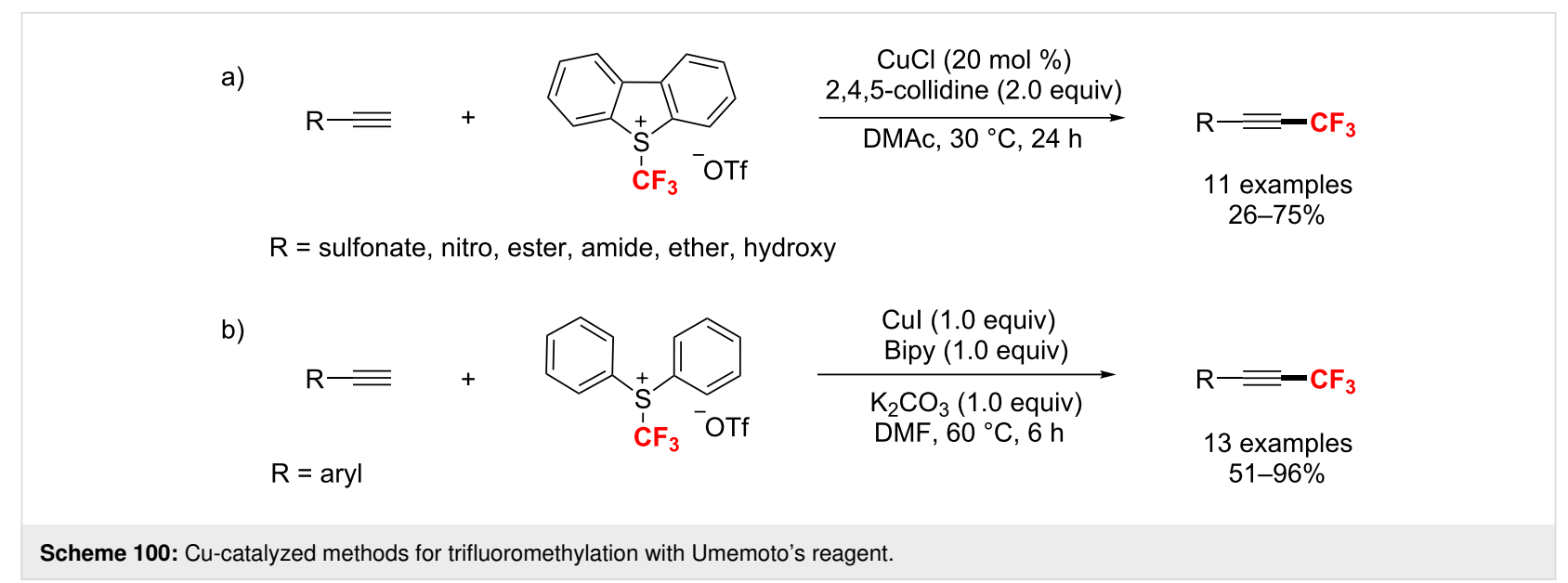

co-workers [172]. With $f a c$-[Ir(ppy $\left.)_{3}\right]$ as photocatalyst and $\mathrm{KO} t-\mathrm{Bu}$ as a base, the reaction was achieved under blue LED irradiation in moderate yields (Scheme 101). However, this approach was not suitable for aliphatic alkynes.

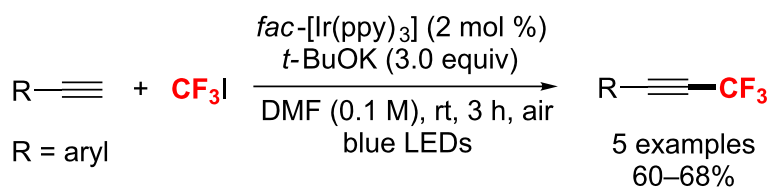

Scheme 101: The synthesis of alkynyl- $\mathrm{CF}_{3}$ compounds in the presence of $f a c$-[Ir(ppy $\left.)_{3}\right]$ under visible-light irradiation.

Compared with the trifluoromethylation and fluorination mentioned above, the methodological research on difluoromethylation, trifluoromethylthiolation and trifluoromethoxylation of organic molecules are quite rare and scattered. Here we summarize the new developments within recent years.

\section{Difluoromethylation}

The introduction of a difluoromethylene $\left(\mathrm{CF}_{2}\right)$ group into organic molecules can significantly improve their metabolic stability and oral bioavailability [3]. Therefore, the difluoroalkylation has become a powerful strategy for regulating the biological activity of organic molecules. It is noteworthy that transition-metal-catalyzed difluoroalkylation is an effective route to obtain these valuable difluoroalkylated backbones. There are four modes of catalytic difluoroalkylation, including nucleophilic difluoroalkylation, electrophilic difluoroalkylation, radical difluoroalkylation, and metal-difluorocarbene coupling (MeDiC) [173]. Finally, a wide range of difluoroalkylated (hetero)arenes [(Het)Ar- $\mathrm{CF}_{2} \mathrm{R}, \mathrm{R}=\mathrm{PO}(\mathrm{OEt})_{2}, \mathrm{CO}_{2} \mathrm{Et}$, $\mathrm{CONR}^{1} \mathrm{R}^{2}, \mathrm{COR}^{1}$, (Het)Ar, alkenyl, alkynyl, alkyl, H] and alkenes were obtained with excellent functional group tolerance.

In 2012, the Reutrakul group [174] firstly reported a Pd-catalyzed Heck-type reaction of [(bromodifluoro-methyl)sulfonyl]benzene with styrene derivatives (Scheme 102). Notably, the reaction shows a broad substrate scope, including a variety of styrene derivatives, vinyl ethers, vinyl sulfides, and a few heteroaromatic substrates.

In the same year, Yu and co-workers [175] developed an iridium-catalyzed direct $\mathrm{C}-\mathrm{H}$ functionalization of enamides and ene-carbamates with $\mathrm{BrCF}_{2} \mathrm{CO}_{2} \mathrm{Et}$ under visible-light photoredox conditions (Scheme 103). This method shows excellent yields and a wide substrate scope.

Moreover, $\mathrm{Hu}$ et al. [130] established a copper-catalyzed (phenylsulfonyl)-difluoromethylation of $\alpha, \beta$-unsaturated carboxylic acids with excellent $E / Z$ selectivity (Scheme 104). Notably, the Lewis acid $\left(\mathrm{CuF}_{2} \cdot 2 \mathrm{H}_{2} \mathrm{O}\right)$ was used to enhance the electrophilicity of the Togni's reagent and to promote the decarboxylation of the carboxylic acids. The authors proposed that, under these conditions, the Togni's reagent may undergo a $\mathrm{Cu}$-catalyzed bond cleavage to produce the highly electrophilic

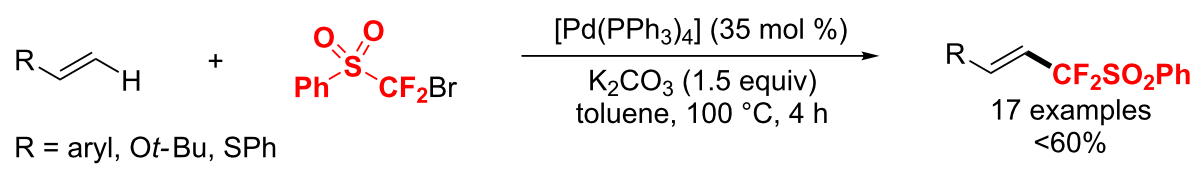




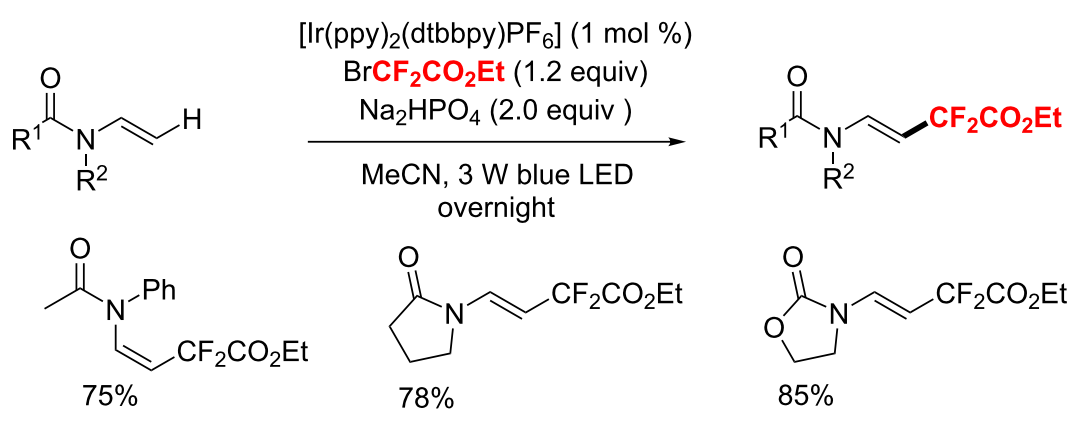

Scheme 103: Difluoromethylation of enamides and ene-carbamates.

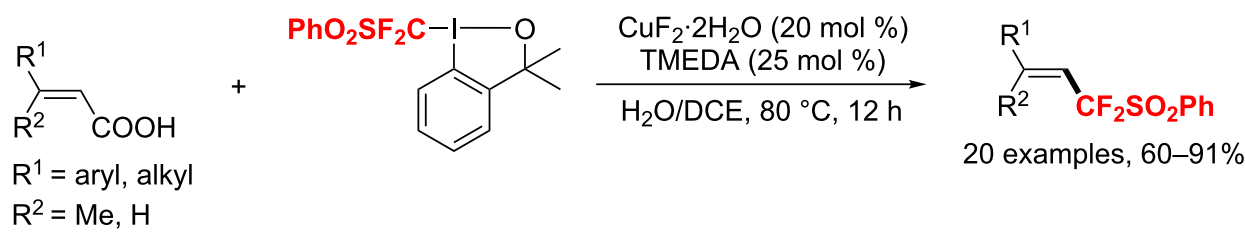

proposed reaction mechanism

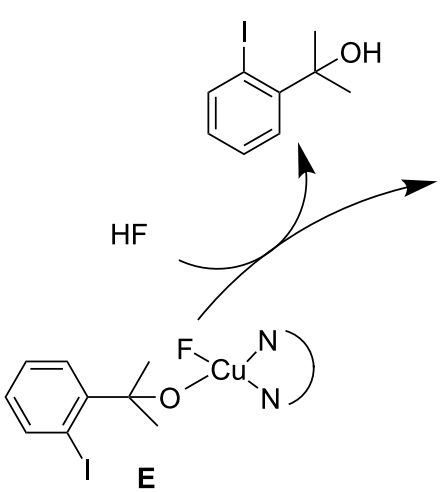

$\mathrm{PhO}_{2} \mathrm{SF}_{2} \mathrm{C}$<smiles>[R]/C(=C/C)C(C)C1CC1C</smiles>

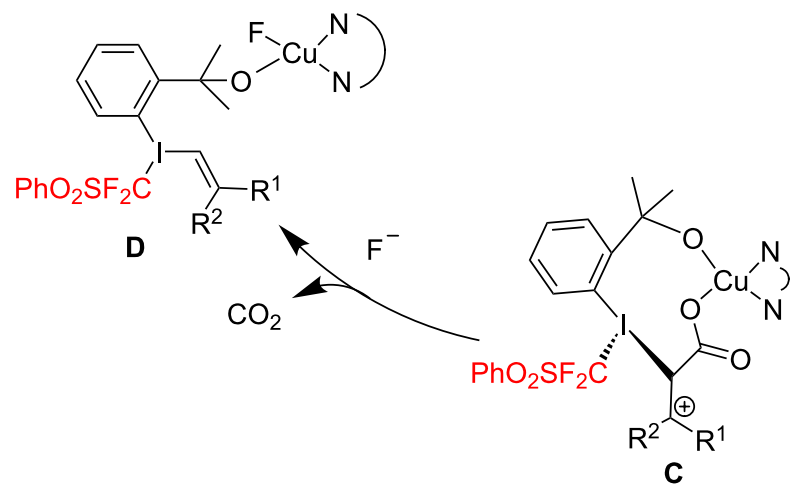

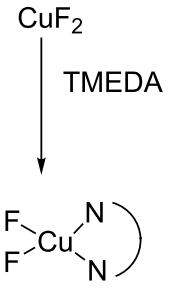

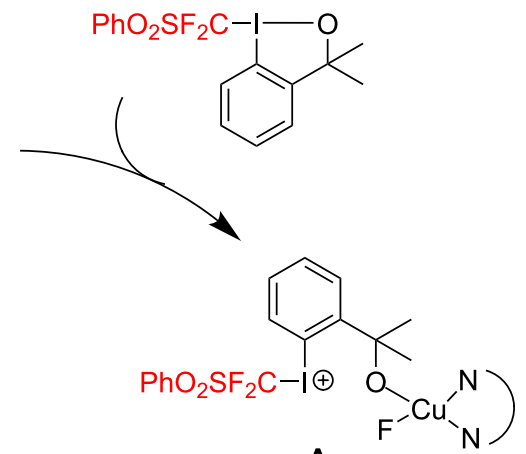

A

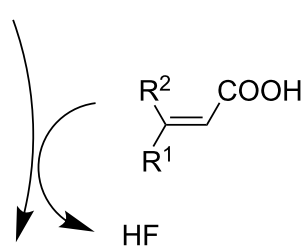

$\oplus$

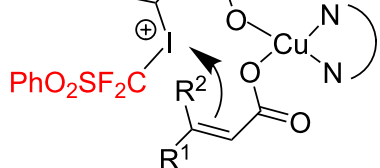

B

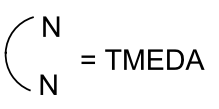


iodonium salt A, which then coordinates to the carboxylic acid functionality to generate the intermediate $\mathbf{B}$. The latter then undergoes - through an intramolecular reaction - decarboxylation and reductive elimination to afford the species $\mathbf{E}$ and the desired product. Finally, species $\mathbf{E}$ reacts with HF regenerating the catalyst.

In 2013, Pannecoucke and co-workers [176] developed a copper-catalyzed regioselective difluoroacetylation of dihydropyrans and glycals on the C-2 position. Notably, the corresponding products were obtained through a $\mathrm{Cu}(\mathrm{I} / \mathrm{III})$ catalytic cycle without the involvement of radicals (Scheme 105a).
Hence, in 2014, the same group extended this method to the olefinic difluoroacetylation of enamides [177]. In this reaction, they obtained the $\beta$-difluoroester-substituted enamides under operationally simple and mild conditions. Also, the method has a broad substrate scope, including cyclic and acyclic enamides (Scheme 105b).

In 2016, a Pd-catalyzed direct difluoroalkylation of aldehyde hydrazones with functionalized difluoromethyl bromides was described by Monteiro's group (Scheme 106a) [178]. The bromodifluoromethylated compounds are effective reagents for the difluoromethylation of aldehyde-derived hydrazones to the a)<smiles>CC1CCCCC1C</smiles>

b)<smiles>CCCCC(C)C(C)C</smiles>

$10 \mathrm{~mol} \% \mathrm{Cu}\left(\mathrm{PF}_{6}\right)(\mathrm{MeCN})_{4}$

$12 \mathrm{~mol} \%$ 1,10-phenanthroline 8.0 equiv $\mathrm{BrCF}_{2} \mathrm{CO}_{2} \mathrm{Et}$

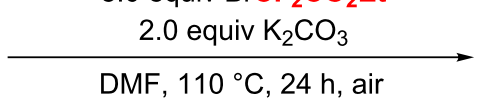

$10 \mathrm{~mol} \% \mathrm{Cu}_{2} \mathrm{O}$

$12 \mathrm{~mol} \%$ 1,10-phenanthroline 2.0 equiv $\mathrm{BrCF}_{2} \mathrm{CO}_{2} \mathrm{Et}$ 2.0 equiv $\mathrm{K}_{2} \mathrm{CO}_{3}$

$\mathrm{CH}_{3} \mathrm{CN}, 80^{\circ} \mathrm{C}, 6-72 \mathrm{~h}$

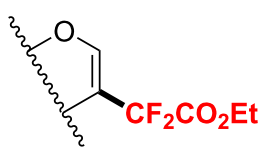

12 examples $39-85 \%$<smiles>CCOC(=O)C(F)(F)C(C)=C(C(C)C)C(C)C</smiles>

18 examples up to $82 \%$

Scheme 105: Copper-catalyzed direct $\mathrm{C}\left(\mathrm{sp}^{2}\right)-\mathrm{H}$ difluoroacetylation reported by Pannecoucke and co-workers.

a)<smiles>[R]/C=N\N([R])[R]</smiles>

$\mathrm{R}^{1}=$ aryl, heteroaryl, $\mathrm{CO}_{2} \mathrm{Et}$ $\mathrm{R}^{2}, \mathrm{R}^{3}=$ alkyl

b)<smiles>[R]/C=N\N([R])[R]</smiles>

(
$2.5 \mathrm{~mol} \%\left[\mathrm{Pd}_{2}(\mathrm{dba})_{3}\right]$ 5 mol \% $t$-BuXantphos 2.0 equiv $\mathrm{AcOK}$

1,4-dioxane, $80^{\circ} \mathrm{C}, 2 \mathrm{~h}$

2.0 equiv

$\mathrm{FG}=$ ester, amide

\% $\%$ CuCl $10 \mathrm{~mol} \%$ 1,10-phenanthroline 2.0 equiv $\mathrm{K}_{2} \mathrm{CO}_{3}$ $\mathrm{MeCN}, 80^{\circ} \mathrm{C}, 5 \mathrm{~h}$

FG = ester, amide, heterocycle

$\mathrm{R}^{1}=$ aryl, heteroaryl, $\mathrm{CO}_{2} \mathrm{Et}$ $\mathrm{R}^{2}, \mathrm{R}^{3}=$ alkyl<smiles>[R]/C(=N/N([R])[R])C(F)(F)F</smiles>

26 examples up to $91 \%$ yield<smiles>[R]/C(F)=N/N([R])[R]</smiles>

19 examples up to $99 \%$ yield 
corresponding difluoromethyl ketone hydrazones. However, this strategy relies on the use of an expensive palladium/ligand catalyst system that makes it less attractive and practical. Subsequently, the same group [179] found that $\mathrm{CuCl}$ could also effectively catalyze the difluoromethylation of hydrazones. This method provided an efficient, cost-effective protocol for the multigram-scale preparation of functionalized difluoromethylketone hydrazines (Scheme 106b).

Compared with Monteiro's approaches, Zhu and co-workers [180] were the first who developed a visible-light-induced direct C-H-bond difluoroalkylation of aldehyde-derived hydrazones (Scheme 107a). Importantly, this unprecedented photoredox protocol is enabled by a novel aminyl radical/polar crossover mechanism. Meanwhile, a first gold-catalyzed photoredox difluoroalkylation of aromatic aldehyde hydrazones under sunlight was reported by Hashmi's group (Scheme 107b) [181]. Both methods smoothly work at room temperature affording the products with modest to excellent yields.

One year later, Ackermann and co-workers [182] presented a ruthenium(II)-catalyzed meta-selective $\mathrm{C}-\mathrm{H}$ difluoromethylation with the cooperation of phosphine and carboxylate. This protocol is compatible with a variety of functional groups, such as pyridyl, pyrimidyl, pyrazolyl, and even purinyl assistance (Scheme 108).

A visible-light photocatalytic decarboxylation strategy for the synthesis of difluoromethylated styrenes with $f a c-\operatorname{Ir}(\mathrm{ppy})_{3}$ and $\mathrm{BrCF}_{2} \mathrm{CO}_{2}$ Et was developed by Noël et al. in 2017 [183]. Herein, meta and para-substituted cinnamic acids afforded the expected $E$-isomers, while ortho-substituted cinnamic acids selectively provided the less stable $Z$-product. Notably, the conversion of the $Z$-isomer into the $E$-isomer was achieved by controlling the reaction time accurately. Furthermore, arylpropiolic acids could also be decarboxylative difluoromethylated by this method (Scheme 109).

Meanwhile, the group of Dilman [184] developed a method for the synthesis of difluorinated ketones with gem-difluorinated organozinc reagents (Scheme 110). Firstly, acyl chlorides reacted with potassium dithiocarbamate to generate $S$-acyl dithiocarbamates. Subsequently, the so-obtained dithiocarbamates were coupled with organozinc to produce the desired difluorinated ketones.

Additionally, Poisson and co-workers [185] developed a simple and efficient way to access various aryl and heteroaryl difluoromethylated phosphonates under mild conditions. The reac- a)<smiles>[R][R19]([R])=[W]</smiles>

b)

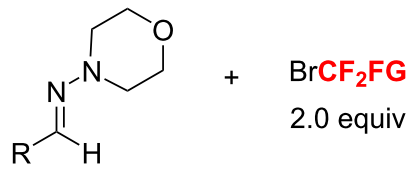

$\mathrm{R}=$ aryl, heteroaryl

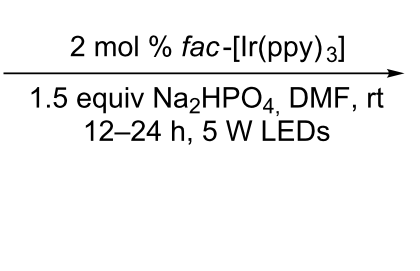

$2 \mathrm{~mol} \%\left[\mathrm{Au}_{2}(\mu-\mathrm{dppm})_{2}\right](\mathrm{OTf})_{2}$ 3.0 equiv 2,6-lutidine, MeCN, rt 24-30 h, sunlight<smiles>[R]/C(F)=N/N([R])[R]</smiles>

21 examples 50-98\%

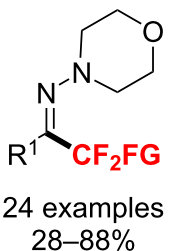

Scheme 107: Photoredox-catalyzed C-H difluoroalkylation of aldehyde-derived hydrazones.

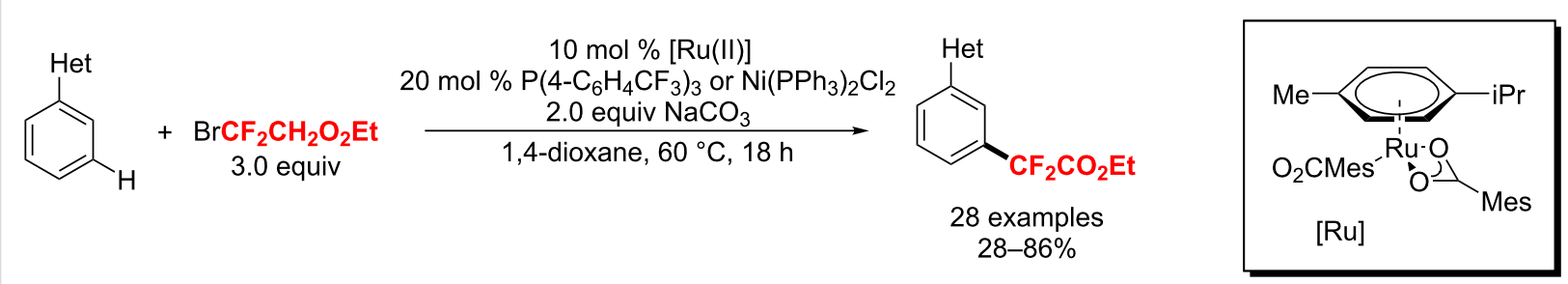


<smiles>O=C(O)C=Cc1[R]ccc1</smiles>

$\mathrm{R}=\mathrm{H}$, alkyl, aryl, $\mathrm{OCF}_{3}, \mathrm{NO}_{2}$, halogen

or<smiles>[R][R]OC(=O)OCC</smiles>

$\mathrm{R}=\mathrm{H}$, alkyl, OMe, SMe, $\mathrm{CO}_{2} \mathrm{Et}, \mathrm{COMe}$, halogen
fac-[Ir(ppy) $\left.)_{3}\right](1 \mathrm{~mol} \%), \mathrm{Na}_{2} \mathrm{HCO}_{3}(2.0$ equiv)

or fac-[Ir(ppy) $\left.{ }_{3}\right](3 \mathrm{~mol} \%), \mathrm{CsOAc}$ (2.0 equiv) $\mathrm{H}_{2} \mathrm{O}$

1,4-dioxane, Ar, blue LEDs, rt, $24 \mathrm{~h}$<smiles>[R][C]OC(=O)[C-]C=Cc1ccccc1</smiles>

up to $89 \%$ yield

or<smiles>[R][C]C(=O)OCC</smiles>

up to $62 \%$ yield

Scheme 109: Visible-light photocatalytic decarboxylation of $\alpha, \beta$-unsaturated carboxylic acids.<smiles>[R16]C(=O)N1CC[C@H]2C[C@H]1C2</smiles>

$\mathrm{R}^{1}=$ aryl, alkyl, alkenyl, heteroaryl $\mathrm{R}^{2}=$ aryl, alkyl, ester<smiles>[R]C(=O)SC(=S)N1CCCC1</smiles>

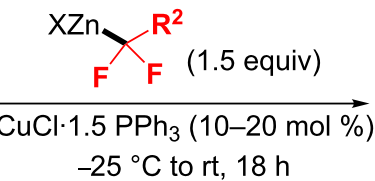

$\mathrm{X}=\mathrm{Cl}, \mathrm{Br}, \mathrm{I}$<smiles>[R]C(=O)C([R])(F)F</smiles>

18 examples $46-80 \%$

Scheme 110: Synthesis of difluorinated ketones via S-alkyl dithiocarbamates obtained from acyl chlorides and potassium dithiocarbamate.

tion proceeds smoothly with $\mathrm{CuCF}_{2} \mathrm{PO}(\mathrm{OEt})_{2}$ and a palladium catalyst in $\mathrm{MeCN}$ (Scheme 111). This transformation enabled the functionalization of various less reactive substrates, such as phenol, boronate, ketones, nitriles, esters, etc.

Notably, the above-mentioned copper-catalyzed highly stereoselective trifluoromethylation reaction of secondary propargyl sulfonates developed by Zhang [116] could also be extended to stereospecific propargylic difluoroalkylation (Scheme 112). In this reaction trimethylsilyldifluoroamide $\left(\mathrm{TMSCF}_{2} \mathrm{CONEt}_{2}\right)$ is chosen as the difluoroalkylating reagent and proceeds under mild reaction conditions with high regioselectivity and stereospecificity (ee up to $99 \%$ ).

In 2018, Zhao et al. [186,187] disclosed a ruthenium(II)enabled para-selective $\mathrm{C}-\mathrm{H}$ difluoromethylation of ketoxime

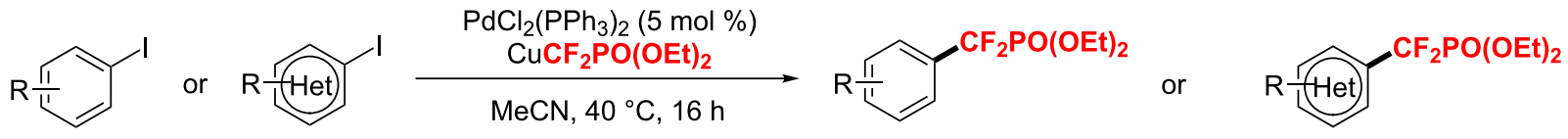

$\mathrm{R}=\mathrm{OMe}, \mathrm{Ph}, \mathrm{CO}_{2} \mathrm{Me}, \mathrm{CN}, \mathrm{COMe}, \mathrm{OH}, \mathrm{NHAc}, \mathrm{F}, \mathrm{Br}$

19 examples, $38-80 \%$

Scheme 111: Synthesis of aryl and heteroaryl difluoromethylated phosphonates.
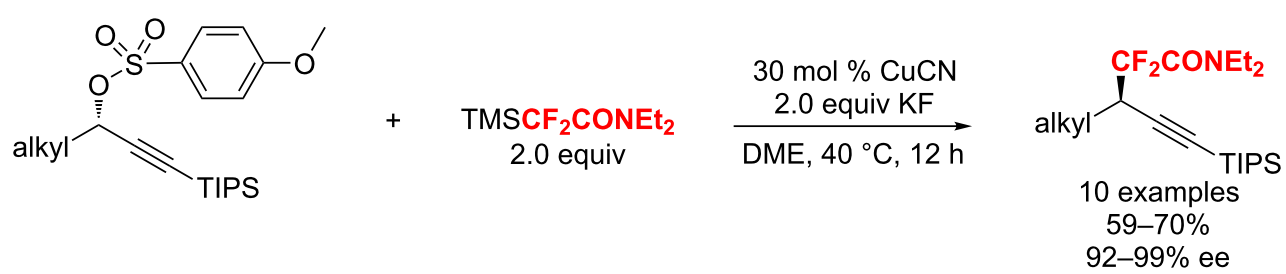

Scheme 112: Difluoroalkylation of secondary propargyl sulfonates using $\mathrm{Cu}$ as the catalyst. 
ethers, anilides, indolines and tetrahydroquinolines (Scheme 113). The protocol is compatible with various functional groups, furnishing the para-difluoromethylated products in moderate to good yields. Moreover, chelation-assisted cycloruthenation plays a key role in the selective activation of para $-\mathrm{C}_{\mathrm{Ar}}-\mathrm{H}$ bonds.

Subsequently, the Zhang group [188] disclosed an iron-catalyzed cross-coupling of a wide range of arylmagnesium and difluoroalkyl bromides with modified $N, N, N^{\prime}, N^{\prime}$-'tetramethyl- ethane-1,2-diamine (TMEDA) as a ligand. Notably, this bulky diamine is critical to improve the catalytic efficiency and suppress the side reaction of defluorination (Scheme 114).

Recently, a synthetic method for difluoroacetylated quinoxalin2(1H)-one derivatives was presented by the same group [189]. The direct difluoroacetylation of diverse quinoxalinones with a wide range of functional groups proceeded regioselectively at the $\mathrm{C}-3$ position with ethyl bromodifluoroacetate under copper catalysis (Scheme 115).<smiles>[R]/C(=N\OC)c1ccccc1</smiles>

$$
\mathrm{R}^{1}=\text { alkyl }
$$

$\mathrm{R}^{2}=\mathrm{Me}, \mathrm{OMe}, \mathrm{Cl}, \mathrm{Br}$, and $\mathrm{CF}_{3}$<smiles>[R]c1cccc(N=[R])c1</smiles>

Piv

$\mathrm{R}^{1}=\mathrm{H}$, alkyl

$\mathrm{R}^{2}=\mathrm{Me}, \mathrm{Et}, \mathrm{OMe}, \mathrm{OPh}, t-\mathrm{Bu}, \mathrm{Cl}, \mathrm{Br}, \mathrm{CO}_{2} \mathrm{Me}$<smiles>c1ccc(C2CCCc3ccccc32)cc1</smiles><smiles>[R]C=C(C(=O)OCC)c1ccc(C([R])=NOC)cc1</smiles>

[Ru(p-cymene) $\left.\mathrm{Cl}_{2}\right]_{2}(5 \mathrm{~mol} \%)$

$\mathrm{AgNTf}_{2}(20 \mathrm{~mol} \%)$

$\mathrm{N}$-Ac-L-Iso $(30 \mathrm{~mol} \%)$ or 1-Ad-OH $(20 \mathrm{~mol} \%)$

$\mathrm{Na}_{2} \mathrm{CO}_{3}$ (2.0 equiv) or $\mathrm{K}_{2} \mathrm{CO}_{3}$ (400 mol \%) $\mathrm{BrCF}_{2} \mathrm{CO}_{2} \mathrm{Et}$ ( 3.0 equiv)

$\mathrm{Ar}, \mathrm{DCE}, 120$ or $150^{\circ} \mathrm{C}, 48 \mathrm{~h}$
30 examples up to $92 \%$ yield

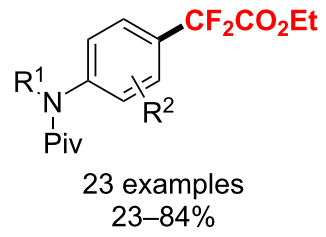
$23-84 \%$<smiles>CCOC(=O)c1ccc2c(c1)CCCC2C(P)c1ccccc1</smiles>

Scheme 113: Ru(II)-mediated para-selective difluoromethylation of anilides and their derivatives.

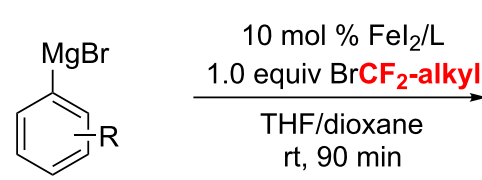

$\mathrm{R}=\mathrm{H}$, alkyl, aryl, $\mathrm{CF}_{3}$, OMe, TMS<smiles>Oc1cccc(C(F)(F)[AlH2])c1</smiles>

32 examples $24-93 \%$

Scheme 114: Bulky diamine ligand promoted cross-coupling of difluoroalkyl bromides.<smiles>[R]n1c(=O)cnc2cc[R1]cc21</smiles>

$\mathrm{R}^{1}=\mathrm{Me}, \mathrm{Et}, \mathrm{CH}_{2} \mathrm{Ph}, \mathrm{CH}_{2} \mathrm{COOMe}, \mathrm{CH}_{2} \mathrm{COO}$-Bu, alkenyl $\mathrm{R}^{2}=\mathrm{Me}, \mathrm{F}, \mathrm{Cl}, \mathrm{Br}, \mathrm{CF}_{3}, \mathrm{CN}$
$\left[\mathrm{Cu}\left(\mathrm{CH}_{3} \mathrm{CN}\right)_{4}\right] \mathrm{PF}_{6}(7.5 \mathrm{~mol} \%)$ 1,10-phenanthroline hydrate (20 mol \%)

$\mathrm{K}_{2} \mathrm{CO}_{3}$ (2.0 equiv) $\mathrm{CH}_{3} \mathrm{CN}, 110^{\circ} \mathrm{C}, \mathrm{Ar}$

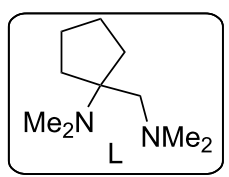

$\mathrm{NMe}_{2}$ 


\section{Trifluoromethylthiolation}

In the past few years, many methods for the direct introduction of trifluoromethylthio groups into organic compounds have been reported. Depending on the type of the trifluoromethylthiolating reagent used in the chemical conversion, the methods can also be classified into three classes: radical, nucleophilic and electrophilic trifluoromethylthiolation. Some reviews in this area focused on several aspects such as the syntheses of aromatic and heterocyclic perfluoroalkyl sulfides [190], direct trifluoromethylthiolation reactions [191-194], sulfur-based fluorination and fluoroalkylation reagents [195], trifluoromethylthio cation-donating ability $\left(\mathrm{Tt}^{+} \mathrm{DA}\right)$ [196], or synthetic methods leading to compounds containing $\mathrm{CF}_{3}-\mathrm{S}$ units [197]. Herein, based on the transition-metal catalysis, recent research advances in these types of synthetic methods are described in this section of this review.

In 2013, Shibata's group [198] developed an electrophilic trifluoromethansulfonyl hypervalent iodonium ylide for the trifluoromethylthiolation of enamines, indoles and $\beta$-ketoesters cata- lyzed by copper(I) chloride (Scheme 116). The desired $\mathrm{CF}_{3} \mathrm{~S}$ substituted products were formed with good yields in short times at room temperature.

In 2014, Gade et al. [199] applied a copper-boxmi complex as highly enantioselective catalyst to effect electrophilic trifluoromethylthiolations (Scheme 117). A number of $\alpha-\mathrm{SCF}_{3}$-substituted $\beta$-ketoesters were obtained in good yields with high enantiomeric excess (ee) under mild conditions.

The group of Rueping [200] employed $N$-(trifluoromethylthio)phthalimide as an electrophilic source of $\mathrm{F}_{3} \mathrm{CS}^{+}$for the direct trifluoromethylthiolation of boronic acids and alkynes under copper catalysis in 2014 (Scheme 118). Based on the mild conditions, this approach features high functional group tolerance and a broad substrate scope.

In the same year, a powerful protocol for the direct synthesis of $\alpha$-trifluoromethylthio-substituted ketones was reported by Weng and co-workers [201]. Notably, the trifluoromethylthiola-

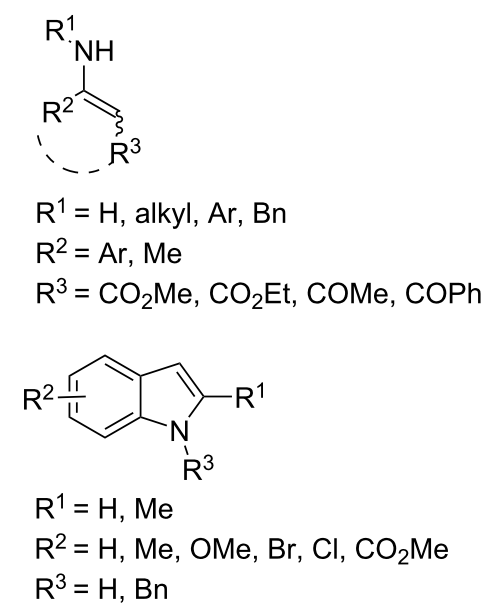<smiles>CC(C)=C(C(=O)OC(C)C)C(=O)c1ccccc1</smiles>

$\mathrm{CuCl}(20 \mathrm{~mol} \%)$ or $\mathrm{CuCl} / \mathrm{PhNMe}_{2}(20 \mathrm{~mol} \%)$

dioxane, rt, 5-15 $\mathrm{min}$
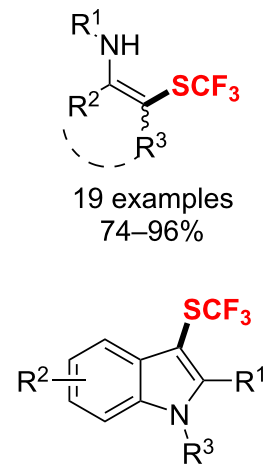

9 examples $32-84 \%$

Scheme 116: Copper(I) chloride-catalyzed trifluoromethylthiolation of enamines, indoles and $\beta$-ketoesters.<smiles>[R][R]C1Cc2cc[R1]([H])cc2C1=O</smiles>

$\mathrm{R}^{1}=\mathrm{OMe}, \mathrm{Me}, \mathrm{H}, \mathrm{Cl}, \mathrm{Br}, \mathrm{F}$ $\mathrm{R}^{2}=\mathrm{Me}, t-\mathrm{Bu}$<smiles>CC1(C)OI(c2ccccc2)c2ccccc21</smiles>

2.0 equiv

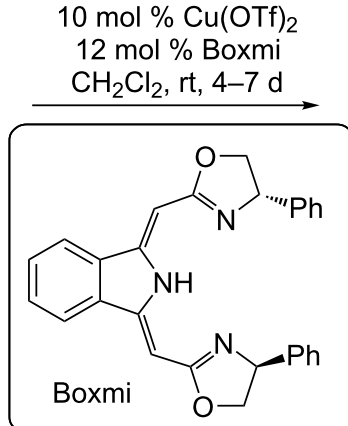

22 examples

$81-93 \%$

up to $>99 \%$ ee 


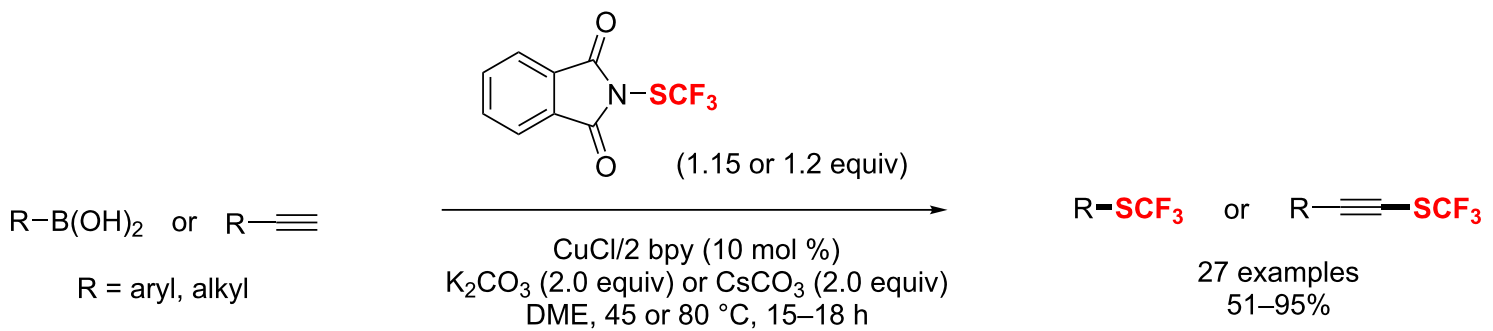

Scheme 118: Direct Cu-catalyzed trifluoromethylthiolation of boronic acids and alkynes.

tion reactions of primary and secondary $\alpha$-bromoketones worked well with $\mathrm{CF}_{3} \mathrm{SiMe}_{3}$ and elemental sulfur as precursors (Scheme 119). Furthermore, this strategy shows a broad substrate scope and tolerates a variety of functional groups.

In 2016, a variety of enamines, indoles, $\beta$-keto esters, pyrroles, and anilines were trifluoromethylthiolated efficiently by Shibata's group [202] in the presence of diazotriflone and copper catalysis through an electrophilic-type reaction (Scheme 120).

In 2016, Glorius et al. [203] introduced the synthesis of vinyl$\mathrm{SCF}_{3}$ compounds using $N$-(trifluoromethylthio)phthalimide as $\mathrm{SCF}_{3}$ source under blue LEDs irradiation. Notably, a variety of alkenes could be converted to vinyl- $\mathrm{SCF}_{3}$ compounds with the cooperation of an $[\mathrm{Ir}]$ photocatalyst and an ammonium bromide

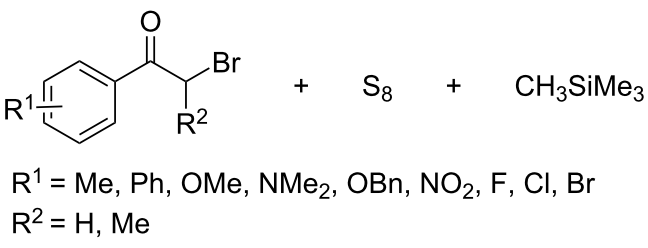

$\mathrm{Cu}(\mathrm{OTf})_{2}(20-30 \mathrm{~mol} \%)$

1,10-phenanthroline $(20-30 \mathrm{~mol} \%)$

$\mathrm{KF}(20-30 \mathrm{~mol} \%)$

$\mathrm{CH}_{2} \mathrm{Cl}_{2}, 40^{\circ} \mathrm{C}, 16 \mathrm{~h}$<smiles>[R]C(SC(F)(F)F)C(=O)c1cc[R1]([H])cc1</smiles>

20 examples up to $88 \%$ yield

Scheme 119: Cu-catalyzed synthesis of $\alpha$-trifluoromethylthio-substituted ketones.<smiles>[R][R]([R])=CC([R])=O</smiles>

$\mathrm{R}^{1}=\mathrm{Bn}, \mathrm{Ph}, p-\mathrm{Tol}$

$\mathrm{R}^{2}=\mathrm{Me}, \mathrm{Ph}, 4-\mathrm{BrC}_{6} \mathrm{H}_{4}, 3-\mathrm{MeC}_{6} \mathrm{H}_{4}$

$\mathrm{R}^{3}=\mathrm{Ph}, \mathrm{OMe}, \mathrm{OEt}$

$\mathrm{NuH}$

indoles, $\beta$-keto ester, pyrrole, aniline

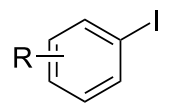

$\mathrm{R}=\mathrm{Me}, \mathrm{Ph}, \mathrm{COMe}, \mathrm{CO}_{2} \mathrm{Me}, \mathrm{OMe}, \mathrm{NO}_{2}$
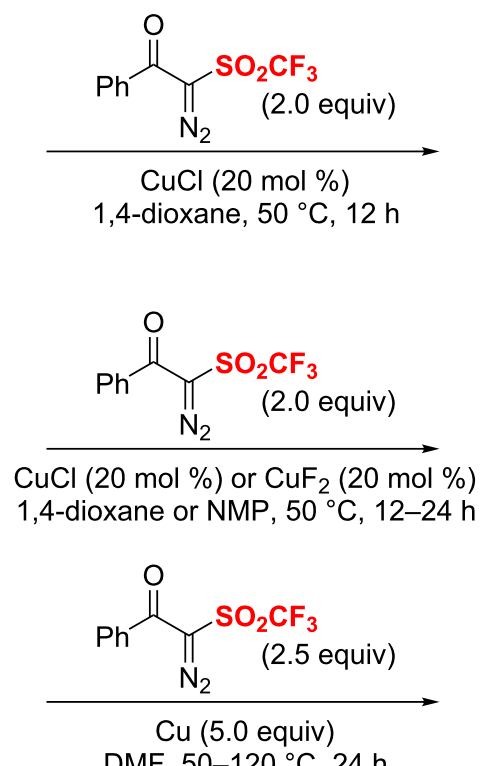

DMF, $50-120^{\circ} \mathrm{C}, 24 \mathrm{~h}$

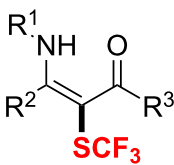

8 examples $46-82 \%$

$\mathrm{Nu}-\mathrm{SCF}_{3}$

6 examples

$55-83 \%$

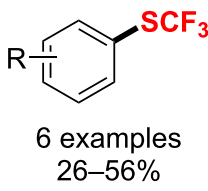


salt (Scheme 121). The formed adduct could be triggered via an oxidative quenching cycle and delivered a $\mathrm{SCF}_{3}$ radical. Under similar conditions, they also demonstrated a tandem photoinduced trifluoromethylthiolation/semi-pinacol-type rearrangement of ketones.

Meanwhile, the same group [204] developed a visible-lightmediated trifluoromethylthiolation of alkyl carboxylic acids with [Ir] and phtalimide- $\mathrm{SCF}_{3}$ as the trifluoromethylthiolating reagent (Scheme 122a). Moreover, tertiary, secondary, and primary alkyl carboxylic acids afforded the desired products in good to excellent yields. Notably, the use of an external sacrificial hydrogen atom donor, mesitylene or methyl (3-methyl)benzoate, avoided the bistrifluoromethylthiolation reaction in this process. Subsequently, the group [205] demonstrated that the Phth- $\mathrm{SCF}_{3}$ reagent could also be used for the direct trifluoromethylthiolation of $\mathrm{C}-\mathrm{H}$ bonds under similar mild conditions (Scheme 122b). Also, a wide range of aliphatic substrates were converted to their trifluoromethylthiolated analogues in very good yields.

Additionally, the group of Goossen [206] disclosed a simple and practical strategy for the conversion of $\alpha$-diazo esters to the corresponding trifluoromethylthiolated esters with a $\mathrm{Me}_{4} \mathrm{NSCF}_{3}$ salt. In the presence of copper thiocyanate, this transformation afforded the products with up to $98 \%$ yields at room temperature and was applied to a wide range of easily available $\alpha$-diazo esters (Scheme 123).

Recently, the formation of arenes- $\mathrm{SCF}_{3}$ was shown by the Jacobi von Wangelin group [207], the Zhao group [208] as well as the Tlili group [193] (Scheme 124). All three methodologies

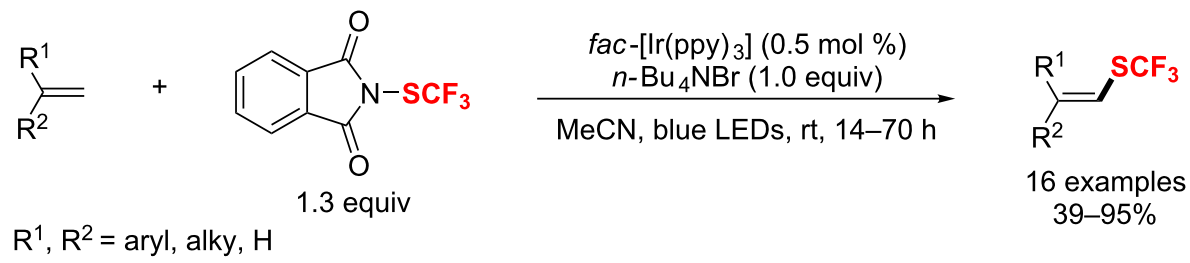

Scheme 121: Halide activation of $N$-(trifluoromethylthio)phthalimide.

a)<smiles></smiles>

$\mathrm{R}=$ alkyl, aryl, alkenyl, heteroaryl
$\mathrm{PCl}(2-3 \mathrm{~mol} \%)$ or $\mathrm{PCll}(5 \mathrm{~mol} \%)$ $\mathrm{CsOBz}$ ( 0.2 equiv), $\mathrm{A}$ or $\mathrm{B}$ (2.0 equiv)

$\mathrm{C}_{6} \mathrm{H}_{5} \mathrm{~F}$, blue LEDs, rt, $4 \mathrm{~h}$

$\mathrm{R}-\mathrm{SCF}_{3}$

18 examples

$49-94 \%$

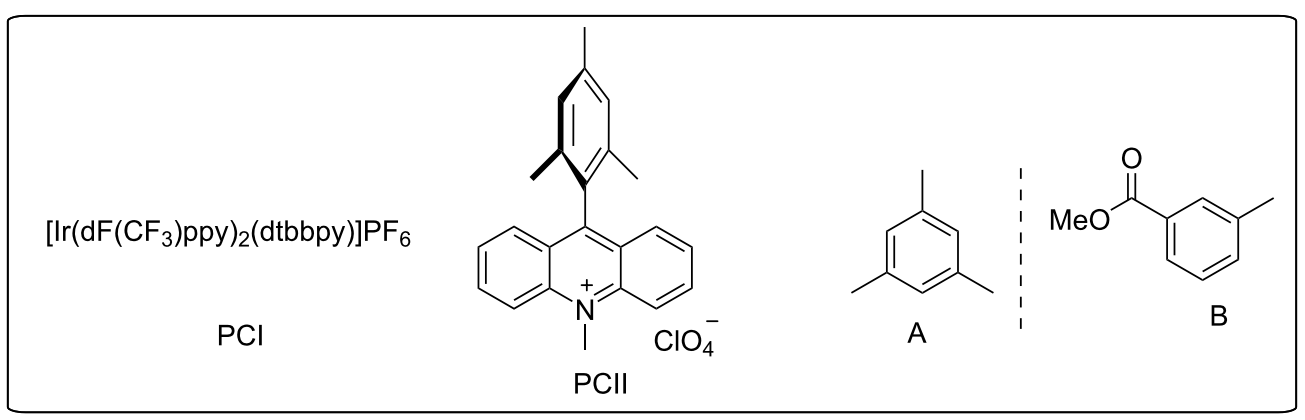

b)<smiles>[R][R]OC(F)(F)[Si]N1C(=O)c2ccccc2C1=O</smiles>

$\left[\operatorname{Ir}\left(\mathrm{dF}\left(\mathrm{CF}_{3}\right) \mathrm{ppy}\right)_{2}(\mathrm{dtbbpy})\right] \mathrm{PF}_{6}(1 \mathrm{~mol} \%)$

$5 \mathrm{~W}$ blue LEDs $\left(\lambda_{(\max )}=455 \mathrm{~nm}\right)$ $\mathrm{MeCN}, \mathrm{rt}$ 


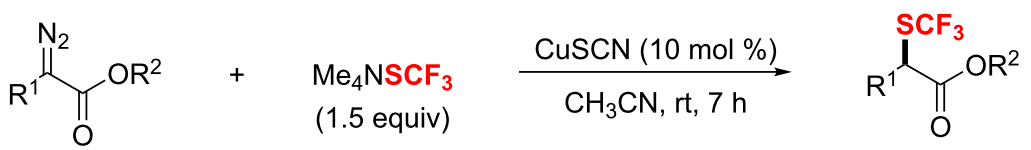

$$
\begin{aligned}
& \mathrm{R}^{1}=\mathrm{H}, \mathrm{Me}, \mathrm{CH}_{2} \mathrm{Ph}, \mathrm{Bu}, \mathrm{HO}-\mathrm{CH}_{2}, \mathrm{HO}-\mathrm{Ph}, \mathrm{OMe}-\mathrm{Ph}, \quad 27 \text { examples } \\
& \mathrm{SMe}-\mathrm{Ph}, \mathrm{CN}-\mathrm{Ph} \text {, Hal-Ph, } \mathrm{Py}, \mathrm{Ph}-\mathrm{CH}=\mathrm{CH}_{2} \\
& \mathrm{R}^{2}=\mathrm{Me}, \mathrm{Et}, \mathrm{Bn}, 4-\mathrm{Me}-\mathrm{Ph}, 4-\mathrm{Ph}-\mathrm{Ph}, 4-\mathrm{NO}_{2}-\mathrm{Ph}, 4-\mathrm{NO}_{2}-\mathrm{Ph}, \mathrm{Hal}-\mathrm{Ph}, \mathrm{Py}
\end{aligned}
$$

Scheme 123: Synthesis of $\alpha$-trifluoromethylthioesters via Goossen's approach.

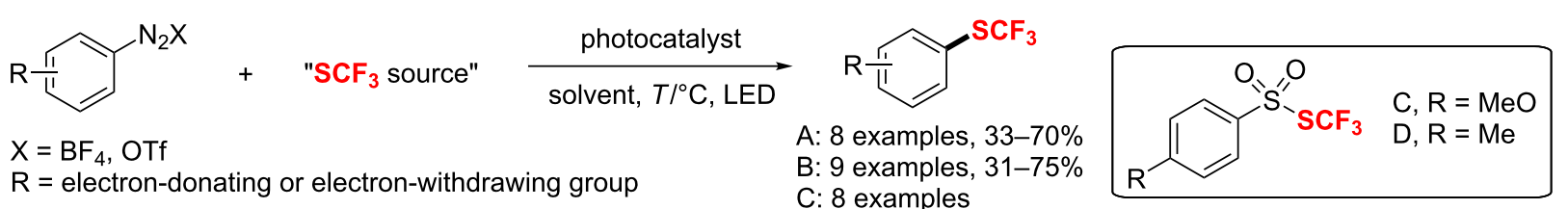

Jacobi von Wangelin, $\mathbf{A}$ : $\left[\mathrm{Ru}(\mathrm{bpy})_{3}\right] \mathrm{Cl}_{2}(0.5 \mathrm{~mol} \%), \mathrm{F}_{3} \mathrm{CSSCF}_{3}\left(1.0\right.$ equiv), LED $(450 \mathrm{~nm}), \mathrm{DMSO}, 2{ }^{\circ} \mathrm{C}, 1 \mathrm{~h}$

Zhao, B: $\left[\mathrm{Ru}(\mathrm{bpy})_{3}\right] \mathrm{Cl}_{2}(0.5 \mathrm{~mol} \%), \mathrm{C}(1.4$ equiv), white LEDs, DMSO, $\mathrm{rt}, 1 \mathrm{~h}$

Tlili, C: [Ru(phen) $)_{3} \mathrm{Cl}_{2}(5 \mathrm{~mol} \%), \mathrm{D}(3.0$ equiv), white LEDs, DMSO, rt, $16 \mathrm{~h}$

Scheme 124: Photoinduced trifluoromethylthiolation of diazonium salts.

have been developed based on a [Ru]-based photocatalyst under LED irradiation. The group of Jacobi von Wangelin used the bis(trifluoromethyl) disulfide $\left(\mathrm{CF}_{3} \mathrm{SSCF}_{3}\right)$ as the source of trifluoromethyl sulfide, while the other two groups employed shelf-stable reagents $\mathbf{C}$ and $\mathbf{D}$ for trifluoromethylthiolation, arenesulfonate- $\mathrm{SCF}_{3}$.

\section{Trifluoromethoxylation}

The introduction of a trifluoromethoxy $\left(\mathrm{OCF}_{3}\right)$ group into a molecule can improve its metabolic stability and membrane permeability. Some strategies for the synthesis of trifluoromethoxylated compounds have been reviewed: Poisson [209] and Billard [210] discussed the recent advances toward the synthesis of $\mathrm{OCF}_{3}$-containing molecules; Hopkinson [211] depicted a radical revolution for trifluoromethoxylation; recently, Ngai [212] summarized some photoredox-based approaches to form tri- and difluoromethoxylated compounds. Despite the great interest in this functional group, only a few transition-metal-catalyzed methods have been developed for the synthesis of trifluoromethoxylated compounds over the past decade. This may be due to the fact that $\mathrm{C}-\mathrm{OCF}_{3}$ bond formation reactions have many limitations, including reversible decomposition of the trifluoromethoxide anion in solution above room temperature to afford carbonic difluoride and fluoride [213,214], as well as $\beta$-fluoride elimination from transitionmetal-trifluoromethoxide complexes [215,216].

In 2011, the first report of a transition-metal-mediated $\mathrm{C}_{\text {aryl }}-\mathrm{OCF}_{3}$ bond formation was described by the Ritter group (Scheme 125) [217]. Aryl trifluoromethyl ethers could be

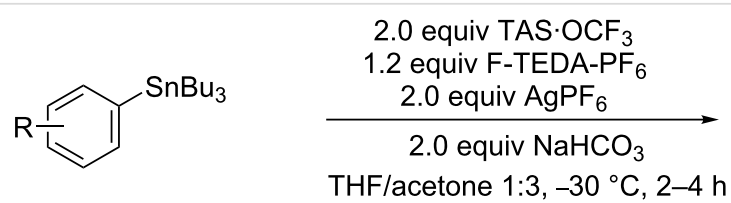

$\mathrm{R}=$ alkyl, aryl, ester, ether

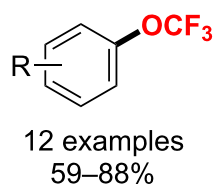

$59-88 \%$

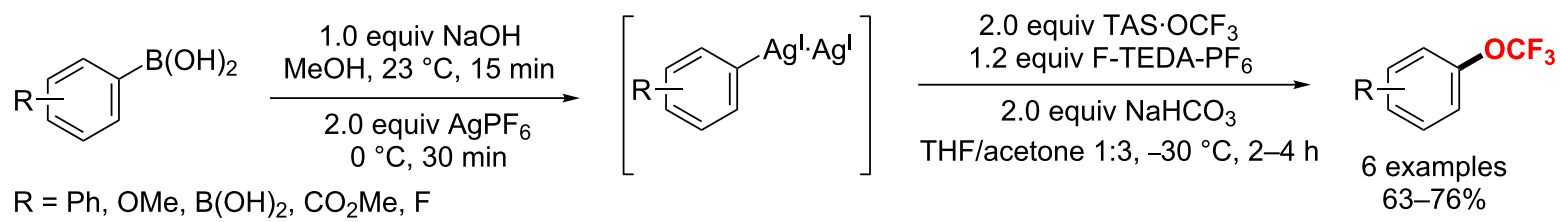

Scheme 125: Ag-mediated trifluoromethoxylation of aryl stannanes and arylboronic acids. 
accessed through a silver-mediated cross-coupling of trifluoromethoxide with arylstannanes and arylboronic acids.

In 2018, Ngai and co-workers [218] reported a direct C-H trifluoromethoxylation of (hetero)arenes under visible light irradiation. This approach proceeded at room temperature by employing the redoxactive catalyst $\mathrm{Ru}(\mathrm{bpy})_{3}\left(\mathrm{PF}_{6}\right)_{2}$ (Scheme 126). Mechanism studies suggest a SET from the excited photoredox catalyst to 1 resulting in exclusive liberation of the $\mathrm{OCF}_{3}$ radical. The reaction of the trifluoromethoxyl radical with (hetero)arenes provides trifluoromethoxylated cyclohexadienyl radicals that undergo oxidation and deprotonation to generate the desired products.

Recently, Ngai's group [219] as well as the Togni group [220] independently developed cationic $\mathrm{N}-\mathrm{OCF}_{3}$ reagents. Both reagents are reducible with an excited ruthenium-based photocatalyst. Herein, Togni synthesized a series of $\mathrm{N}$-trifluoromethoxypyridinium reagents (Scheme 127a), while Ngai prepared a series of $1-\mathrm{CF}_{3} \mathrm{O}$-benzotriazole reagents
(Scheme 127b). These reagents exhibit the best results for the direct C-H trifluoromethoxylation of (hetero)arenes. Notably, both groups used the same photocatalyst $\left(\left[\mathrm{Ru}(\mathrm{bpy})_{3}\right]\left(\mathrm{PF}_{6}\right)_{2}\right)$ under blue LED irradiation. Of note, the cationic $\mathrm{N}-\mathrm{OCF}_{3}$ reagents presented an impressive substrate scope tolerance including halides ( $\mathrm{I}, \mathrm{Br}, \mathrm{Cl}$ and $\mathrm{F}$ ), nitriles, ketones, amides, acids and phosphonates.

\section{Conclusion}

The development of methods for the transition-metal-catalyzed incorporation of fluorine-containing groups into target molecules is an active area of chemical research. In this review, we summarized the major advances in the field of transition-metalcatalyzed fluorination and fluoroalkylation reactions over the past few years. A variety of methods shows significant advantages in view of atom-economy, reaction diversity, selectivity and functional-group compatibility. The suitable catalytic systems and the newly developed reagents play a critical role in these reactions. Further, different directing groups also contribute greatly to the success of these reactions. Notably, copper<smiles>[R]C1CCC(C)CC1</smiles>

$\mathrm{R}=$ alkyl, aryl, halogen, $\mathrm{CO}_{2} \mathrm{H}, \mathrm{CO}_{2} \mathrm{Me}, \mathrm{OCOPh}, \mathrm{SO}_{2} \mathrm{Ph}, \mathrm{OMe}, \mathrm{CN}, \mathrm{CHO}, \mathrm{CO}_{2} \mathrm{Et}$

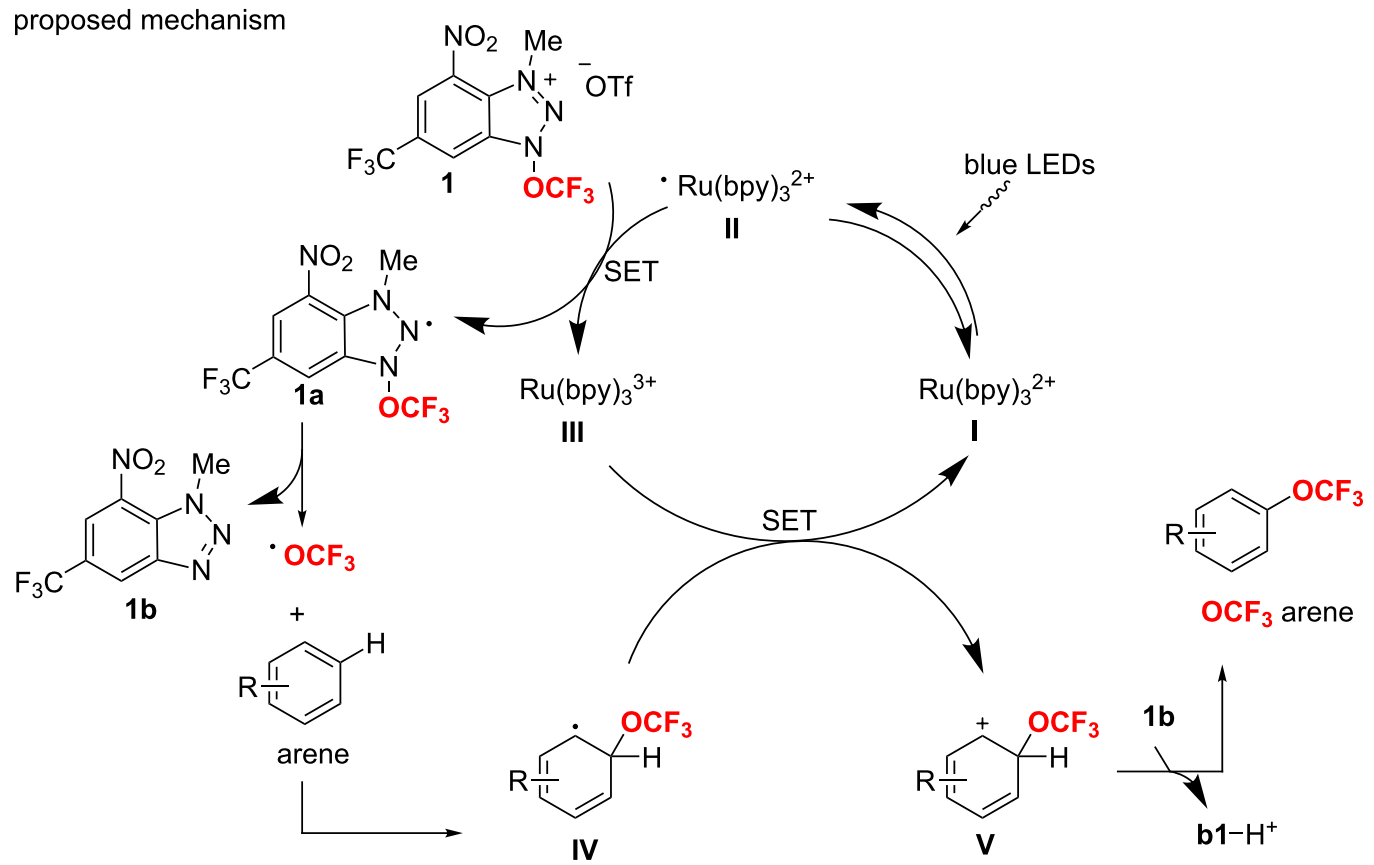


a)<smiles>[R]1ccccc1</smiles>

(5.0 equiv)

$$
\frac{\mathrm{Ru}(\mathrm{bpy})_{3}\left(\mathrm{PF}_{6}\right)_{2}(5 \mathrm{~mol} \%)}{\mathrm{E}(1.0 \text { equiv })}
$$

$\mathrm{R}=\mathrm{H}$, halogen, alkyl, ester, nitriles, ketones, amides, acids, phosphonates

b)

$$
\mathrm{R} \frac{\widehat{A r l}}{\mathrm{Het}}
$$

(hetero)arene (1-10.0 equiv)

$$
\begin{gathered}
\mathrm{Ru}(\mathrm{bpy})_{3}\left(\mathrm{PF}_{6}\right)_{2}(1 \mathrm{~mol} \%) \\
\mathrm{F}(1.0 \text { equiv })
\end{gathered}
$$

$10 \mathrm{~W}$ blue LED $(402 \mathrm{~nm})$

MeCN/DCM 1:1(0.2 M), $16 \mathrm{~h}$

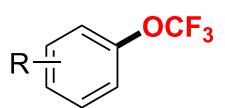

40 examples, $21-66 \%$
$\mathrm{R}=\mathrm{H}$, halogen, alkyl, ester, nitriles, ketones, amides, acids, phosphonates

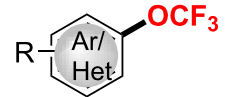

24 examples, $20-75 \%$

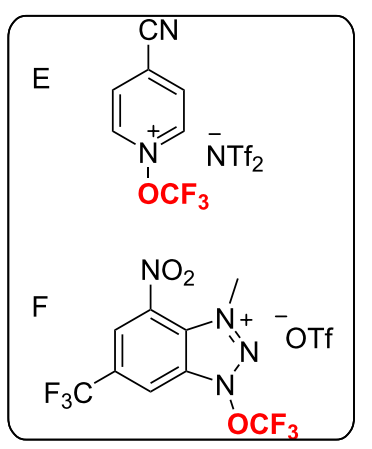

Scheme 127: Photoinduced C-H-bond trifluromethoxylation of (hetero)arenes.

shows a wider range of applications involving the catalysis of fluorination/fluoroalkylation reactions of various alkyl-, aryland vinyl- as well as alkynyl substrates, while palladium-catalyzed reactions in combination with suitable ligands show improved selectivity in some reactions. Also, because of milder and cleaner reaction conditions, photocatalysts have received extensive attention and have greatly applied recently. Despite diverse methods for the transition-metal-catalyzed fluorination/ fluoroalkylation have been reported, chemists still face many challenges that need to be overcome. More economical, green, selective, general and practical strategies remain sought after. A suitable catalytic system and an effective fluorination reagent are two important aspects for achieving this goal. Overall, we hope that this review will provide further insight into this field and inspire chemists to develop new fluorination/fluoroalkylation reactions. Meanwhile, we believe that the methodologies mentioned in this review will contribute to future advances in the late-stage functionalization of molecules.

\section{Acknowledgements}

This work was supported by the Funded by Key research and development project of Shandong province (2018GSF118200), National Program for Support of Top-notch Young Professionals, Fund of Taishan scholar project, Shandong Provincial Natural Science Foundation for Distinguished Young Scholars (JQ201722), NSFC-Shandong Joint Fund (U1706213), Qingdao Marine Biomedical Science and Technology Innovation Center project (2017-CXZX01-1-1, 2017-CXZX01-3-9)

\section{References}

1. Yang, X.; Wu, T.; Phipps, R. J.; Toste, F. D. Chem. Rev. 2015, 115, 826-870. doi:10.1021/cr500277b
2. Purser, S.; Moore, P. R.; Swallow, S.; Gouverneur, V. Chem. Soc. Rev. 2008, 37, 320-330. doi:10.1039/b610213c

3. Muller, K.; Faeh, C.; Diederich, F. Science 2007, 317, 1881-1886. doi:10.1126/science. 1131943

4. Jeschke, P. ChemBioChem 2004, 5, 570-589. doi:10.1002/cbic.200300833

5. Hung, M. H.; Farnham, W. B.; Feiring, A. E.; Rozen, S. Functional Fluoromonomers and Fluoropolymers. In Fluoropolymers 1: Synthesis; Hougham, G.; Cassidy, P. E.; Johns, K.; Davidson, T., Eds.; Topics in Applied Chemistry; Kluwer Academic Publishers: Boston, AMA, U.S.A., 1999; pp 51-66. doi:10.1007/0-306-46918-9_4

6. Ametamey, S. M.; Honer, M.; Schubiger, P. A. Chem. Rev. 2008, 108, 1501-1516. doi:10.1021/cr0782426

7. Wang, J.; Sánchez-Roselló, M.; Aceña, J. L.; del Pozo, C.; Sorochinsky, A. E.; Fustero, S.; Soloshonok, V. A.; Liu, H. Chem. Rev. 2014, 114, 2432-2506. doi:10.1021/cr4002879

8. Gribble, G. W. In Progress in the Chemistry of Organic Natural Products; Kinghord, A. D.; Falk, H.; Kobayashi, J., Eds.; Springer: Berlin, Germany, 2009; pp 1-613.

9. Gribble, G. W. In Progress in the Chemistry of Organic Natural Products; Herz, W.; Kirby, G. W.; Moore, R. E.; Steglich, W.; Tamm, C., Eds.; Progress in the Chemistry of Organic Natural Products, Vol. 68; Springer Vienna: Vienna, Austria, 1996. doi:10.1007/978-3-7091-6887-5

10. Podder, G.; Moitra, S. K.; Chakravarti, N. N. Bull. Calcutta Sch. Trop. Med. 1973, 21, 8-9.

11. Schubert, W. M.; Sweeney, W. A.; Latourette, H. K. J. Am. Chem. Soc. 1954, 76, 5462-5466. doi:10.1021/ja01650a060

12. Hodgson, H. H. Chem. Rev. 1947, 40, 251-277. doi:10.1021/cr60126a003

13. Snieckus, V. Chem. Rev. 1990, 90, 879-933. doi:10.1021/cr00104a001

14. Song, H.-X.; Han, Q.-Y.; Zhao, C.-L.; Zhang, C.-P. Green Chem. 2018, 20, 1662-1731. doi:10.1039/c8gc00078f

15. Miura, M.; Feng, C.-G.; Ma, S.; Yu, J.-Q. Org. Lett. 2013, 15, 5258-5261. doi:10.1021/ol402471y

16. Liu, H.; Gu, Z.; Jiang, X. Adv. Synth. Catal. 2013, 355, 617-626. doi:10.1002/adsc.201200764 
17. Furuya, T.; Kamlet, A. S.; Ritter, T. Nature 2011, 473, 470-477. doi:10.1038/nature10108

18. Jazzar, R.; Hitce, J.; Renaudat, A.; Sofack-Kreutzer, J.; Baudoin, O. Chem. - Eur. J. 2010, 16, 2654-2672. doi:10.1002/chem.200902374

19. Trost, B. Science 1991, 254, 1471-1477. doi:10.1126/science. 1962206

20. Petrone, D. A.; Ye, J.; Lautens, M. Chem. Rev. 2016, 116, 8003-8104. doi:10.1021/acs.chemrev.6b00089

21. Besset, T.; Poisson, T.; Pannecoucke, X. Chem. - Eur. J. 2014, 20 , 16830-16845. doi:10.1002/chem.201404537

22. Champagne, P. A.; Desroches, J.; Hamel, J.-D.; Vandamme, M.; Paquin, J.-F. Chem. Rev. 2015, 115, 9073-9174. doi:10.1021/cr500706a

23. Sather, A. C.; Buchwald, S. L. Acc. Chem. Res. 2016, 49, 2146-2157 doi:10.1021/acs.accounts.6b00247

24. Lin, X.; Weng, Z. Dalton Trans. 2015, 44, 2021-2037. doi:10.1039/c4dt03410d

25. Szpera, R.; Moseley, D. F. J.; Smith, L. B.; Sterling, A. J.; Gouverneur, V. Angew. Chem., Int. Ed. 2019. doi:10.1002/anie.201814457

26. Marzo, L.; Pagire, S. K.; Reiser, O.; König, B. Angew. Chem., Int. Ed. 2018, 57, 10034-10072. doi:10.1002/anie.201709766

27. Ishida, S.; Sheppard, T.; Nishikata, T. Tetrahedron Lett. 2018, 59, 789-798. doi:10.1016/j.tetlet.2018.01.044

28. Evano, G.; Nitelet, A.; Thilmany, P.; Dewez, D. F. Front. Chem. (Lausanne, Switz.) 2018, 6, 114. doi:10.3389/fchem.2018.00114

29. Chen, C.; Fu, L.; Chen, P.; Liu, G. Chin. J. Chem. 2017, 35, 1781-1788. doi:10.1002/cjoc.201700489

30. Cresswell, A. J.; Davies, S. G.; Roberts, P. M.; Thomson, J. E. Chem. Rev. 2015, 115, 566-611. doi:10.1021/cr5001805

31. Campbell, M. G.; Ritter, T. Chem. Rev. 2015, 115, 612-633. doi:10.1021/cr500366b

32. Li, Y.; Wu, Y.; Li, G.-S.; Wang, X.-S. Adv. Synth. Catal. 2014, 356, 1412-1418. doi:10.1002/adsc.201400101

33. Brooks, A. F.; Topczewski, J. J.; Ichiishi, N.; Sanford, M. S.; Scott, P. J. H. Chem. Sci. 2014, 5, 4545-4553. doi:10.1039/c4sc02099e

34. Liu, J.; Zheng, L. Adv. Synth. Catal. 2019, 361, 1710-1732. doi:10.1002/adsc.201801307

35. Katcher, M. H.; Doyle, A. G. J. Am. Chem. Soc. 2010, 132, 17402-17404. doi:10.1021/ja109120n

36. Katcher, M. H.; Sha, A.; Doyle, A. G. J. Am. Chem. Soc. 2011, 133, 15902-15905. doi:10.1021/ja206960k

37. Hollingworth, C.; Hazari, A.; Hopkinson, M. N.; Tredwell, M.; Benedetto, E.; Huiban, M.; Gee, A. D.; Brown, J. M.; Gouverneur, V. Angew. Chem., Int. Ed. 2011, 50, 2613-2617. doi:10.1002/anie.201007307

38. Lauer, A. M.; Wu, J. Org. Lett. 2012, 14, 5138-5141. doi:10.1021/ol302263m

39. Braun, M.-G.; Doyle, A. G. J. Am. Chem. Soc. 2013, 135, 12990-12993. doi:10.1021/ja407223g

40. Suzuki, S.; Kitamura, Y.; Lectard, S.; Hamashima, Y.; Sodeoka, M. Angew. Chem., Int. Ed. 2012, 51, 4581-4585. doi:10.1002/anie.201201303

41. Zhang, R.; Wang, D.; Xu, Q.; Jiang, J.; Shi, M. Chin. J. Chem. 2012, 30, 1295-1304. doi:10.1002/cjoc.201200289

42. Wang, F.; Li, J.; Hu, Q.; Yang, X.; Wu, X.-Y.; He, H. Eur. J. Org. Chem. 2014, 3607-3613. doi:10.1002/ejoc.201402072
43. McMurtrey, K. B.; Racowski, J. M.; Sanford, M. S. Org. Lett. 2012, 14, 4094-4097. doi:10.1021/ol301739f

44. Lee, S. J.; Brooks, A. F.; Ichiishi, N.; Makaravage, K. J.; Mossine, A. V.; Sanford, M. S.; Scott, P. J. H. Chem. Commun. 2019, 55, 2976-2979. doi:10.1039/c9cc00641a

45. Jacquet, O.; Clément, N. D.; Blanco, C.; Belmonte, M. M.; Benet-Buchholz, J.; van Leeuwen, P. W. N. M. Eur. J. Org. Chem. 2012, 4844-4852. doi:10.1002/ejoc.201200223

46. Woo, S. B.; Suh, C. W.; Koh, K. O.; Kim, D. Y. Tetrahedron Lett. 2013, 54, 3359-3362. doi:10.1016/j.tetlet.2013.04.054

47. Zhang, Q.; Yin, X.-S.; Chen, K.; Zhang, S.-Q.; Shi, B.-F. J. Am. Chem. Soc. 2015, 137, 8219-8226. doi:10.1021/jacs.5b03989

48. Miao, J.; Yang, K.; Kurek, M.; Ge, H. Org. Lett. 2015, 17, 3738-3741. doi:10.1021/acs.orglett.5b01710

49. Zhu, Q.; Ji, D.; Liang, T.; Wang, X.; Xu, Y. Org. Lett. 2015, 17, 3798-3801. doi:10.1021/acs.orglett.5b01774

50. Park, H.; Verma, P.; Hong, K.; Yu, J.-Q. Nat. Chem. 2018, 10 , 755-762. doi:10.1038/s41557-018-0048-1

51. Wannberg, J.; Wallinder, C.; Ünlüsoy, M.; Sköld, C.; Larhed, M. J. Org. Chem. 2013, 78, 4184-4189. doi:10.1021/jo400255m

52. Mazzotti, A. R.; Campbell, M. G.; Tang, P.; Murphy, J. M.; Ritter, T. J. Am. Chem. Soc. 2013, 135, 14012-14015. doi:10.1021/ja405919z

53. Lee, H. G.; Milner, P. J.; Buchwald, S. L. Org. Lett. 2013, 15, 5602-5605. doi:10.1021/ol402859k

54. Lee, H. G.; Milner, P. J.; Buchwald, S. L. J. Am. Chem. Soc. 2014, 136, 3792-3795. doi:10.1021/ja5009739

55. Sather, A. C.; Lee, H. G.; De La Rosa, V. Y.; Yang, Y.; Müller, P.; Buchwald, S. L. J. Am. Chem. Soc. 2015, 137, 13433-13438. doi:10.1021/jacs.5b09308

56. Yamamoto, K.; Li, J.; Garber, J. A. O.; Rolfes, J. D.; Boursalian, G. B.; Borghs, J. C.; Genicot, C.; Jacq, J.; van Gastel, M.; Neese, F.; Ritter, T. Nature 2018, 554, 511-514. doi:10.1038/nature25749

57. Chan, K. S. L.; Wasa, M.; Wang, X.; Yu, J.-Q. Angew. Chem., Int. Ed. 2011, 50, 9081-9084. doi:10.1002/anie.201102985

58. Ding, Q.; Ye, C.; Pu, S.; Cao, B. Tetrahedron 2014, 70, 409-416. doi:10.1016/j.tet.2013.11.034

59. Lou, S.-J.; Xu, D.-Q.; Xu, Z.-Y. Angew. Chem., Int. Ed. 2014, 53, 10330-10335. doi:10.1002/anie.201404423

60. Chen, C.; Wang, C.; Zhang, J.; Zhao, Y. J. Org. Chem. 2015, 80, 942-949. doi:10.1021/jo502365b

61. Chen, X.-Y.; Sorensen, E. J. J. Am. Chem. Soc. 2018, 140, 2789-2792. doi:10.1021/jacs.8b00048

62. Ning, X.-Q.; Lou, S.-J.; Mao, Y.-J.; Xu, Z.-Y.; Xu, D.-Q. Org. Lett. 2018, 20, 2445-2448. doi:10.1021/acs.orglett.8b00793

63. Mao, Y.-J.; Lou, S.-J.; Hao, H.-Y.; Xu, D.-Q. Angew. Chem., Int. Ed. 2018, 57, 14085-14089. doi:10.1002/anie.201808021

64. Lee, J. B.; Kang, M. E.; Kim, J.; Lee, C. Y.; Kee, J.-M.; Myung, K.; Park, J.-U.; Hong, S. Y. Chem. Commun. 2017, 53, 10394-10397. doi:10.1039/c7cc05794f

65. Gutierrez, D. A.; Lee, W.-C. C.; Shen, Y.; Li, J. J. Tetrahedron Lett. 2016, 57, 5372-5376. doi:10.1016/j.tetlet.2016.10.079

66. Lou, S.-J.; Xu, D.-Q.; Xia, A.-B.; Wang, Y.-F.; Liu, Y.-K.; Du, X.-H.; Xu, Z.-Y. Chem. Commun. 2013, 49, 6218-6220. doi:10.1039/c3cc42220h

67. Bloom, S.; Pitts, C. R.; Miller, D. C.; Haselton, N.; Holl, M. G.; Urheim, E.; Lectka, T. Angew. Chem., Int. Ed. 2012, 51, 10580-10583. doi:10.1002/anie.201203642

68. Liu, Y.; Chen, C.; Li, H.; Huang, K.-W.; Tan, J.; Weng, Z. Organometallics 2013, 32, 6587-6592. doi:10.1021/om4008967 
69. Dang, H.; Mailig, M.; Lalic, G. Angew. Chem., Int. Ed. 2014, 53, 6473-6476. doi:10.1002/anie.201402238

70. Zhang, Z.; Wang, F.; Mu, X.; Chen, P.; Liu, G. Angew. Chem., Int. Ed. 2013, 52, 7549-7553. doi:10.1002/anie.201301891

71. Shibatomi, K.; Narayama, A.; Soga, Y.; Muto, T.; Iwasa, S. Org. Lett. 2011, 13, 2944-2947. doi:10.1021/ol201007e

72. Shibatomi, K.; Narayama, A.; Soga, Y.; Muto, T.; Iwasa, S. Synlett 2013, 24, 375-378. doi:10.1055/s-0032-1318027

73. Balaraman, K.; Vasanthan, R.; Kesavan, V. Tetrahedron: Asymmetry 2013, 24, 919-924. doi:10.1016/j.tetasy.2013.07.004

74. Peng, J.; Du, D.-M. RSC Adv. 2014, 4, 2061-2067. doi:10.1039/c3ra45438

75. Gu, X.; Zhang, Y.; Xu, Z.-J.; Che, C.-M. Chem. Commun. 2014, 50, 7870-7873. doi:10.1039/c4cc01631a

76. Nishikata, T.; Ishida, S.; Fujimoto, R. Angew. Chem., Int. Ed. 2016, 55, 10008-10012. doi:10.1002/anie.201603426

77. Ye, Y.; Schimler, S. D.; Hanley, P. S.; Sanford, M. S. J. Am. Chem. Soc. 2013, 135, 16292-16295. doi:10.1021/ja408607r

78. Truong, T.; Klimovica, K.; Daugulis, O. J. Am. Chem. Soc. 2013, 135, 9342-9345. doi:10.1021/ja4047125

79. Ichiishi, N.; Canty, A. J.; Yates, B. F.; Sanford, M. S. Org. Lett. 2013, 15, 5134-5137. doi:10.1021/ol4025716

80. Mu, X.; Zhang, H.; Chen, P.; Liu, G. Chem. Sci. 2014, 5, 275-280. doi:10.1039/c3sc51876k

81. Yin, F.; Wang, Z.; Li, Z.; Li, C. J. Am. Chem. Soc. 2012, 134, 10401-10404. doi:10.1021/ja3048255

82. Liu, W.; Huang, X.; Cheng, M.-J.; Nielsen, R. J.; Goddard, W. A.; Groves, J. T. Science 2012, 337, 1322-1325. doi:10.1126/science. 1222327

83. Liu, W.; Groves, J. T. Angew. Chem., Int. Ed. 2013, 52, 6024-6027. doi:10.1002/anie.201301097

84. Huang, X.; Liu, W.; Ren, H.; Neelamegam, R.; Hooker, J. M.; Groves, J. T. J. Am. Chem. Soc. 2014, 136, 6842-6845. doi:10.1021/ja5039819

85. Bloom, S.; Sharber, S. A.; Holl, M. G.; Knippel, J. L.; Lectka, T. J. Org. Chem. 2013, 78, 11082-11086. doi:10.1021/jo401796g

86. Bloom, S.; Pitts, C. R.; Woltornist, R.; Griswold, A.; Holl, M. G.; Lectka, T. Org. Lett. 2013, 15, 1722-1724. doi:10.1021/ol400424s

87. Mizuta, S.; Stenhagen, I. S. R.; O’Duill, M.; Wolstenhulme, J.; Kirjavainen, A. K.; Forsback, S. J.; Tredwell, M.; Sandford, G.; Moore, P. R.; Huiban, M.; Luthra, S. K.; Passchier, J.; Solin, O.; Gouverneur, V. Org. Lett. 2013, 15, 2648-2651. doi:10.1021/ol4009377

88. Xia, J.-B.; Ma, Y.; Chen, C. Org. Chem. Front. 2014, 1, 468-472. doi:10.1039/c4qo00057a

89. Li, Z.; Wang, Z.; Zhu, L.; Tan, X.; Li, C. J. Am. Chem. Soc. 2014, 136, 16439-16443. doi:10.1021/ja509548z

90. Danahy, K. E.; Cooper, J. C.; Van Humbeck, J. F. Angew. Chem., Int. Ed. 2018, 57, 5134-5138. doi:10.1002/anie.201801280

91. Guan, H.; Sun, S.; Mao, Y.; Chen, L.; Lu, R.; Huang, J.; Liu, L. Angew. Chem., Int. Ed. 2018, 57, 11413-11417. doi:10.1002/anie.201806434

92. Topczewski, J. J.; Tewson, T. J.; Nguyen, H. M. J. Am. Chem. Soc. 2011, 133, 19318-19321. doi:10.1021/ja2087213

93. Mixdorf, J. C.; Sorlin, A. M.; Zhang, Q.; Nguyen, H. M. ACS Catal. 2018, 8, 790-801. doi:10.1021/acscatal.7b03786

94. Benedetto, E.; Tredwell, M.; Hollingworth, C.; Khotavivattana, T.; Brown, J. M.; Gouverneur, V. Chem. Sci. 2013, 4, 89-96. doi:10.1039/c2sc21789a
95. Zhang, Q.; Stockdale, D. P.; Mixdorf, J. C.; Topczewski, J. J.; Nguyen, H. M. J. Am. Chem. Soc. 2015, 137, 11912-11915. doi:10.1021/jacs.5b07492

96. Kawatsura, M.; Hayashi, S.; Komatsu, Y.; Hayase, S.; Itoh, T. Chem. Lett. 2010, 39, 466-467. doi:10.1246/cl.2010.466

97. Kang, S. H.; Kim, D. Y. Adv. Synth. Catal. 2010, 352, 2783-2786. doi:10.1002/adsc.201000515

98. Jacquet, O.; Clément, N. D.; Freixa, Z.; Ruiz, A.; Claver, C.; van Leeuwen, P. W. N. M. Tetrahedron: Asymmetry 2011, 22, 1490-1498. doi:10.1016/j.tetasy.2011.08.023

99. Deng, Q.-H.; Wadepohl, H.; Gade, L. H. Chem. - Eur. J. 2011, 17, 14922-14928. doi:10.1002/chem.201102375

100.Li, J.; Cai, Y.; Chen, W.; Liu, X.; Lin, L.; Feng, X. J. Org. Chem. 2012, 77, 9148-9155. doi:10.1021/jo301705t

101.Groendyke, B. J.; AbuSalim, D. I.; Cook, S. P. J. Am. Chem. Soc. 2016, 138, 12771-12774. doi:10.1021/jacs.6b08171

102.Tang, P.; Furuya, T.; Ritter, T. J. Am. Chem. Soc. 2010, 132 , 12150-12154. doi:10.1021/ja105834t

103.Zhang, J.; Jin, C.; Zhang, Y. Chin. J. Org. Chem. 2014, 34, 662-680. doi:10.6023/cjoc201310039

104.Guyon, H.; Chachignon, H.; Cahard, D. Beilstein J. Org. Chem. 2017, 13, 2764-2799. doi:10.3762/bjoc.13.272

105. Charpentier, J.; Früh, N.; Togni, A. Chem. Rev. 2015, 115, 650-682. doi:10.1021/cr500223h

106. Alonso, C.; Martínez de Marigorta, E.; Rubiales, G.; Palacios, F. Chem. Rev. 2015, 115, 1847-1935. doi:10.1021/cr500368h

107.Zhu, W.; Wang, J.; Wang, S.; Gu, Z.; Aceña, J. L.; Izawa, K.; Liu, H.; Soloshonok, V. A. J. Fluorine Chem. 2014, 167, 37-54. doi:10.1016/j.jfluchem.2014.06.026

108.Liu, X.; Xu, C.; Wang, M.; Liu, Q. Chem. Rev. 2015, 115, 683-730. doi:10.1021/cr400473a

109.Li, G.-b.; Zhang, C.; Song, C.; Ma, Y.-d. Beilstein J. Org. Chem. 2018, 14, 155-181. doi:10.3762/bjoc.14.11

110.Levin, M. D.; Chen, T. Q.; Neubig, M. E.; Hong, C. M.; Theulier, C. A.; Kobylianskii, I. J.; Janabi, M.; O'Neil, J. P.; Toste, F. D. Science 2017, 356, 1272-1276. doi:10.1126/science.aan1411

111. Parsons, A. T.; Buchwald, S. L. Angew. Chem., Int. Ed. 2011, 50, 9120-9123. doi:10.1002/anie.201104053

112.Wang, X.; Ye, Y.; Zhang, S.; Feng, J.; Xu, Y.; Zhang, Y.; Wang, J. J. Am. Chem. Soc. 2011, 133, 16410-16413. doi:10.1021/ja207775a

113.Shimizu, R.; Egami, H.; Hamashima, Y.; Sodeoka, M. Angew. Chem., Int. Ed. 2012, 51, 4577-4580. doi:10.1002/anie.201201095

114. Mizuta, S.; Galicia-López, O.; Engle, K. M.; Verhoog, S.; Wheelhouse, K.; Rassias, G.; Gouverneur, V. Chem. - Eur. J. 2012, 18, 8583-8587. doi:10.1002/chem.201201707

115.Deng, Q.-H.; Wadepohl, H.; Gade, L. H. J. Am. Chem. Soc. 2012, 134, 10769-10772. doi:10.1021/ja3039773

116.Gao, X.; Xiao, Y.-L.; Wan, X.; Zhang, X. Angew. Chem., Int. Ed. 2018, 57, 3187-3191. doi:10.1002/anie.201711463

117.Liu, Z.; Xiao, H.; Zhang, B.; Shen, H.; Zhu, L.; Li, C. Angew. Chem., Int. Ed. 2019, 58, 2510-2513. doi:10.1002/anie.201813425

118. Mizuta, S.; Engle, K. M.; Verhoog, S.; Galicia-López, O.; O’Duill, M.; Médebielle, M.; Wheelhouse, K.; Rassias, G.; Thompson, A. L.; Gouverneur, V. Org. Lett. 2013, 15, 1250-1253. doi:10.1021/ol400184t

119.Tan, X.; Liu, Z.; Shen, H.; Zhang, P.; Zhang, Z.; Li, C. J. Am. Chem. Soc. 2017, 139, 12430-12433. doi:10.1021/jacs.7b07944 
120.Kautzky, J. A.; Wang, T.; Evans, R. W.; MacMillan, D. W. C. J. Am. Chem. Soc. 2018, 140, 6522-6526. doi:10.1021/jacs.8b02650

121.Cho, E. J.; Senecal, T. D.; Kinzel, T.; Zhang, Y.; Watson, D. A.; Buchwald, S. L. Science 2010, 328, 1679-1681. doi:10.1126/science.1190524

122.Wang, X.; Truesdale, L.; Yu, J.-Q. J. Am. Chem. Soc. 2010, 132, 3648-3649. doi:10.1021/ja909522s

123.Mu, X.; Chen, S.; Zhen, X.; Liu, G. Chem. - Eur. J. 2011, 17, 6039-6042. doi:10.1002/chem.201100283

124.Cho, E. J.; Buchwald, S. L. Org. Lett. 2011, 13, 6552-6555. doi:10.1021/ol202885w

125.Zhang, X.-G.; Dai, H.-X.; Wasa, M.; Yu, J.-Q. J. Am. Chem. Soc. 2012, 134, 11948-11951. doi:10.1021/ja305259n

126.Zhang, L.-S.; Chen, K.; Chen, G.; Li, B.-J.; Luo, S.; Guo, Q.-Y.; Wei, J.-B.; Shi, Z.-J. Org. Lett. 2013, 15, 10-13. doi:10.1021/ol302814x

127.Zou, L.; Li, P.; Wang, B.; Wang, L. Chem. Commun. 2019, 55, 3737-3740. doi:10.1039/c9cc01014a

128.Liu, T.; Shen, Q. Org. Lett. 2011, 13, 2342-2345. doi:10.1021/ol2005903

129.Li, Y.; Wu, L.; Neumann, H.; Beller, M. Chem. Commun. 2013, 49, 2628-2630. doi:10.1039/c2cc36554e

130.He, Z.; Luo, T.; Hu, M.; Cao, Y.; Hu, J. Angew. Chem., Int. Ed. 2012, 51, 3944-3947. doi:10.1002/anie.201200140

131.Egami, H.; Shimizu, R.; Sodeoka, M. Tetrahedron Lett. 2012, 53, 5503-5506. doi:10.1016/j.tetlet.2012.07.134

132.Feng, C.; Loh, T.-P. Chem. Sci. 2012, 3, 3458-3462. doi:10.1039/c2sc21164e

133.Feng, C.; Loh, T.-P. Angew. Chem., Int. Ed. 2013, 52, 12414-12417. doi:10.1002/anie.201307245

134.Li, Z.; Cui, Z.; Liu, Z.-Q. Org. Lett. 2013, 15, 406-409. doi:10.1021/ol3034059

135.Prieto, A.; Landart, M.; Baudoin, O.; Monteiro, N.; Bouyssi, D. Adv. Synth. Catal. 2015, 357, 2939-2943. doi:10.1002/adsc.201500237

136. Prieto, A.; Jeamet, E.; Monteiro, N.; Bouyssi, D.; Baudoin, O. Org. Lett. 2014, 16, 4770-4773. doi:10.1021/ol5022228

137.Pair, E.; Monteiro, N.; Bouyssi, D.; Baudoin, O. Angew. Chem., Int. Ed. 2013, 52, 5346-5349. doi:10.1002/anie.201300782

138.Wang, X.-P.; Lin, J.-H.; Zhang, C.-P.; Xiao, J.-C.; Zheng, X. Beilstein J. Org. Chem. 2013, 9, 2635-2640. doi:10.3762/bjoc.9.299

139. Yin, J.; Li, Y.; Zhang, R.; Jin, K.; Duan, C. Synthesis 2013, 46, 607-612. doi:10.1055/s-0033-1338578

140.Fang, Z.; Ning, Y.; Mi, P.; Liao, P.; Bi, X. Org. Lett. 2014, 16, 1522-1525. doi:10.1021/ol5004498

141.Wu, L.-H.; Zhao, K.; Shen, Z.-L.; Loh, T.-P. Org. Chem. Front. 2017, 4, 1872-1875. doi:10.1039/c7qo00416h

142.Cai, S.; Chen, C.; Sun, Z.; Xi, C. Chem. Commun. 2013, 49, 4552-4554. doi:10.1039/c3cc41331d

143. Ilchenko, N. O.; Janson, P. G.; Szabó, K. J. Chem. Commun. 2013, 49, 6614-6616. doi:10.1039/c3cc43357a

144.Wang, X.; Ye, Y.; Ji, G.; Xu, Y.; Zhang, S.; Feng, J.; Zhang, Y.; Wang, J. Org. Lett. 2013, 15, 3730-3733. doi:10.1021/014016095

145.Ji, X.-M.; Wei, L.; Chen, F.; Tang, R.-Y. RSC Adv. 2015, 5 , 29766-29773. doi:10.1039/c5ra02888d

146.Zhang, X.; Huang, P.; Li, Y.; Duan, C. Org. Biomol. Chem. 2015, 13, 10917-10922. doi:10.1039/c5ob01516b

147.Jin, L.-K.; Lu, G.-P.; Cai, C. Org. Chem. Front. 2016, 3, 1309-1313. doi:10.1039/c6qo00369a
148.Shen, C.; Xu, J.; Ying, B.; Zhang, P. ChemCatChem 2016, 8 , 3559-3564. doi:10.1002/cctc.201601457

149. Xu, J.; Cheng, K.; Shen, C.; Bai, R.; Xie, Y.; Zhang, P. ChemCatChem 2018, 10, 965-970. doi:10.1002/cctc.201701596

150.Parsons, A. T.; Senecal, T. D.; Buchwald, S. L. Angew. Chem., Int. Ed. 2012, 51, 2947-2950. doi:10.1002/anie.201108267

151. Iqbal, N.; Choi, S.; Kim, E.; Cho, E. J. J. Org. Chem. 2012, 77, 11383-11387. doi:10.1021/jo3022346

152. Yasu, Y.; Koike, T.; Akita, M. Chem. Commun. 2013, 49, 2037-2039. doi:10.1039/c3cc39235j

153. Tomita, R.; Yasu, Y.; Koike, T.; Akita, M. Beilstein J. Org. Chem. 2014, 10, 1099-1106. doi:10.3762/bjoc.10.108

154.Xu, P.; Abdukader, A.; Hu, K.; Cheng, Y.; Zhu, C. Chem. Commun. 2014, 50, 2308-2310. doi:10.1039/c3cc48598f

155. Huang, P.; Li, Y.; Fu, X.; Zhang, R.; Jin, K.; Wang, W.; Duan, C. Tetrahedron Lett. 2016, 57, 4705-4708. doi:10.1016/j.tetlet.2016.09.016

156. Nagib, D. A.; MacMillan, D. W. C. Nature 2011, 480, 224-228. doi:10.1038/nature10647

157. Mejía, E.; Togni, A. ACS Catal. 2012, 2, 521-527. doi:10.1021/cs300089y

158.Xie, J.; Yuan, X.; Abdukader, A.; Zhu, C.; Ma, J. Org. Lett. 2014, 16, 1768-1771. doi:10.1021/ol500469a

159.Monir, K.; Bagdi, A. K.; Ghosh, M.; Hajra, A. J. Org. Chem. 2015, 80, 1332-1337. doi:10.1021/j0502928e

160.Beatty, J. W.; Douglas, J. J.; Miller, R.; McAtee, R. C.; Cole, K. P.; Stephenson, C. R. J. Chem. - Eur. J. 2016, 1, 456-472. doi:10.1016/j.chempr.2016.08.002

161.Li, C.; Suzuki, K.; Yamaguchi, K.; Mizuno, N. New J. Chem. 2017, 41, 1417-1420. doi:10.1039/c6nj03654f

162.Xu, J.; Qiao, L.; Shen, J.; Chai, K.; Shen, C.; Zhang, P. Org. Lett. 2017, 19, 5661-5664. doi:10.1021/acs.orglett.7b02823

163. Xia, C.; Wang, K.; Wang, G.; Duan, G. Org. Biomol. Chem. 2018, 16, 2214-2218. doi:10.1039/c8ob00511g

164.Gao, X.; Geng, Y.; Han, S.; Liang, A.; Li, J.; Zou, D.; Wu, Y.; Wu, Y. Org. Lett. 2018, 20, 3732-3735. doi:10.1021/acs.orglett.8b01216

165.Chu, L.; Qing, F.-L. J. Am. Chem. Soc. 2010, 132, 7262-7263. doi:10.1021/ja102175w

166.Jiang, X.; Chu, L.; Qing, F.-L. J. Org. Chem. 2012, 77, 1251-1257. doi:10.1021/jo202566h

167.Zhang, K.; Qu, X.-L.; Huang, Y.; Qing, F.-L. Eur. J. Org. Chem. 2012, 58-61. doi:10.1002/ejoc.201101550

168.Weng, Z.; Li, H.; He, W.; Yao, L.-F.; Tan, J.; Chen, J.; Yuan, Y.; Huang, K.-W. Tetrahedron 2012, 68, 2527-2531. doi:10.1016/j.tet.2011.12.085

169.Zheng, H.; Huang, Y.; Wang, Z.; Li, H.; Huang, K.-W.; Yuan, Y.; Weng, Z. Tetrahedron Lett. 2012, 53, 6646-6649. doi:10.1016/j.tetlet.2012.09.083

170.Luo, D.-F.; Xu, J.; Fu, Y.; Guo, Q.-X. Tetrahedron Lett. 2012, 53, 2769-2772. doi:10.1016/j.tetlet.2012.03.107

171.Wang, X.; Lin, J.; Zhang, C.; Xiao, J.; Zheng, X. Chin. J. Chem. 2013, 31, 915-920. doi:10.1002/cjoc.201300393

172. lqbal, N.; Jung, J.; Park, S.; Cho, E. J. Angew. Chem., Int. Ed. 2014, 53, 539-542. doi:10.1002/anie.201308735

173.Feng, Z.; Xiao, Y.-L.; Zhang, X. Acc. Chem. Res. 2018, 51, 2264-2278. doi:10.1021/acs.accounts.8b00230

174. Surapanich, N.; Kuhakarn, C.; Pohmakotr, M.; Reutrakul, V. Eur. J. Org. Chem. 2012, 5943-5952. doi:10.1002/ejoc.201200613 
175.Jiang, H.; Huang, C.; Guo, J.; Zeng, C.; Zhang, Y.; Yu, S. Chem. - Eur. J. 2012, 18, 15158-15166. doi:10.1002/chem.201201716

176. Belhomme, M.-C.; Poisson, T.; Pannecoucke, X. Org. Lett. 2013, 15 , 3428-3431. doi:10.1021/ol401483j

177.Caillot, G.; Dufour, J.; Belhomme, M.-C.; Poisson, T.; Grimaud, L.; Pannecoucke, X.; Gillaizeau, I. Chem. Commun. 2014, 50, 5887-5890. doi:10.1039/c4cc01994f

178. Prieto, A.; Bouyssi, D.; Monteiro, N. Asian J. Org. Chem. 2016, 5 , 742-745. doi:10.1002/ajoc.201600160

179.Prieto, A.; Melot, R.; Bouyssi, D.; Monteiro, N. ACS Catal. 2016, 6, 1093-1096. doi:10.1021/acscatal.5b02755

180.Xu, P.; Wang, G.; Zhu, Y.; Li, W.; Cheng, Y.; Li, S.; Zhu, C. Angew. Chem., Int. Ed. 2016, 55, 2939-2943. doi:10.1002/anie.201508698

181.Xie, J.; Zhang, T.; Chen, F.; Mehrkens, N.; Rominger, F.; Rudolph, M.; Hashmi, A. S. K. Angew. Chem., Int. Ed. 2016, 55, 2934-2938. doi:10.1002/anie.201508622

182. Ruan, Z.; Zhang, S.-K.; Zhu, C.; Ruth, P. N.; Stalke, D.; Ackermann, L. Angew. Chem., Int. Ed. 2017, 56, 2045-2049. doi:10.1002/anie.201611595

183.Wei, X.-J.; Boon, W.; Hessel, V.; Noël, T. ACS Catal. 2017, 7, 7136-7140. doi:10.1021/acscatal.7b03019

184.Ashirbaev, S. S.; Levin, V. V.; Struchkova, M. I.; Dilman, A. D. J. Org. Chem. 2018, 83, 478-483. doi:10.1021/acs.joc.7b02598

185. Poisson, T.; Ivanova, M.; Besset, T.; Pannecoucke, X. Synthesis 2018, 50, 778-784. doi:10.1055/s-0036-1589140

186. Yuan, C.; Zhu, L.; Zeng, R.; Lan, Y.; Zhao, Y. Angew. Chem., Int. Ed. 2018, 57, 1277-1281. doi:10.1002/anie.201711221

187.Yuan, C.; Zhu, L.; Chen, C.; Chen, X.; Yang, Y.; Lan, Y.; Zhao, Y. Nat. Commun. 2018, 9, 1189. doi:10.1038/s41467-018-03341-6

188.An, L.; Xiao, Y.-L.; Zhang, S.; Zhang, X. Angew. Chem., Int. Ed. 2018, 57, 6921-6925. doi:10.1002/anie.201802713

189.Wang, L.; Liu, H.; Li, F.; Zhao, J.; Zhang, H.-Y.; Zhang, Y. Adv. Synth. Catal. 2019, 361, 2354-2359. doi:10.1002/adsc.201900066

190. Boiko, V. N. Beilstein J. Org. Chem. 2010, 6, 880-921. doi:10.3762/bjoc.6.88

191. Toulgoat, F.; Alazet, S.; Billard, T. Eur. J. Org. Chem. 2014, 2415-2428. doi:10.1002/ejoc.201301857

192. Tlili, A.; Billard, T. Angew. Chem., Int. Ed. 2013, 52, 6818-6819. doi:10.1002/anie.201301438

193.Ghiazza, C.; Billard, T.; Tlili, A. Chem. - Eur. J. 2019, 25, 6482-6495. doi:10.1002/chem.201806234

194. Rossi, S.; Puglisi, A.; Raimondi, L.; Benaglia, M. ChemCatChem 2018, 10, 2717-2733. doi:10.1002/cctc.201800170

195. Ni, C.; Hu, M.; Hu, J. Chem. Rev. 2015, 115, 765-825. doi: $10.1021 /$ cr5002386

196. Li, M.; Guo, J.; Xue, X.-S.; Cheng, J.-P. Org. Lett. 2016, 18, 264-267. doi:10.1021/acs.orglett.5b03433

197.Xu, X.-H.; Matsuzaki, K.; Shibata, N. Chem. Rev. 2015, 115, 731-764. doi:10.1021/cr500193b

198. Yang, Y.-D.; Azuma, A.; Tokunaga, E.; Yamasaki, M.; Shiro, M.; Shibata, N. J. Am. Chem. Soc. 2013, 135, 8782-8785. doi:10.1021/ja402455f

199.Deng, Q.-H.; Rettenmeier, C.; Wadepohl, H.; Gade, L. H. Chem. - Eur. J. 2014, 20, 93-97. doi:10.1002/chem.201303641

200.Pluta, R.; Nikolaienko, P.; Rueping, M. Angew. Chem., Int. Ed. 2014, 53, 1650-1653. doi:10.1002/anie.201307484
201.Huang, Y.; He, X.; Lin, X.; Rong, M.; Weng, Z. Org. Lett. 2014, 16 , 3284-3287. doi:10.1021/ol501290p

202. Huang, Z.; Okuyama, K.; Wang, C.; Tokunaga, E.; Li, X.; Shibata, N. ChemistryOpen 2016, 5, 188-191. doi:10.1002/open.201500225

203. Honeker, R.; Garza-Sanchez, R. A.; Hopkinson, M. N.; Glorius, F. Chem. - Eur. J. 2016, 22, 4395-4399. doi:10.1002/chem.201600190

204. Candish, L.; Pitzer, L.; Gómez-Suárez, A.; Glorius, F. Chem. - Eur. J. 2016, 22, 4753-4756. doi:10.1002/chem.201600421

205. Mukherjee, S.; Maji, B.; Tlahuext-Aca, A.; Glorius, F. J. Am. Chem. Soc. 2016, 138, 16200-16203. doi:10.1021/jacs.6b09970

206. Matheis, C.; Krause, T.; Bragoni, V.; Goossen, L. J. Chem. - Eur. J. 2016, 22, 12270-12273. doi:10.1002/chem.201602730

207. Koziakov, D.; Majek, M.; Jacobi von Wangelin, A. Eur. J. Org. Chem. 2017, 6722-6725. doi:10.1002/ejoc.201701339

208.Zhao, X.; Zheng, X.; Tian, M.; Tong, Y.; Yang, B.; Wei, X.; Qiu, D.; Lu, K. Org. Chem. Front. 2018, 5, 2636-2640. doi:10.1039/c8qo00401c

209. Besset, T.; Jubault, P.; Pannecoucke, X.; Poisson, T. Org. Chem. Front. 2016, 3, 1004-1010. doi:10.1039/c6qo00164e 210. Tlili, A.; Toulgoat, F.; Billard, T. Angew. Chem., Int. Ed. 2016, 55, 11726-11735. doi:10.1002/anie.201603697

211.Sahoo, B.; Hopkinson, M. N. Angew. Chem., Int. Ed. 2018, 57, 7942-7944. doi:10.1002/anie.201804939

212.Lee, J. W.; Lee, K. N.; Ngai, M.-Y. Angew. Chem., Int. Ed. 2019, 58, 11171-11181. doi:10.1002/anie.201902243

213. Kolomeitsev, A. A.; Vorobyev, M.; Gillandt, H. Tetrahedron Lett. 2008, 49, 449-454. doi:10.1016/j.tetlet.2007.11.105

214. Taylor, S. L.; Martin, J. C. J. Org. Chem. 1987, 52, 4147-4156. doi:10.1021/jo00228a001

215. Fout, A. R.; Scott, J.; Miller, D. L.; Bailey, B. C.; Pink, M.; Mindiola, D. J. Organometallics 2009, 28, 331-347. doi:10.1021/om800910q

216. Kraft, B. M.; Lachicotte, R. J.; Jones, W. D. Organometallics 2002, 21 , 727-731. doi:10.1021/om010888f

217. Huang, C.; Liang, T.; Harada, S.; Lee, E.; Ritter, T. J. Am. Chem. Soc. 2011, 133, 13308-13310. doi:10.1021/ja204861a

218.Zheng, W.; Morales-Rivera, C. A.; Lee, J. W.; Liu, P.; Ngai, M.-Y. Angew. Chem., Int. Ed. 2018, 57, 9645-9649. doi:10.1002/anie.201800598

219.Zheng, W.; Lee, J. W.; Morales-Rivera, C. A.; Liu, P.; Ngai, M.-Y. Angew. Chem., Int. Ed. 2018, 57, 13795-13799. doi:10.1002/anie.201808495

220.Jelier, B. J.; Tripet, P. F.; Pietrasiak, E.; Franzoni, I.; Jeschke, G.; Togni, A. Angew. Chem., Int. Ed. 2018, 57, 13784-13789. doi:10.1002/anie.201806296 


\section{License and Terms}

This is an Open Access article under the terms of the Creative Commons Attribution License (http://creativecommons.org/licenses/by/4.0). Please note that the reuse, redistribution and reproduction in particular requires that the authors and source are credited.

The license is subject to the Beilstein Journal of Organic Chemistry terms and conditions:

(https://www.beilstein-journals.org/bjoc)

The definitive version of this article is the electronic one which can be found at:

doi:10.3762/bjoc. 15.218 